\title{
I. Der Durchbruch der Fasci
}

\section{Anfänge des Faschismus in der Region}

Der Faschismus konnte in der Provinz Massa-Carrara wie auch im südlich angrenzenden Marmorgebiet der Versilia lucchese organisatorisch erst relativ spät Fuß fassen. Im nahen La Spezia wurde der Fascio di combattimento zwar schon im März 1919 gebildet, doch diesem gelang es lange nicht, den sozialen Rahmen des städtischen Ursprungsfaschismus zu sprengen. Er hatte so nur geringen Einfluß auf die Entwicklungen in der angrenzenden Lunigiana und der Marmorregion ${ }^{1}$.

Unabhängig vom Fascio von $\mathrm{La}$ Spezia bildete sich eine kleine faschistische Zelle in Pontremoli. Ihre organisatorische Basis hatte sie in der Combattenti- und der Kriegsversehrtenvereinigung. Der Eisenbahner Gino Dani war der Wortführer dieser Gruppe. Er stand schon ab August 1919 in Kontakt mit dem Zentralkomitee der Fasci in Mailand. Er sorgte für die Verbreitung von Propagandamaterial und den Verkauf der faschistischen Wochenzeitung Il Fascio. Es gelang ihm jedoch nicht, die von Mailand geforderte Gründung eines faschistischen Ortsvereins zu bewerkstelligen ${ }^{2}$. Das gesellschaftliche und politische Pflaster war hier denkbar ungünstig für den Faschismus, denn im Umland von Pontremoli dominierte das bäuerliche Kleineigentum ${ }^{3}$. Ausdruck der geringen sozialen Polarisierung war die politische Dominanz des Partito popolare und eines gemäßigten Sozialismus unter der Führung des angesehenen Rechtsanwalts Pietro Bologna, die beide jeweils 40 Prozent der Wählerschaft repräsentierten ${ }^{4}$. Bürgertum und Mittelstand waren zahlenmäßig äußerst schwach, und der lokale Liberalismus führte seit dem Weltkrieg nur noch ein Schattendasein 5 .

${ }^{1}$ Bianchi, Lotte sociali, S. 64.

2 ACS, MRF, b. 37, f. 113, sf. 394: Generalsekretär Pasella an Gino Dani vom 2. 9. 1919; Dani an Comitato centrale vom 16.9.1919.

${ }^{3} \mathrm{Im}$ „circondario" von Pontremoli, das die Gemeinden Pontremoli, Zeri, Mulazzo, Filattiera, Bagnone und Villafranca umfaßt, stellten die bäuerlichen Eigentümer 48,9\% der Erwerbsbevölkerung, während die landwirtschaftlichen Lohnarbeiter und die Pächter nur 15,8\% bzw. 14,0\% ausmachten (Quoten berechnet nach: Censimento della popolazione 1921, Bd. 7, S. 294 f.). Die Sozialstruktur der Alta Lunigiana unterscheidet sich also radikal von der der Hochburgen des Agrarfaschismus, wo entweder die Landarbeitermassen (Emilia) oder die mezzadri und coloni dominierten (weite Teile der Toskana). Vgl. hierzu die Daten der Provinz Ferrara: bäuerliche Eigentümer (5\%), Pächter (8,7\%), landwirtschaftliche Tagelöhner (42,6\%), und der Provinz Siena: bäuerliche Eigentümer $(5 \%)$, mezzadri/coloni $(46,7 \%)$, landwirtschaftliche Tagelöhner $(12 \%)$. Berechnet nach ebenda, S. 320 f. und Bd. 8, S. 308 f. Siehe auch die Tabellen zur Berufsstruktur im Anhang, S. 286.

4 Die Kommunalverwaltung von Pontremoli stellten die "popolari“, die bei den Gemeindewahlen im Herbst 1920 auch die bürgerlichen Stimmen auf sich vereinigen konnten. Bei den nationalen Wahlen vom Mai 1921 erlangten die "popolari“ 40,3\% der Stimmen und die Sozialisten 40,5\%. Berechnet nach Angaben von La Battaglia vom 21. 5.1921.

5 Kaufleute, Akademiker, Lehrer und Angestellte machten im „circondario“ von Pontremoli zusammengenommen nur 3\% der Erwerbsbevölkerung aus. Berechnet nach: Censimento popolazione 1921, Bd. 7, S. 308-319. Der „Blocco nazionale“ erlangte 1921 in der Gemeinde Pontremoli nur 10,3\% der Stimmen, und von liberalen und monarchistischen Organisationen nach 1918 findet sich in den betreffenden Polizeiakten keine Spur (ASM, Questura Massa, b. 15 „Associazioni politiche Pontremoli $\left.1901-1926^{\prime \prime}\right)$. 
Die führende Stellung der Sympathisanten der faschistischen Bewegung in den Heimkehrerorganisationen konnte anscheinend nicht für den Aufbau des Fascio nutzbar gemacht werden, denn obwohl der lokale Ortsverein der Associazione nazionale combattenti mit seinen rund 480 Mitgliedern noch vor der sozialistischen Partei die größte örtliche Vereinigung war ${ }^{6}$, kam es erst am 13. November 1920, also mehr als ein Jahr nach den ersten Bemühungen, zur Gründung der faschistischen Organisation. An der Zusammensetzung des direttorio des anfangs knapp 40 Mitglieder starken Fascio pontremolese di combattimento läßt sich eine Kontinuität erkennen, die vom Vorkriegsliberalismus über den combattentismo zum Faschismus führt ${ }^{7}$.

In Pontremoli, wo von Bolschewismus kaum die Rede sein $\mathrm{kann}^{8}$, wurde der militante „Antibolschewismus“ das Vehikel, mit dem die bürgerlichen Kräfte versuchten, politisches Terrain zurückzugewinnen. Doch trotz viel gutem Willen und dem Rückenwind, in dem die faschistische Bewegung seit den Durchbrüchen des Agrarfaschismus in der Emilia segelte, kam die Organisation in Pontremoli zunächst nicht recht vorwärts. Immer wieder mußte Dani das Zentralkomitee in Mailand um Geld und Waffen anbetteln: „Wir befinden uns in einer sehr armen Gegend, wo es niemanden gibt, der uns hilft [...]. Die Expeditionen sind sehr schwierig auszuführen, da die Mehrzahl unserer Leute unbewaffnet ist"9, lautete die Klage noch im April 1921, zu einer Zeit, als die Offensive der Squadren schon weite Teile der Po-Ebene und der Toskana erfaßt hatte, großzügig finanziert von Agrariern und Industriellen.

Probleme der Waffenbeschaffung und der Finanzknappheit hinderten die Faschisten von Pontremoli allerdings nicht daran, zu militanten Aktionen überzugehen: Anfang März 1921 überfielen sie einen sozialistischen Eisenbahner und fügten ihm leichte Verletzungen $\mathrm{zu}^{10}$. Im April festigte sich dann die faschistische Organisation in der Lunigiana etwas durch die Gründung der Fasci von Bagnone ${ }^{11}$ und Aulla, und gleichzeitig ereigneten sich die ersten größeren Auseinandersetzungen. Am 10. April kam es nach einer Kundgebung in Aulla, an der auch Faschisten aus Pontremoli und La Spezia teilgenom-

${ }^{6}$ ASM, Questura Massa, b. 15: „prospetto statistico“ der Sezione socialista Pontremoli e Annunziata vom 6. 10. 1920; „prospetto statistico“ der Sezione combattenti vom 15. 4. 1921.

7 Das "direttorio“ bestand aus Gino Dani (segr. polit.), Pietro Ceppellini, Antonio Baracchini, Guido Caldi, Enrico Curadi (ACS, MRF, b. 37, f. 113, sf. 394: Dani an Pasella vom 14. 11. 1920). Der Weltkriegshauptmann Caldi hatte die Sezione combattenti im August 1919 aus der Taufe gehoben. Weitere faschistische Führungsmitglieder der örtlichen ANC waren Ernesto Buttini (Vorsitzender), der später „fiduciario provinciale“ der Fasci für die Provinz Massa-Carrara wurde, und der Angestellte Curadi. Als führende Mitglieder des „Circolo giovanile monarchico", der von 1912 bis 1915 bestanden hatte, werden u. a. Guglielmo Dani, Ottorino Buttini und Carlo Baracchini genannt. Auch wenn der exakte Verwandtschaftsgrad nicht ermittelt werden konnte, kann hier von familiären Kontinuitäten ausgegangen werden (ASM, Questura Massa, b. 15: „prospetto statistico" des "Circolo giovanile monarchico" vom 8. 1.1912).

${ }_{8}$ Der kommunistische Ortsverein von Pontremoli hatte ganze 35 Mitglieder (ASM, Questura Massa, b. 15: „prospetto statistico “ vom 25. 3. 1921), und bei der nationalen Wahl 1921 bekamen die Kommunisten im Gemeindegebiet von Pontremoli nur 115 Stimmen $(=4,7 \%)$. Angabe in La Battaglia vom 21. 5. 1921.

9 ACS, MRF, b. 37, f. 113, sf. 394: Dani an Giovanni Marinelli vom 19. 4. 1921.

10 La Battaglia vom 12. 3. 1921.

${ }^{11}$ Für den von dem Obst- und Brennstoffhändler Emilio Negrari gegründeten und circa 30 Mitglieder zählenden Fascio von Bagnone sind allerdings bis in den Hochsommer 1921 hinein ebenfalls katastrophale finanzielle Verhältnisse dokumentiert (ACS, MRF, b. 23, f. 113, sf. 42). 
men hatten, vor der Casa del popolo zu einer Schießerei. Aus den Quellen läßt sich nicht genau entnehmen, ob die Faschisten das Gebäude von vorneherein stürmen wollten oder ob sie erst dazu übergingen, nachdem sie von den Sozialisten, die sich dort verbarrikadiert hatten, beschossen worden waren. Jedenfalls verschossen die Faschisten circa 50 Patronen gegen das Gebäude, konnten aber von den Polizeikräften am Eindringen gehindert werden, so daß der Zwischenfall ohne Verletzte abging ${ }^{12}$.

Ernstere Folgen waren zwei Wochen später in Caprio di Filattiera zu beklagen. Nach einer Wahlkundgebung für den Blocco nazionale gerieten hier die heimkehrenden Faschisten aus Pontremoli in der kleinen unterhalb des Ortes gelegenen Siedlung Ponticello mit einigen Bauern und Landarbeitern in Konflikt, die sich vor dem örtlichen Gasthaus versammelt hatten. Auch hier ist die Rekonstruktion der Ereignisse aufgrund der stark abweichenden Versionen in den Quellen schwierig. Die Faschisten forderten die Anwesenden anscheinend auf, „Es lebe Italien“ und „Nieder mit Lenin“ zu rufen. Es folgte eine Auseinandersetzung, in deren Verlauf von seiten einheimischer Jugendlicher Steine flogen und - wohl hauptsächlich von seiten der Faschisten -Schußwaffen eingesetzt wurden. Vier Faschisten wurden von den Steinwürfen und anscheinend auch von einer Schrotladung leicht verletzt, und in der Gruppe der Einheimischen erlitt der 62jährige Bauer Antonio Angella neben Schußverletzungen an den Beinen eine Stichverletzung am Kopf, an deren Folgen er kurz darauf starb ${ }^{13}$.

Diese erste Bluttat der Faschisten in der Provinz Massa trägt fast absurde Züge: Im betroffenen Ort und in den unmittelbaren Nachbarorten gab es keinerlei Organisationen der Linken. Das Opfer selbst gehörte keiner Partei an und war als kirchlich orientiert bekannt. Trotz dieser Umstände präsentierte Gino Dani in einem Brief an das Zentralkomitee der Fasci den Vorfall bezeichnenderweise als einen „Hinterhalt" der Antifaschisten, der die Notwendigkeit des Erwerbs zusätzlicher Waffen verdeutliche ${ }^{14}$. Die lokale Öffentlichkeit reagierte allerdings feindselig, so daß der Fascio von Pontremoli es vorzog, die für den nächsten Sonntag geplante feierliche Einweihung seines Wimpels „aus regionalen Gründen“ auf bessere Zeiten zu vertagen. Eine Machtdemonstration bei dieser Gelegenheit hätte in der Logik der faschistischen Strategie gelegen, wäre aber nur durch den Aufmarsch von Squadren aus anderen Provinzen möglich gewesen. Wie aus der Anfrage des segretario regionale der toskanischen Fasci, Dino Perrone Compagni, hervorgeht, hätte aber der Fascio von Pontremoli diese Aktion finanzieren müssen, wovon angesichts seiner finanziellen Verhältnisse nicht die Rede sein konnte ${ }^{15}$.

12 Nach dem Bericht des Präfekten der Provinz Massa vom 13.4. 1921 wurden die abziehenden Faschisten ohne Grund aus der "Casa del popolo" heraus beschossen (ACS, MI, DGPS 1921, b. 101). Die Objektivität dieser Darstellung ist allerdings in Frage zu stellen, weil sie auf der Version des diensthabenden Beamten, Vizekommissar De Gattis, beruht, der sich später wiederholt als sehr parteilich erweisen sollte. Die Linkspresse (La Battaglia und La Battaglia comunista vom 16. 4. 1921) stellt dagegen die Faschisten als die Angreifer dar.

13 ACS, MI, DGPS 1921, b. 101: Präfekt Grignolo an Innenministerium vom 27. 4. 1921. Auch hier gibt der Bericht des Präfekten den Gegnern der Faschisten die Schuld, erwähnt aber auch Augenzeugenberichte, die dem widersprechen. Die vorliegende Darstellung folgt im wesentlichen der plausibleren Version der Battaglia vom 30. 4. 1921.

14 ACS, MRF, b. 37, f. 113, sf. 394: Dani an Marinelli vom 27. 4. 1921.

15 Zur Vertagung der Zeremonie: Il Popolo d'Italia vom 26. 4. 1921. Zum Finanzierungsproblem: APC, b. B 9, Bd. I, S. 10: Perrone Compagni an Buttini vom 4. 4. 1921. 
Parallel mit dem Auftreten des Faschismus in der Lunigiana erfolgte die Gründung der ersten Fasci auch in der Versilia vor dem Hintergrund eines langwierigen und harten Arbeitskampfes in der Marmorwirtschaft: am 8. März in Pietrasanta, am 22. April in Forte dei Marmi, am 28. April in Querceta, einem Ort der zur Gemeinde Seravezza gehört $^{16}$. Mit dem Fascio von Querceta begann die Erfassung der Marmorregion durch den Faschismus. Sein Initiator, der aus Carrara stammende Marmorhändler Camillo Fontana, war ein Squadrenführer, wie er für die Region typisch werden sollte: Militanter Nationalismus floß bei ihm mit durchaus materiell bedingten Ressentiments gegen die organisierte Arbeiterschaft zusammen. Fontana hatte im Februar durch einen Angriff auf den sozialistischen Parlamentsabgeordneten Misiano von sich reden gemacht, der wegen seiner Desertion im Weltkrieg zur beliebten Zielscheibe aller Nationalisten geworden war ${ }^{17}$. Anfang Mai nutzte er dann die Gelegenheit eines zufälligen Zusammentreffens mit dem Sekretär der Camera del lavoro, Alberto Meschi, im Postamt von Carrara zu einer weiteren bemerkenswerten Individualaktion. Weil dieser ihn angeblich provokatorisch angeschaut hatte, begann er, ihn wüst zu beschimpfen, und hielt ihm seinen Revolver mit den Worten vor das Gesicht, er sei auch bereit, auf ihn zu schießen ${ }^{18}$.

In Massa und Carrara scheinen die Führungsgruppen der Arbeiterorganisationen von dem sich im Frühjahr 1921 abzeichnenden schleichenden Eindringen des Faschismus in die Region nicht besonders beunruhigt gewesen zu sein. Es findet sich jedenfalls kein Hinweis auf eine Auseinandersetzung in der lokalen Linken über die Eventualität einer Konfrontation, obwohl in der Emilia und anderen Teilen der Toskana schon überdeutlich geworden war, daß eine solche nicht auf die leichte Schulter zu nehmen war. Bei ihrem Kongreß am 30. und 31. Januar hatte die Camera del lavoro eine Protestresolution gegen "das faschistische Verbrechertum" verabschiedet, die dazu einlud, „der Gewalt überall mit Gewalt entgegenzutreten " ${ }^{19}$. Dieser Akt des Verbalradikalismus, der zu einem Zeitpunkt erfolgte, als man in der Region den Faschismus praktisch nur aus Zeitungsberichten kannte, war allerdings durch keinerlei konkrete Maßnahmen, etwa zur Organisation eines Selbstschutzes, begleitet. Die Aufforderung zur individuellen gewalttätigen Reaktion im Falle des Auftretens des Squadrismus blieb abstrakt und unverbindlich. Als in den Monaten März und April sich dann tatsächlich eine konkrete Gefahr abzuzeichnen begann, wurde sie von der Linken kaum beachtet. Sozialisten und Kommunisten waren mit der lokalen Aufarbeitung der Parteispaltung und später mit dem Wahl-

16 Bianchi, Lotte sociali, S. 145.

17 ASM, Commissariato Carrara, b. 55: Kommissar an Questore von Massa vom 12. 2. 1921. Dabei hatte er dem Sekretär Misianos einen Fausthieb ins Gesicht versetzt.

${ }^{18}$ Ebenda: Kommissar an Questore vom 12. 2. 1921. Nach dem Vorfall wurden ihm von der Polizei die Waffe und der Waffenschein entzogen, aber bezeichnenderweise mit der ausdrücklichen Genehmigung des Questore schon nach vier Wochen wieder ausgehändigt; ebenda: Questore Frosoli an Polizeikommissar von Carrara Barcucci vom 1. 6. 1921.

19 Il Cavatore vom 5. 2. 1921. Ein Vorfall mag verdeutlichen, wie wenig die reale Bedrohung durch den Faschismus im Bewußtsein der lokalen Linken präsent war. Nur einen guten Monat, bevor die Faschisten hier mit ihrer ersten Aktion auf den Plan traten, am 3. 4. 1921, begab sich eine Gruppe von Carrareser Anarchisten des Circolo Germinal in den Vorort Torano, wo sie sich offensichtlich aus mehr oder weniger privaten Motiven eine Schlägerei mit einigen örtlichen Kommunisten lieferten. Das kommunistische Lokalblatt apostrophierte die Anarchisten daraufhin sogleich unbekümmert als „Faschisten“ (La Battaglia comunista vom 9. und 23. 4. 1921). 
kampf befaßt, und die Camera del lavoro war vollständig vom Arbeitskampf in der Versilia und internen Auseinandersetzungen absorbiert. Außerdem scheint eine kollektive Verdrängung des Problems eine Rolle gespielt zu haben: Der Marmorregion mit ihren starken revolutionären Traditionen scheint man eine Art Immunität gegenüber dem Faschismus zugesprochen zu haben, zumal es in ihrem Zentrum, in Massa und Carrara, noch keinen organisatorischen Niederschlag der Bewegung gab.

Der faschistischen Bewegung in der Region gelang das „Abheben“ erst mit der Gründung des Fascio di combattimento von Carrara. In der lokalen Associazione democratica liberale machte sich schon seit Anfang des Jahres die Aktivität eine Gruppe junger ehemaliger Frontoffiziere bemerkbar, die später das Rückgrat des Fascio bilden sollten. Als Aktivster tat sich in diesem Kreis der zweifach dekorierte Bersaglieri-Leutnant Renato Ricci hervor, der mit D'Annunzio in Fiume gewesen und erst im Januar nach der gewaltsamen Beendigung des militärischen Abenteuers durch reguläre Truppen nach Carrara zurückgekehrt war. Ricci stammte aus einfachsten Verhältnissen, sein Vater Ernesto war ursprünglich Steinbrucharbeiter gewesen und erlangte später eine bescheidene Anstellung bei der Gemeinde ${ }^{20}$. Trotz der proletarischen Verhältnisse, in denen die Riccis lebten, waren sie schon immer monarchistisch eingestellt und nahmen so im traditionell „subversiven“ Arbeitermilieu von Carrara gewissermaßen eine Außenseiterposition ein. Unter großen Opfern ermöglichte Ernesto Ricci seinen beiden Söhnen, Renato und Umberto, eine „höhere" Ausbildung und schaffte so die Basis für ihren sozialen Aufstieg, der sich für ersteren im Krieg zunächst in der Offizierslaufbahn konkretisierte.

Bei der Neubesetzung der Leitungsorgane des liberalen Ortsvereins von Carrara am 3. April 1921 wurde Renato Ricci in das consiglio direttivo gewählt, und für seinen Vater fiel ein Sitz in der Wahlkommission ab. Auch die späteren Squadrenführer Giuseppe Aloisi und Ugo Dell'Amico zogen in die Leitungsgremien der Associazione democratica liberale von Carrara ein ${ }^{21}$.

Der Aktivismus dieser Gruppe der „ganz Jungen“ begann nachhaltig das Erscheinungsbild der Liberalen Carraras zu prägen, was sich etwa in den zunehmenden soldatisch-patriotischen Tönen des Giornale di Carrara ausdrückte ${ }^{22}$. Auf dem Kongreß im April waren die jugendlichen Aktivisten so stark, daß der segretario politico Oreste Nori sich veranlaßt sah, eine von Frontkampfrhetorik triefende Rede zu halten: Er beschwor die Schlachtfelder des Piave, auf denen die „Wiederauferstehung des Vaterlands“ seinen Anfang genommen habe und wo sich die Kämpfer „alle Pflichten, aber auch alle Rechte erworben" hätten ${ }^{23}$. Nori sind diese Worte sicherlich nicht schwer von den Lippen gegangen, schließlich war er, wie schon erwähnt, einer der Wortführer des liberalen Interventionismus in Carrara gewesen und selbst stark in diesem Denken beheimatet. Die Anpassung des Sprachgebrauchs an den Geschmack des Parteinachwuchses reichte den jungen Radikalen aber nicht. Sie forderten durch den Mund von Bernardo Pocherra, der sich zu ihrem „Mentor“ gemacht hatte, daß die Politik der liberalen Stadträte von Car-

20 Vgl. Setta, Ricci, S. 15.

21 Il Giornale di Carrara vom 9. 4. 1921.

22 Typisch hierfür ist ein langer Artikel vom 12.3. 1921 über eine Rekrutenvereidigung in Carrara.

23 Il Giornale di Carrara vom 2. 4. 1921. 
rara sich stärker an den Vorstellungen der Parteibasis orientieren solle, wo sich zu diesem Zeitpunkt schon unversöhnliche Positionen durchgesetzt hatten ${ }^{24}$.

Die offizielle Haltung der Liberalen von Carrara gegenüber dem Faschismus war bisher durchaus zwiespältig gewesen. In einem Grundsatzartikel des Giornale di Carrara vom 12. März 1921 heißt es:

„Die faschistische Bewegung [ist] die Bewegung der Revolte des siegreichen Italiens, das im Krieg gekämpft hat, gegen jene, die diesen Krieg feig sabotierten, eine schmerzliche, aber notwendige Erscheinung zur Wiederherstellung des inneren politischen Gleichgewichts, das so grundlegend von den Sozialisten gestört worden ist."

Dieses Gleichgewicht sah der Autor Giorgio Casoni, ein Liberaler der „alten Schule“, aber mit den Anfangserfolgen des Faschismus schon als wiederhergestellt an, noch bevor er in Carrara überhaupt aufgetaucht war. Er warnte vor einer weiteren Eskalation der Gewalt, die Italien in die Zustände einer „mittelalterlichen Stadtrepublik“ stürzen und die Faschisten aller Sympathien berauben würde, die sie sich bisher erworben hätten. Casoni schließt mit dem emphatischen Ausruf: „Italienisches Blut darf nicht die italienischen Fahnen beflecken, nie mehr! "Der Tenor des Artikels kann als Indiz dafür gewertet werden, daß Teile des lokalen Liberalismus ein Übergreifen der Bürgerkriegszustände auf Carrara und die Marmorregion nicht wünschten. Die Bemühungen des liberalen Establishments, ihren Nachwuchs zu bremsen, sind jedenfalls deutlich erkennbar. Auch der Polizeikommissar von Carrara und das örtliche Carabinieri-Kommando arbeiteten gegen die in der Luft liegende Fascio-Gründung ${ }^{25}$. Offensichtlich sah man die Eventualität in diesen Kreisen als eine unnötige Provokation des lokalen sovversivismo an, der in der Nachkriegszeit zu keiner außerordentlichen Beunruhigung Anlaß gegeben hatte, dem man aber ein großes „schlafendes“ Militanzpotential zusprach.

Der Mitte April einsetzende Wahlkampf förderte nachhaltig die politische Polarisierung und schuf damit die Voraussetzung für die Aktion des Faschismus in Carrara. Dem amtierenden Ministerpräsidenten Giovanni Giolitti war es gelungen, die bürgerlichen Kräfte von der Democrazia sociale bis zu den Faschisten landesweit in den Listen des Blocco nazionale zusammenzufassen. Nach dem politischen Kalkül Giolittis sollte die Einbindung der Faschisten längerfristig zu ihrer "Parlamentarisierung“ und „Domestizierung " führen ${ }^{26}$. Als unmittelbarer Effekt zeigte sich allerdings, daß sich in den Hochburgen des Faschismus die Tendenz der bürgerlichen Sammlung um den Faschismus verstärkte, während in Gebieten, wo der Faschismus schwach war, die Aufnahme von faschistischen Kandidaten in den bürgerlichen Block ihm zu einem oft nicht unwesentlichen Rückenwind verhalf.

Letzteres geschah in der Marmorregion. Auf der Liste des Blocco im Wahlkreis Pisa, Livorno, Lucca und Massa-Carrara dominierten die alten Notabeln des lokalen Liberalismus; als solchen kann man durchaus auch den Vertreter der Provinz Massa, den eng mit den Interessen der Marmorwirtschaft verbundenen Carrareser Anwalt Camillo Micheli, ansehen. Doch wurde durch die Aufnahme der beiden faschistischen Kandidaten aus Livorno, des Admirals und Kriegshelden Costanzo Ciano und des Schuldirektors Nello Menicanti, sowie des Vorsitzenden der Combattenti-Organisation von

24 Ebenda.

${ }^{25}$ ASM, Commissariato Carrara, b. 55: Kommissar an Questore vom 18. 5. 1921.

${ }^{26}$ Einzelheiten zu diesem komplexen Problem bei De Felice, Mussolini il fascista 1, S. 3 - 99. 
Viareggio, Michelangiolo Chiapparini, auch den Vorstellungen der „jungen Kräfte Rechnung getragen.

Die breite Plattform des Wahlbündnisses ermöglichte es der Gruppe um Pocherra und Renato Ricci, dem Wahlkampf im Raum Carrara ihren Stempel aufzudrücken. Unter den aktivsten Wahlpropagandisten waren neben diesen beiden der schon genannte FascioMitbegründer Ugo Dell'Amico und ein weiteres Mitglied des späteren faschistischen direttorio, der Student und ehemalige Feldwebel Luciano Bacciola, sowie der Fuhrmann und liberale "Vorzeigeproletarier" Pietro Procuranti, auch er ein Faschist der "ersten Stunde“.

Auf den großen Wahlkundgebungen Anfang Mai in Massa und Carrara dominierten die kriegerischen Töne. Wieder preschte Oreste Nori vor: Er hielt in Carrara eine Rede, die ganz auf der metaphorischen Gleichsetzung von äußerem und innerem Feind, von Weltkrieg und politischem Kampf, von geographischen und spirituellen Grenzen des Vaterlands basierte und in einer uneingeschränkten Lobpreisung der faschistischen Aktion gipfelte. Auch Ciano nutzte die Kundgebungen in Massa und Carrara - außer für weihevolle Worte über seine eigene militärische Vergangenheit - in erster Linie zur Propadanda für die Fasci, während Menicanti bei diesen Gelegenheiten gar schon den faschistischen Totalitätsanspruch verkündete: „Es wird der Tag kommen, da wird die ganze Kammer faschistisch sein und das Land auch. ${ }^{\text {" } 7}$

Dieses Wahlkampfklima förderte den Prozeß der politischen Selbstfindung in den Kreisen, die dem Faschismus zuneigten. Am 30. April wurde von Ubaldo Bellugi der Fascio di combattimento in der Provinzhauptstadt Massa gegründet, und schon wenig später kam es auf einer Wahlveranstaltung der liberalen Dissidentenliste von Tullio Benedetti zu einem Ansatz von Gewalttätigkeiten von seiten der Faschisten ${ }^{28}$. Am 12. Mai, noch gerade rechtzeitig, um am nächsten Tag bei der letzten Wahlkundgebung des Blocco organisiert auftreten zu können, erfolgte dann die Gründung des Fascio in Carrara. Die knapp 60 Gründungsmitglieder sind quellenmäßig nicht zu erfassen. Mit Sicherheit gehörte die genannte Gruppe der jungen liberalen Aktivisten um Renato Ricci, Giuseppe Aloisi, Ugo Dell'Amico und Luciano Bacciola dazu. Unter den liberalen Parteivertretern, die sofort oder relativ bald zum Fascio stießen, sind neben ihrem „Ziehvater“ Pocherra weitere Weltkriegsteilnehmer, zumeist Offiziere, zu nennen, der Buchhalter Rizieri Lombardini, der Juwelier Pietro Prayer Galetti und die Brüder Renato und Eugenio Picciati aus dem Vorort Bergiola, beide Studenten und ehernalige rrditt $^{29}$. Die liberale Kerntruppe des frischgebackenen Fascio zeichnete sich durch eine starke Präsenz der Kriegsteilnehmer und, im Gegensatz zur sozialen Herkunft der meisten anderen exponierten Liberalen Carraras, durch eine eher kleinbürgerliche Zusammensetzung aus.

27 Genaue Berichterstattung über die Wahlkundgebungen in Il Giornale di Carrara vom 8. 5. 1921.

${ }^{28}$ Ebenda.

29 "Arditi“ (wörtlich: die Tollkühnen) hießen die italienischen Stoßtruppen des Ersten Weltkriegs. Nach dem Krieg wurde um sie ein Kämpfermythos gesponnen, der vor allem im frühen Squadrismus eine große Rolle spielte. Siehe hierzu Rochat, Arditi, passim. Der ältere der Brüder, Renato Picciati, war hochdekorierter Arditi-Leutnant gewesen, der jüngere Eugenio kam als Angehöriger des Jahrgangs 1900 nur noch kurz am Ende des Kriegs zum Einsatz und hatte daher keine Chance, Offizier zu werden (Alalà vom 21. 1. 1922). 
Einen gewissen Anteil an der Fascio-Gründung scheint auch die örtliche Organisation der legionari fiumani gehabt zu haben, aber - außer Renato Ricci selbst - erlangte keiner der Fiume-Heimkehrer eine führende Stellung im Carrareser Faschismus ${ }^{30}$. Dagegen spielten einige Marmorunternehmerfamilien von Anfang an eine nicht unmaßgebliche Rolle im Fascio von Carrara; sie sorgten dafür, daß dieser, im Unterschied zu den armen Fasci der Lunigiana, keinerlei Geldsorgen kannte. Am stärksten involviert war offensichtlich die Firma der Brüder Faggioni; Ghino Faggioni wurde bei oder unmittelbar nach der Gründung zum presidente des Fascio gewählt, ein Ehrenamt, das üblicherweise von exponierten Geldgebern der faschistischen Bewegung bekleidet wurde. Unter den führenden Faschisten der „ersten Stunde“ befanden sich außerdem drei Angehörige mittelständischer Marmorunternehmerfamilien: Oreste Giorgi und Ugo Dell'Amico, die beide von Anfang an Mitglieder des direttorio waren, und der Schriftsteller Cesare Lodovici, der der erste Chefredakteur der faschistischen Lokalzeitung Alalà wurde ${ }^{31}$. Die herausragende Stellung des Studenten und Weltkriegsleutnants Gualtiero Betti, eines Halbbruders der Grafen Lazzoni, die zu den reichsten Marmorindustriellen Carraras gehörten, in der Führungsgruppe des Fascio ist zwar kein Indiz für die bedingungslose Unterstützung des Fascio durch die anderen Mitglieder dieser Unternehmerfamilie, ein baldiges finanzielles Engagement der Firma Lazzoni ist allerdings recht wahrscheinlich ${ }^{32}$. Ferner muß hier erwähnt werden, daß auch im Fußvolk der faschistischen Organisation sehr bald die Söhne von einigen kleinen und mittleren Marmorunternehmern anzutreffen sind ${ }^{33}$.

Zusammenfassend kann man von drei Elementen sprechen, die in der Führungstruppe des aufkommenden Faschismus von Carrara präsent waren: die junge liberale Rechte, ehemalige Frontoffiziere und junge Angehörige der Marmorunternehmerschaft. Es handelte sich allerdings nicht um getrennte soziale Gruppen, sondern diese Elemente überschnitten sich zum Teil erheblich. So waren etwa die meisten ,jungen“ Liberalen gleichzeitig Weltkriegsoffiziere. Was die Marmorunternehmerschaft betrifft, so waren eher die kleinen und mittleren Industriellen, meistens personell vertreten durch ihre Söhne, im Faschismus engagiert, während sie dazu neigten, sich selbst als Geldgeber im Hintergrund zu halten. Die führenden Großunternehmer, so etwa die Firma Walton oder der Marmormagnat Carlo Andrea Fabbricotti, zeigten sich distanzierter gegenüber der

${ }^{30}$ Dies geht sowohl aus einem Überblicksbericht des Polizeikommissars von Carrara Barcucci über die Entstehung des örtlichen Faschismus (ASM, Commissariato Carrara, b. 55: Bericht ohne Datum) als auch aus einer autobiographischen Aufzeichnung Renato Riccis (Setta, Ricci, S. 21, Anm. 22) hervor. Bei den Fiume-Heimkehrern unter den Faschisten handelte es sich um Renato Ricci, Alberto Carli (eigentlich ein Nationalist), Mario Sanguinetti, Eliseo Lorieri, Carlo Piccioli, Egisto Fabiano, Ottaviano Roppa, Guido Milani, Ovidio Passani und Emilio Cucurnia (Alalà vom 19. 11. 1921). Letzter erlangte als "capitano d'azione“ des Fascio von Marina di Carrara noch die größte Bedeutung.

${ }^{31}$ Eine engere Verwandtschaftsbeziehung von Goffredo Corsi, einem weiteren Mitglied des ersten „direttorio“, zur Marmorunternehmerfamilie der Corsi ist nicht zu rekonstruieren, aber durchaus wahrscheinlich.

32 Der „antibürgerliche“ Habitus von Gualtiero Betti (siehe seinen Artikel „Borghesia“ in Alalà vom 22. 10. 1921) spricht gegen ein sehr enges Verhältnis zu seinen schwerreichen Halbbrüdern, die allerdings später selbst eine gewisse, wenn auch innerlich wohl etwas distanzierte Rolle im PNF spielen sollten. Vgl. weiter unten, S. $245 \mathrm{f}$.

${ }^{33} \mathrm{Zu}$ ihnen sind z. B. zu zählen: Andrea Nicoli, Bruno Lagomarsini, Pietro Gattini, Alessandro Manfredi. 
faschistischen Bewegung, obwohl auch von dieser Seite finanzielle Zuwendungen an den Fascio gegangen sein dürften ${ }^{34}$. So waren es junge, meist durch den Weltkrieg sozialisierte und wirtschaftlich nicht übermäßig potente Männer aus dem Mittelstand und dem Bürgertum $^{35}$, die anfangs das Rückgrat des Carrareser Faschismus bildeten. Politisch kamen sie in ihrer Mehrheit aus der Tradition des „Liberalismus“, der aber schon längst deutlich protofaschistische Züge angenommen hatte und selbst im Begriff war, das enge Kleid eines „konstitutionellen“ Notabelnwahlvereins zu sprengen.

Sehr bald gelang es dem Fascio di combattimento, auch Arbeiter und Angehörige des Subproletariats für seine Aktion zu gewinnen. Es gibt Hinweise dafür, daß eine Gruppe von ehemaligen anarchistischen arditi, unter ihnen der später als squadrista zu lokalem „Ruhm“ gelangte Maurer Ottaviano Roppa, schon unmittelbar nach der Gründung zur faschistischen Organisation gestoßen ist, die als "anarcho-nationalistische Gruppe" schon 1919 mit einer wirren Militanz in Erscheinung getreten war ${ }^{36}$. Der Faschismus erfaßte ein ungleich größeres soziales Spektrum als jemals die alten liberalen Gruppierungen. Durch die Militanz und die soziale Dynamik des Faschismus verdrängt, verlor der traditionelle Liberalismus nach und nach jede eigene Initiative, die Associazione democratica liberale sollte bald nur noch im Schlepptau des Fascio agieren.

Die Parlamentswahlen vom Mai 1921 brachten im ganzen gesehen für die Region keine großen Überraschungen. Es zeigte sich jedoch eine klare Tendenzwende. Der Stimmenanteil von Sozialisten und Kommunisten zusammengenommen erreichte nicht einmal die Höhe, die der PSI vor der Spaltung allein erzielt hatte. Auch die katholischen popolari verloren leicht, die Republikaner erheblich. Dem Blocco nazionale hingegen gelang es, mehr Stimmen als beide bürgerlich-liberalen Listen des Jahres 1919 zusammengenommen zu gewinnen, obwohl er gleichzeitig der liberalen Dissidentenliste acht Prozentpunkte überlassen mußte.

Ergebnisse der Parlamentswahlen in der Provinz Massa-Carrara 1919 und 1921 im Vergleich ${ }^{37}$ :

\begin{tabular}{lllllllll}
\hline $\begin{array}{l}\text { Costitu- } \\
\text { zionali }\end{array}$ & $\begin{array}{l}\text { Blocco } \\
\text { naz. }\end{array}$ & $\begin{array}{l}\text { Lib. } \\
\text { diss. }\end{array}$ & $\begin{array}{l}\text { Demo- } \\
\text { cratici }\end{array}$ & PPI & PRI & PSI & PCd'I \\
\hline 1919 & 12,3 & - & - & 8,4 & 22,5 & 24,6 & 32,4 & - \\
1921 & - & 22,2 & 8,1 & - & 21,1 & 18,1 & 22,7 & 7,6 \\
\hline
\end{tabular}

34 Für den Sommer/Herbst 1922 sind große Zuwendungen von C. A. Fabbricotti dokumentiert (ACS, MI, Gabinetto Finzi, b. 12, f. 145: Memorandum von E. Viola ohne Datum, circa Mai 1924). Allgemeine Aussagen über die Finanzierung des Fascio von Carrara durch die Marmorindustriellen finden sich in zahlreichen Polizeiberichten. Siehe etwa ACS, MI, DGPS 1921, b. 98: Bericht des Generalinspektors Trani vom 4. 8. 1921 (abgedruckt bei Costantini, Sarzana, S. 92 100) und DGPS 1922, b. 134: Bericht des Generalinspektors Paolella vom 26. 1. 1922.

${ }^{35}$ Für die kleineren und mittleren Unternehmen war die Lage im Schatten der großen Unternehmen, die den Export kontrollierten, in dieser Krisensituation sehr schwierig. Siehe weiter unten, S. $217 \mathrm{f}$.

36 La Sveglia repubblicana vom 2. 8. 1919. Borgioli, Movimenti, S. 150, spricht (ohne Beleg) von lokalen Anarchisten, die in den Strafeinheiten der ,arditi“ in den Ardennen zum Einsatz kamen und dort eine politische Verwandlung durchmachten. Der Einsatz von Roppa 1918 in Frankreich ist dokumentiert (ASM, DM, cl. 1897, nm. 7336). Zu den ehemaligen anarchistischen „arditi“ im Faschismus siehe auch weiter unten, S. 162.

${ }^{37}$ Daten bei Bianchi, Lotte sociali, S. 87 und 155. 
Der Wahlausgang deutet auf eine Umorientierung mittelständischer Wählerschichten nach rechts hin. Noch wesentlich deutlicher zeigt sich dies an der Entwicklung in den Gemeinden Carrara und Massa. Dort verloren die marxistischen Parteien ein Drittel ihrer Wähler. Die bürgerlich-liberalen Gruppierungen dagegen, die bei den Wahlen 1919 völlig eingebrochen waren, konnten ihren Wähleranteil in Carrara mit 25,3 Prozent der Stimmen verdoppeln und in Massa mit 14,1 Prozent sogar vervierfachen ${ }^{38}$. Es ist unübersehbar, daß der Blocco nazionale mit seinem von den Faschisten maßgeblich bestimmten aggressiven Wahlkampf einen wesentlich größeren Teil des konservativnational-liberalen Wählerpotentials mobilisieren konnte als die „konstitutionellen“ Notabelnlisten des Jahres 1919. Die Rechte hatte offensichtlich auch in der Provinz Massa-Carrara ihren Nachkriegsschock überwunden. Freilich war die politische Linke in der Region immer noch so stark, daß eine Umkehrung des politischen Kräfteverhältnisses selbst auf längere Sicht nicht absehbar war. Erdrutschartige Verschiebungen hatte es bei dieser Wahl nur in jenen Gebieten Italiens gegeben, wo der faschistische Squadrismus die Linke schon mit Gewalt niedergerungen und die politischen Freiheiten teilweise oder ganz außer Kraft gesetzt hatte ${ }^{39}$. Im Vergleich dazu hielt sich der konservative Wahlerfolg in der Marmorregion in Grenzen. Die lokale Elite war noch weit davon entfernt, ihre alte politische Hegemonie zurückzugewinnen. Auch das war aus dem Wahlergebnis herauszulesen, und dies gab wohl für Teile dieser Elite den letzten Anstoß, jetzt ganz auf die faschistische Karte zu setzen.

\section{Erste Auseinandersetzungen in Carrara und Massa}

Bei einer Wahlkundgebung des Blocco nazionale in Marina di Carrara, dem Hafenvorort, trat die noch kleine faschistische Kerntruppe um Renato Ricci zum ersten Mal organisiert auf. Auf dem Hauptplatz des Ortes waren circa 350 Anhänger des Blocco und etwas abseits etwa 70 Republikaner und Sozialisten versammelt ${ }^{1}$. Diese warteten auf den noch nicht eingetroffenen republikanischen Abgeordneten Carupi, der sich einem Streitgepräch mit den Kundgebungsrednern zu stellen gedachte, eine in den italienischen Wahlkämpfen der damaligen Zeit übliche Praxis. Nachdem als erster Redner Ottorino Biscioni gesprochen hatte, ergriff der exponierte „Mentor ${ }^{\text {“ }}$ der Faschisten innerhalb der liberalen Parteiorganisation, Bernardo Pocherra, das Wort, wurde aber durch beständige Zwischenrufe aus der republikanisch-sozialistischen Gruppe gestört. Sogleich traten die Faschisten unter der Führung von Ricci in Aktion: Mit erhobenen Stöcken gingen sie gegen die gegnerische Gruppe los. Kurz nachdem die beiden Gruppen miteinander in Berührung gekommen waren, fielen zwei Pistolenschüsse, von denen einer den brigadiere der Guardia di finanza Giuseppe Caragnano, der sich am Ort im Polizeieinsatz

${ }^{38}$ Ebenda, S. 88 und 156.

${ }^{39}$ Musterbeispiel ist hier der Wahlkreis Ferrara/Bologna/Ravenna/Forlí, wo die Faschisten auf der Liste des Blocco nazionale drei Kandidaten (Mussolini, Grandi, Oviglio) durchbrachten. Es handelte sich dabei in erster Linie um einen faschistischen Sieg, wie die große Mehrheit der Präferenzstimmen für Mussolini zeigt. Vgl. De Felice, Mussolini il fascista 1, S. 92.

1 ASM, Commissariato Carrara, b. 55: Abschlußbericht vom 23. 5. 1921 (unsigniert). 
befand, tödlich in den Kopf traf. Es entwickelte sich eine Schießerei, die wohl in der Hauptsache von den Faschisten ausging, welche den nun in eine Seitenstraße fliehenden Republikanern und Sozialisten hinterherschossen. Die bewaffneten Auseinandersetzungen setzten sich noch eine Weile im benachbarten Viertel fort. Später fand die Polizei dort die Leiche des sozialistischen Seemanns Gino Bertoloni, ebenfalls durch einen Kopfschuß getroffen ${ }^{2}$. Genauer Hergang der Ereignisse und Verantwortung für die Todesschüsse sind von Polizei und Justiz nicht einmal im Ansatz geklärt worden ${ }^{3}$. Die Polizei konzentrierte sich ganz auf die Ermittlung des ersten Todesschützen. Auf die Aussage eines angeblichen Augenzeugen hin wurde Marino Dinucci, der Sohn des einflußreichen republikanischen Parteisekretärs von Marina di Carrara, für den Tod Caragnanos verantwortlich gemacht, aber schon im Verlauf der staatsanwaltlichen Ermittlungen mußte die Beschuldigung fallengelassen werden. Die Quellen lassen die Vermutung $\mathrm{zu}$, daß der Zeuge, der Dinucci belastet hatte, ein nicht parteigebundener Seemann, mit Hilfe von Einschüchterungen zu einer glatten Falschaussage getrieben worden war ${ }^{4}$.

Noch verwickelter wird der Fall durch den mysteriösen Tod eines anderen Zeugen, des republikanischen Steinmetzen Silvio Viviani, der eine Woche nach den Vorfällen unter einer schweren Marmorplatte zerquetscht aufgefunden wurde ${ }^{5}$. Viviani war am Abend vorher verhört worden, nachdem der Polizei gegenüber behauptet worden war, er kenne den Todesschützen, was er allerdings entschieden abstritt. Am Morgen darauf sollte er weiter verhört und der Person, die die Polizei informiert hatte, gegenübergestellt werden. Trotz der äußerst ungewöhnlichen Todesart spricht schon der erste Bericht der örtlichen Carabinieri-Station von Selbstmord, eine These, von der die offiziellen Stellen später nicht mehr abgingen ${ }^{6}$.

Durch die Art, wie die polizeilichen Ermittlungen geführt wurden, entstand zumindest in der bürgerlichen Öffentlichkeit der Eindruck, daß die Verantwortung für den Tod von Caragnano und damit für alles, was darauf folgte, bei den sovversivi läge, eine Sichtweise, die allen voran vom liberalen Lokalblatt Il Giornale di Carrara propagiert wur$\mathrm{de}^{7}$. In diesem Licht erschien der „Selbstmord“ von Viviani als die Verzweiflungstat eines Augenzeugen, der einen Gesinnungsgenossen nicht belasten wollte. Völlig unter den Tisch fiel dabei der einzige unzweifelhafte Tatbestand, daß nämlich die Faschisten im Verlauf der Tätlichkeiten „zahlreiche Schüsse“ abgegeben hatten und Renato Ricci sowie Ugo Dell'Amico deshalb von der Polizei wegen „Schußwaffengebrauch in einer Schlä-

2 Ebenda.

3 Das Strafverfahren gegen die Faschisten Renato Ricci und Ugo Dell'Amico sowie den Republikaner Nello Vatteroni wegen „Beteiligung an einer Schlägerei“ („partecipazione a una rissa“) endete am 27. 12. 1922 mit Freisprüchen für alle Beteiligten, bei den beiden Faschisten aufgrund der Amnestie vom 22. 12. 1922, bei Vatteroni wegen mangelnden Beweises (ASM, Tribunale Massa, Sentenza penale 1922/262).

4 Nach dem Polizeibericht (wie Anm. 1) war der parteilose Zeuge durch die Drohung von nicht genauer bezeichneter Seite, er könne wegen seiner Anwesenheit bei den Vorfällen verhaftet werden, dazu bewogen worden, diese Aussage zu machen.

5 ASM, Commissariato Carrara, b. 55: Bericht der Carabinieri-Station Marina di Carrara vom 21. 5. 1921.

${ }^{6}$ Ebenda: Kommissar von Carrara an Carabinieri vom 24. 5. 1921. Hier ist einfach vom „Selbstmörder Viviani“ die Rede.

7 Il Giornale di Carrara vom 21. 5. und vom 28. 5. 1921. 
gerei $^{\text {“ }}$ angezeigt werden mußten ${ }^{8}$. Die lokalen Faschisten konnten so, ohne schon ein eigenes Presseorgan zur Verfügung zu haben, einen optimalen Propagandagewinn aus den fatti di Marina ziehen. Sie stellten sich als die „Hüter der Freiheit aller“ dar, die nur entschieden gegen die Vergewaltigung der Meinungsfreiheit von seiten der sovversivi vorgegangen wären". Der Finanzpolizist Caragnano wurde zum ersten „Märtyrer“ der Bewegung in Carrara stilisiert, obwohl er mit den Faschisten gar nichts zu tun hatte ${ }^{10}$.

Strukturell ähnliche Ereignisse wie die fatti di Marina haben auch in anderen Orten den Durchbruch der faschistischen Bewegung stark begünstigt. Es seien hier nur exemplarisch genannt: die blutigen Auseinandersetzungen um die Rathäuser von Bologna und Ferrara im Herbst 1920 und die Ereignisse, die dem Bombenattentat auf eine patriotische Demonstration im Februar 1921 in Florenz folgten ${ }^{11}$. In allen Fällen blieb die moralische und strafrechtliche Verantwortung für das auslösende Ereignis weitgehend ungeklärt, und trotzdem konnte eine breite öffentliche Entrüstung gegen die Linke gelenkt werden, die unmittelbar der Legitimation der folgenden gezielten faschistischen Gewalt diente. Die ersten squadristi demonstrierten, daß sie fähig waren, effizient und ohne viel Skrupel gegen die sovversivi vorzugehen, ihre Gewalt erschien aber gleichzeitig als eine von der Gegenseite provozierte Reaktion und konnte so ohne allzu große Schwierigkeiten von der bürgerlichen Öffentlichkeit „verdaut “ werden.

Eine Schlüsselrolle für die Herausbildung einer neuen politischen Atmosphäre in Carrara hatten die folgenden Trauerfeierlichkeiten. Geschickt nutzten die Faschisten die Gelegenheit des Trauerzuges für den brigadiere Caragnano, um sich in Szene zu setzen ${ }^{12}$. Die Squadren wurden zum bestimmenden Element im Rahmen eines offiziellen Aktes, mit dem sich alle staatstragenden Kräfte identifizieren konnten. Als die partiti sovversivi und die Camera del lavoro ihrerseits eine Trauerkundgebung für den toten Bertoloni ansetzten, drohte der Fascio, er werde sie notfalls mit Waffengewalt verhindern ${ }^{13}$. Angesichts ihrer begrenzten Kräfte mußten die Faschisten, um ihrer Drohung Nachdruck zu verleihen, in Florenz beim segretario regionale für die Toskana, Dino Perrone Compagni, beim Fascio-Sekretär von Pisa, Bruno Santini, und in den anderen Orten der Provinz um Verstärkung anfragen ${ }^{14}$. Das Polizeikommissariat von Carrara rechnete mit über 500 auswärtigen Faschisten und bürgerkriegsähnlichen Auseinandersetzungen und beantragte die Entsendung einer Kavallerieschwadron, doch dann gelang es ihm, durch die Vermittlung des republikanischen Bürgermeisters Edgardo Starnuti einen Verzicht der linken Gruppierungen auf die Veranstaltung zu erwirken ${ }^{15}$.

An dieser ersten großen politischen Niederlage der Arbeiterbewegung in Carrara, deren demoralisierende Wirkung auf die Basis nicht unterschätzt werden sollte, haben

8 Polizeibericht (wie Anm. 1).

9 ASM, Commissariato Carrara, b. 55: Flugblatt der Faschisten ohne Datum.

${ }^{10}$ Chiurco nimmt ihn kurzerhand mit der Bezeichnung ,uno dei primi soldati dell'ideale“ in sein "Toskanisches Märtyrerverzeichnis“ auf: Chiurco, Martirologio, S. 65.

11 Zu den Ereignissen in Bologna siehe Onofri, La strage, S. 269-89 und Cardoza, Agrarian Elites, S. 306 - 15; zu Ferrara: Roveri, Fascismo a Ferrara, S. 100 - 106 und Corner, Fascism, S. $114-$ 120; zu Florenz: Cantagalli, Fascismo fiorentino, S. 147-60.

12 Il Giornale di Carrara vom 21. 5. 1921.

13 ASM, Commissariato Carrara, b. 55: Polizeikommissar an Questore von Massa vom 19. 5. 1921.

14 Ebenda: 2. Phonogramm vom 19. 5. 1921.

15 Ebenda: Polizeikommissar an Questore von Massa vom 21. 5. 1921. 
die Polizeiverantwortlichen einen entscheidenden Anteil. Ihr Vorgehen war kaum verhohlen parteiisch. Alle ihre Aktivitäten waren dahin gerichtet, die Trauerkundgebung, die natürlich als antifaschistische Demonstration konzipiert war, zu verhindern, während sie gegen die Faschisten, die öffentlich schwerste Straftaten ankündigten, nicht vorgingen $^{16}$. Der Einsatzplan der Polizei sah keineswegs vor, die auswärtigen Faschisten vor dem Eindringen in die Stadt abzuhalten, sondern beachsichtigte eine Konzentration der Kräfte in unmittelbarer Nähe des Demonstrationszugs ${ }^{17}$. Im Falle eines faschistischen Angriffs auf die Kundgebung, der mit allergrößter Wahrscheinlichkeit erfolgt wäre, hätten die sovversivi von seiten der Polizei keinen nennenswerten Schutz erwarten können ${ }^{18}$. Eine jahrzehntelange Tradition der gegenseitigen Feindseligkeiten und die tendenziöse Art, mit der die Polizei die Ermittlungen in der Sache fatti di Marina geführt hatte, ließen das absehen. Es ergab sich somit die merkwürdige Situation, daß die politischen Kräfte, die zusammengenommen in der Gemeinde Carrara weit über 70 Prozent der Bevölkerung repräsentierten ${ }^{19}$, nicht in der Lage waren, ihr Recht auf eine friedliche Demonstration durchzusetzen, obwohl ihnen zu diesem Zeitpunkt nur circa 60 einheimische Faschisten gegenüberstanden ${ }^{20}$.

Die Führung der Arbeiterorganisationen hatte allerdings möglicherweise keine Alternative zum Verzicht auf die Kundgebung, denn eine militante Antwort auf die faschistische Einschüchterung hätte sehr wahrscheinlich ein gemeinsames Vorgehen von Faschisten und Polizei und damit eine sichere Niederlage der Linken zur Folge gehabt, zumal die Arbeiterbewegung in Carrara trotz verbalradikaler Reminiszenzen und gelegentlicher militanter Individualaktionen, vor allem von anarchistischer Seite, auf Bürgerkriegsauseinandersetzungen psychologisch, politisch und organisatorisch nicht vorbereitet war.

Nicht einmal zehn Tage nach dem ersten organisierten Auftreten der Faschisten in Carrara befanden sich die sovversivi hoffnungslos in der Defensive. Dies läßt sich aus der lokalen Situation allein nicht erklären. Nur vor dem Hintergrund der in weiten Teilen der Emilia und der Toskana schon etablierten Machtpositionen des Faschismus war dieser rasche Erfolg möglich. Die Faschisten konnten auf andernorts mit Erfolg erprob-

${ }^{16}$ Der Polizeikommissar berichtet dem Questore über die faschistischen Drohungen, ohne auch nur eine einzige Maßnahme zu ergreifen oder vorzuschlagen. Aus den Dokumenten ist nicht zu erkennen, daß der Questore das Verhalten des Kommissars mißbilligt.

17 Einsatzbefehl (ordine di servizio) des Polizeikommissars von Carrara an Comandante del presidio militare vom 21. 5. 1921.

${ }^{18} \mathrm{Daß}$ die Arbeiterführer die Situation sehr nüchtern und zutreffend einschätzten, zeigen die Ausführungen in der sozialistischen Lokalzeitung La Battaglia vom 28. 5. 1921: „Und weil die staatlichen Stellen [...], die behaupten, ihnen läge Freiheit und Ordnung so am Herzen, nicht nur nicht die Ankunft der Faschisten verhindert, sondern mit den zahlreichen in Carrara kasernierten "guardie regie" ihren Schutz übernommen hätten, entschlossen sich die politischen und gewerkschaftlichen Organisationen, die Kundgebung abzublasen, um ein unnötiges Blutvergießen zu vermeiden."

19 Bei den Parlamentswahlen vom Mai 1921 erhielten in Carrara (Gemeinde) die Republikaner $50,5 \%$, die Sozialisten 16,6\% und die Kommunisten 5,6\% der Stimmen (Bianchi, Lotte sociali, S. 156). Hinzu kommen noch die Wahlenthaltung übenden Anarchisten.

${ }^{20}$ Das jedenfalls scheint der Mitgliederstand zum Zeitpunkt der Gründung am 12. 5. 1921 gewesen zu sein; ASM, Commissariato Carrara, b. 55: Bericht zur Entstehung der faschistischen Bewegung ohne Datum, circa Ende Juli 1921. 
te Aktionsformen und auf die Einschüchterungswirkung der kampfstarken auswärtigen Squadren zurückgreifen. Auch die versteckte Unterstützung von seiten der Polizeiorgane war an anderen Orten schon erprobt und hatte sich für die einzelnen sympathisierenden Staatsdiener meistens als ziemlich risikofrei erwiesen.

Die allgemein unerwarteten Ereignisse von Marina di Carrara spielten die Rolle einer Initialzündung für eine nicht abreißende Kette von gewalttätigen Auseinandersetzungen, in deren Verlauf die Faschisten zunehmend an Boden zu gewinnen vermochten, während sich der Aktionsspielraum der Linken immer stärker einengte. Im Anschluß an die Vorfälle bei der Wahlkundgebung des Blocco nazionale hatten die Faschisten die Gunst der Stunde genutzt und waren in die Räumlichkeiten der Lega dei marinat ${ }^{21}$ und des Circolo socialista von Marina eingedrungen, wo sie das Mobiliar zerschlugen ${ }^{22}$. Damit fand diese "klassische“, in den Provinzen des Agrarfaschismus schon tausendfach praktizierte Aktionsform auch Eingang in den Alltag der Marmorprovinz. Die spedizioni punitive $e^{23}$ gegen die Einrichtungen der Arbeiterbewegung erwiesen sich, auch wenn keine Menschen zu Schaden kamen, als ein äußerst wirksames Mittel zur Einschüchterung und Demoralisierung, denn nicht selten wurden die Früchte jahrzehntelanger Organisations- und Spartätigkeit im Handumdrehen vernichtet. Ebenfalls noch am gleichen Tag zogen Gruppen von Faschisten erst durch die Straßen von Marina und später auch durch den Stadtkern von Carrara, wo sie stadtbekannte sovversivi mit gezücktem Revolver bedrohten und durchsuchten, zum Teil unter den Augen der Polizei ${ }^{24}$.

Auf diese Offensive der Gewalt reagierte die Linke zunächst mit großer Hilflosigkeit. Il Cavatore, die Zeitung der Camera del lavoro, bemühte sich, die faire Praxis der Arbeitskämpfe und den „Geist der ritterlichen Toleranz" in den politischen Auseinandersetzungen der Vergangenheit herauszustellen, was - so das Gewerkschaftsblatt - die bürgerliche Seite wiederholt zur Feststellung veranlaßt habe, der Faschismus sei „hier nicht vonnöten “25. Von seiten des kleinen Kerns der Fundamentalanarchisten hingegen kam eine militante Antwort. In der Nacht zum 18. Mai wurde vor der Haustür des Marmorindustriellen Gino Nicoli, dessen Sohn als Faschist bekannt war, eine Bombe mit starker Sprengkraft gefunden, die wegen der beschädigten Zündschnur nicht explodiert war. Die Polizei verdächtigte sofort die Angehörigen der beiden anarchistischen Zirkel Bruno Filippi und Germinal. Tatsächlich fanden die Beamten in einem zum Circolo Germinal gehörenden Garten ein Loch, in dem die Bombe anscheinend aufgewahrt worden war, und zwei weitere vergrabene Bombenhülsen, sowie 50 Zentimeter Zündschnur und eine Zündkapsel ${ }^{26}$. Das Polizeikommissariat erstattete auf Drängen der Questura von Massa gegen neun maßgebende Mitglieder des Zirkels Anzeige, ohne eine konkrete Verantwortung feststellen zu können ${ }^{27}$.

${ }^{21}$ Deutsch etwa: Gewerkverein der Seeleute.

${ }_{22}$ Il Cavatore vom 21. 5. 1921.

${ }^{23}$ Deutsch: Strafexpeditionen.

24 Wie Anm. 22.

${ }^{25}$ Ebenda.

${ }^{26}$ ASM, Commissariato Carrara, b. 55: Polizeikommissar an den Pretore von Carrara vom 20. 5. 1921.

${ }^{27}$ Ebenda: „Cenno sommario“ (Überblick) des Polizeikommissars zu den gewalttätigen Auseinandersetzungen Mai - Juli 1921 ohne Datum. 
Wenn man nicht, angesichts der geradezu operettenhaften Umstände des Attentatsversuchs, an eine inszenierte Provokation zu Lasten der Anarchisten denken will, was in diesem Fall weit hergeholt erscheint ${ }^{28}$, so wird hier die politische Naivität der mutmaßlichen Täter offenbar. Der stark verrostete Zustand der für die Bombenherstellung verwendeten Stahlhülsen läßt vermuten, daß das Material in Erwartung „der großen Gelegenheit" schon sehr lange in den Erdlöchern versteckt gelegen hatte ${ }^{29}$. Allein die technischen und konspirativen Unzulänglichkeiten bei der Attentatsvorbereitung machen jedoch deutlich, daß der Terrorismus kein wirklich ernstzunehmender Bestandteil der politischen Strategie der Anarchisten Carraras war, auch nicht ihres „harten Kerns“. Der Attentatsversuch erscheint mehr als eine kopflose Reaktion auf die unerwartete faschistische Offensive, bei der sich die Täter weder die abzusehende polizeiliche Reaktion noch den zu erwartenden politischen Schaden vor Augen geführt hatten, der bei einem geglückten Attentat noch bedeutend größer gewesen wäre ${ }^{30}$. Den radikalen Anarchisten des Germinal- und des Bruno Filippi-Zirkels ist allerdings zuzugestehen, daß sie die einzigen waren, die den Faschisten auf der Ebene der militanten Auseinandersetzungen in den folgenden Wochen nennenswert entgegentraten, wenn auch ihre weitgehend ziellosen Individualaktionen den Squadrismus nicht wirklich aufzuhalten vermochten.

Trotz des Verzichts der Arbeiterführer Carraras auf die Trauerkundgebung für den in Marina umgekommenen Sozialisten Gino Bertoloni trafen am frühen Morgen des 22. Mai Squadren aus Massa, Pietrasanta, Florenz und La Spezia in Carrara ein. Anscheinend ohne die Führung des lokalen Fascio informiert zu haben, drang eine kleine Gruppe Florentiner squadristi in den Sitz der Camera del lavoro ein, zertrümmerte Bilder von Errico Malatesta und Francisco Ferrer und entwendete unter anderem eine rote Fahne und eine Hellebarde. Der Sekretär der Camera del lavoro Alberto Meschi informierte sofort telephonisch den Vizekommissar Paolo Licata, der nicht weit vom Tatort entfernt Marcello Tallarigo, Sohn des Generals Armando Tallarigo, aber ansonsten eine drittrangige Figur innerhalb des florentinischen Faschismus, mit den „beschlagnahmten“ Gegenständen verhaftete ${ }^{31}$. Daraufhin rotteten sich circa 300, wahrscheinlich größtenteils auswärtige Faschisten vor dem Polizeikommissariat zusammen und forderten lautstark die Freilassung von Tallarigo. Der Kommissar nahm Fühlung mit der Führung des Fascio von Carrara auf, die offensichtlich über das eigenmächtige Handeln der Florentiner nicht

${ }^{28}$ Bombenattentate und -funde haben in Carrara verschiedentlich als Vorwand für Repressionswellen hauptsächlich gegen die Anarchisten gedient. In der zeitgenössischen Arbeiterpresse wie in der Literatur findet man in diesen Fällen die Vermutung, daß diese Vorwände staatlicherseits oder von der lokalen Rechten "geschaffen “ wurden. Vgl. die Einschätzung zu den zwei Bombenattentaten im Oktober 1920 bei Bianchi, Lotte sociali, S. 99 . Siehe außerdem die Umstände der Schließung der Camera del lavoro im Mai 1922, weiter unten, S. 190-193.

29 Wie Anm. 26. Bei den Anarchisten Carraras hielt sich eine Art eschatologische Revolutionserwartung. Waffen und Sprengstoff waren für den „Tag des Umsturzes“ versteckt, auf den man aber konkret gar nicht hinarbeitete. Ihre Revolutionsvorstellung war stark von der Revolte von 1894 geprägt, die völlig spontan ausgebrochen war und noch ganz im Stil des 19. Jahrhunderts ablief. Siehe hierzu Bernieri, Carrara moderna, S. 143-154.

30 Zwei terroristische Bombenattentate im Frühjahr 1921, die man den Anarchisten zuschrieb, haben der faschistischen Bewegung politisch enorm genützt: das auf die patriotische Demonstration in Florenz (27. 2. 1921) und das im Mailänder Diana-Theater (23.3. 1921). Allgemein zur Rolle der anarchistischen Militanz in dieser Phase: Vivarelli, Origini, Bd. 2, S. 515 - 519.

31 ASM, Commissariato Carrara, b. 55: Bericht des Vizekommissars Paolo Licata vom 23. 5. 1921. 
erfreut war, und arrangierte eine demonstrative Rückgabe der entwendeten Gegenstände an die Verantwortlichen der Camera del lavoro unter Mitwirkung von Renato Ricci und dem Präsidenten des Fascio Ghino Faggioni, die bei dieser Gelegenheit die Vorfälle öffentlich mißbilligten. Die Camera del lavoro verzichtete daraufhin auf eine Anzeige, und so wurde der Weg frei für die Freilassung von Tallarigo, die allerdings unter der Bedingung erfolgte, daß die auswärtigen Faschisten danach aus Carrara abzögen ${ }^{32}$.

Die von der Polizei zum Bahnhof in den Vorort Avenza eskortierten Florentiner Faschisten ließen es sich allerdings nicht nehmen, noch ein wenig die Muskeln zu zeigen: Sie dachten nicht daran, dort auf den nächsten Zug zu warten, sondern zogen weiter nach Marina, wo sie vor dem Sitz des republikanischen Ortsvereins forderten, daß neben der dort aufgezogenen roten Parteifahne auch die Nationalfahne geflaggt werden solle, worauf der streitbare Parteisekretär Ciro Dinucci auf jegliche Beflaggung verzichtete. Erst als die Florentiner im Meer gebadet und ausgiebig getafelt hatten, verließen sie Carrara, nicht ohne großmäulig angekündigt zu haben, sie würden aus Rache für den Verrat der örtlichen Faschisten und das Vorgehen der Polizei das nächste Mal mit zehn Lastwagen und Maschinengewehren zurückkehren und die Stadt „auseinanderneh$\operatorname{men}^{\star 33}$.

Die Interpretation dieser unkoordinierten und politisch mißlungenen ersten Aktion auswärtiger Squadren in Carrara wirft einige Schwierigkeiten auf. Hatten die Faschisten von Carrara ihre auswärtigen Gesinnungsgenossen nicht mehr rechtzeitig vom Verzicht der Linken auf die antifaschistische Kundgebung informieren können, oder waren diese der Eigengesetzlichkeit ihres Aktionismus folgend trotzdem gekommen? Wieso distanzierte sich die Führung des Fascio di combattimento von Carrara so demonstrativ vom Überfall der Florentiner auf die Camera del lavoro? Es spricht vieles dafür, daß der Verzicht auf die Konfrontation von seiten der Arbeiterführer die lokalen wie die auswärtigen Faschisten in eine gewisse Ratlosigkeit über das weitere Vorgehen stürzte. Am geringsten scheint die Ratlosigkeit bei den Florentiner Faschisten gewesen zu sein, die keinerlei Probleme damit hatten, die Arbeiterschaft insgesamt zu brüskieren ${ }^{34}$. Von daher war für sie eine Aktion gegen die Camera del lavoro, dem Herzstück der lokalen Arbeiterbewegung, die nächstliegende Sache. Für die Faschisten Carraras stellte sich das Problem etwas anders. Weder die lokalen Industriellen noch die für die öffentliche Ordnung verantwortlichen Beamten waren zu diesem Zeitpunkt an einer ungeschminkten Herausforderung der Gewerkschaftszentrale interessiert, die noch ohne weiteres in der Lage gewesen wäre, das Wirtschaftsleben der gesamten Region mit einem politischen Generalstreik lahmzulegen. Die Faschisten waren politisch und „militärisch“ noch nicht stark genug, um gegen den ausdrücklichen Willen der Polizeiführung und der tonangebenden

32 ASM, Commissariato Carrara, b. 55: Kommissar an Questore von Massa vom 22. 5. 1921.

${ }^{33}$ Ebenda. Der Kommissar berichtet außerdem sichtlich verunsichert von der Prahlerei des verhafteten Tallarigo, der dem Carabinieri-Hauptmann erzählt hatte, er sei jüngst nach der Verhaftung einiger Faschisten zum verantwortlichen Staatsanwalt gegangen und habe ihm gedroht, daßs er ihn aus dem Fenster werfen werde, falls er sie nicht bis zum nächsten Tag freigelassen habe, was dann auch prompt erfolgt sei.

34 Neben der erwähnten Landknechtsmentalität vieler Florentiner "squadristi“ ist hier in Rechnung zu stellen, daß Squadren sich im auswärtigen Einsatz fast immer skrupelloser verhielten als zuhause. Vgl. das Verhalten der Carrareser „squadristi“ in Monzone und Sarzana, weiter unten S. $91 \mathrm{f}$. 
Industriellen zu agieren. Es kommt hinzu, daß in der Marmorarbeiterstadt Carrara ${ }^{35}$ ein undifferenziert gewerkschaftsfeindliches Vorgehen politisch unklug gewesen wäre, und als solches - so fürchtete wohl die Führung des Fascio - wäre ein nicht „wiedergutgemachter" Überfall auf die Camera del lavoro aufgefaßt worden. Bei den konservativen und nicht parteigebundenen sowie bei der großen Zahl der republikanisch orientierten Gewerkschaftsmitglieder rechneten sich die Faschisten, nicht ganz zu Unrecht, Rekrutierungschancen aus, die sie durch einen frontalen Angriff auf die Camera del lavoro, so vermutlich die Befürchtungen, eventuell zunichte gemacht hätten. Denn untrennbar war ihre Geschichte mit der Verbesserung der Lebens- und Arbeitsbedingungen der Marmorarbeiterschaft verbunden, dessen war sich der Arbeitersohn Renato Ricci sicherlich bewußt. Außerdem verfolgte Ricci in der Anfangszeit den illusorischen Plan, den Gewerkschaftsapparat - eventuell mit Hilfe republikanischer und anderer Überläufer als ganzes zu übernehmen, sobald der Squadrismus die politischen Organisationen der Arbeiterbewegung handlungsunfähig gemacht habe ${ }^{36}$.

Den Faschisten Carraras fiel es anfangs sichtlich schwer, ihre politische Daseinsberechtigung unter Beweis zu stellen. Ein Frontalangriff auf die Gewerkschaftsorganisation war nicht ratsam. Die Kommunisten und Sozialisten waren zu schwach und letztere auch im ganzen zu gemäßigt, um eine geeignete Zielscheibe abzugeben. Der Anarchismus war durch die bewährte faschistische Gewaltstrategie schwer zu fassen. Außer in den Gewerkschaften äußerte er sich nur in kleinen Zirkeln, welche allerdings in einer breiten „gefühlsanarchistischen“ Arbeiterkultur schwammen, die bis weit in die marxistischen Parteien und die republikanische Partei hineinwirkte ${ }^{37}$. Die Republikaner ihrerseits waren sicherlich politisch das größte Hindernis für eine Durchsetzung des Faschismus in Carrara, aber auch sie boten nur geringe Angriffsflächen. Ihnen konnte wirklich kein mangelnder Patriotismus oder gar eine antiitalienische Gesinnung vorgeworfen werden.

Nach der unwillkommenen Aktion der Florentiner, die dem Fascio politisch hauptsächlich geschadet hatte, galt es, am eigenen Profil zu arbeiten. Dazu bot sich der Jahrestag der Kriegserklärung Italiens an Österreich-Ungarn am 24. Mai an. Als Ort für eine patriotische Demonstration wählten die Faschisten die Provinzhauptstadt Massa, in der anders als in Carrara traditionell die ehemaligen „Neutralisten “ - Sozialisten, Kommunisten und popolari-dominierten ${ }^{38}$. Eine klare Konfliktlinie war hiermit gesichert. Außerdem mußte dem noch schwächlichen Fascio von Massa mit einer Kraftdemonstration die notwendige Starthilfe gegeben werden.

35 Im Gemeindegebiet von Carrara waren 1921 allein circa 45\% der Berufstätigen Marmorarbeiter. Die Arbeiterquote insgesamt betrug ungefähr $60 \%$. Daten berechnet nach Censimento della popolazione 1921, Bd. 7, S. 294 - 319; siehe die Tabellen zur Berufsstruktur Carraras im Anhang, S. 286.

${ }^{36}$ Siehe weiter unten, S. $67 \mathrm{f}$.

37 In den zwei Jahrzehnten vor dem Ausbrechen des Ersten Weltkriegs hatte es in Carrara eine enge Allianz zwischen Anarchisten und Republikanern gegeben, die gegen die damals eindeutig reformistischen Sozialisten gerichtet war, und der abgesehen von pragmatischen Erwägungen auch ideologische Gemeinsamkeiten zugrunde lagen (Bernieri, Carrara moderna, S. 161-166). Der sogenannte "repubblicano anarchiggiante" war in der politischen Landschaft der Marmorprovinz von Carrara wie auch in der der Romagna und der Marken eine verbreitete Figur.

${ }^{38}$ Bei den Kommunalwahlen im Oktober 1920 hatten die Sozialisten die relative Mehrheit der Stimmen und wegen der Zersplitterung der restlichen Stimmen auf die anderen Listen 32 der 40 Stadt- 
Am Morgen des 24. Mai 1921 „besetzten“ Faschisten aus Carrara und Massa das Stadtzentrum und erwirkten die Beflaggung der meisten Privathäuser mit der Nationalfahne. Ob auch öffentliche Gebäude geflaggt hatten, darüber gehen die Angaben in den Quellen auseinander ${ }^{39}$. Jedenfalls handelte es sich um keinen offiziellen Staatsfeiertag, und so weigerte sich die sozialistische Kommunalverwaltung am Rathaus zu flaggen. Wahrscheinlich war es ohnehin das Hauptanliegen der Faschisten gewesen, die Masseser Sozialisten zu diesem Akt zu zwingen, der in einem demütigenden Gegensatz zu ihrer Haltung hinsichtlich der italienischen Kriegsbeteiligung gestanden hätte. Zunächst schien es, die Kraftprobe würde zugunsten der Faschisten ausgehen. Sie hißten die Fahne gegen den Widerstand der anwesenden Kommunalangestellten, die aus Protest gegen dieses gewaltsame Vorgehen das Gebäude verließen. Doch wenig später veranlaßten die sozialistischen assessori comunali Nardini und Balloni das Wiedereinholen der Fahne, während sich auf dem Rathausvorplatz schon eine große Anzahl von Sozialisten und Kommunisten versammelten, bereit, den Faschisten gewaltsam entgegenzutreten. Diese holten ihrerseits Verstärkung heran, es gelang ihnen aber nicht, wie beabsichtigt, die Fahne ein zweites Mal aufzuziehen. Ersatzweise versuchten sie, den energischen assessore Rinaldo Balloni zu provozieren. Nach einem üblichen faschistischen Ritual wurde er aufgefordert, zu einem „Verhör“ zum Sitz des örtlichen Fascio mitzugehen, als ob es sich um „eine Nebenstelle der Questura" handle, wie das katholische Lokalblatt La Difesa popolare ironisch bemerkte ${ }^{40}$. Auf die entschiedene Weigerung Ballonis hin stürzte sich ein Faschist auf ihn und riß ihm den Revolver aus der Tasche. Die Tätlichkeiten wurden durch das Eingreifen von Polizisten beendet, die Balloni, Renato Ricci und den Sekretär des Fascio von Massa, Ubaldo Bellugi, in die Questura führten, wo die beiden Faschistenführer den Rücktritt von Balloni gefordert haben sollen. Auf diese Vorfälle hin riefen Gewerkschaften, Sozialisten, Kommunisten, Anarchisten und der kleine Partito mazziniano intransigente einen sechsstündigen allgemeinen Proteststreik aus ${ }^{41}$. Bezeichnenderweise lehnten die Masseser Republikaner die Teilnahme an dem gemeinsamen antifaschistischen Demonstrationsstreik kategorisch ab; viel größer war ihre Distanz zur Arbeiterbewegung als bei ihren Parteigenossen in Carrara. Außerdem bestanden zweifellos gerade in diesem Fall nicht unerhebliche innerparteiliche Sympathien für die patriotische Aktion der Faschisten gegen die in Massa sonst so übermächtigen „Vaterlandsverleugner ${ }^{* 42}$.

ratssitze erlangt. Bei den nationalen Wahlen im Mai 1921 konnten die Republikaner außerordentlich zulegen. Die Ergebnisse: Republikaner 30,53\%, „popolari“ 22,30\%, Sozialisten 20,72\%, Kommunisten 12,38\%, „Blocco nazionale“ $8,26 \%$, „liberali dissidenti“ $5,69 \%$ (Bianchi, Lotte sociali, S. 121 und 159).

39 Die folgende Darstellung folgt im wesentlichen dem Bericht der Difesa popolare und der Battaglia comunista, beide vom 28. 5. 1921. Außerdem Bericht des Präfekten Grignolo an das Innenministerium vom 25. 5. 1921, der zu den Presseberichten zum Teil im Widerspruch steht (ACS, MI, DGPS 1921, b. 101, f. „Fasci Massa“).

40 La Difesa popolare vom 28. 5. 1921.

${ }^{41}$ Bei der Aussage über den Erfolg des Streikaufrufs gehen die Quellen auseinander: La Battaglia comunista vom 28. 5. 1921 berichtet von einem "sehr geschlossenen“ ("compattissimo “) Streik. La Difesa popolare vom 28. 5. 1921 schreibt dagegen, daß der Streik nicht total war, weil die Präfektur die Öffnung der Läden anordnete.

42 Alle Anzeichen sprechen dafür, daß die Mitgliederstruktur der republikanischen Organisationen in Massa mittelständischer als in Carrara war. Die politische Kluft zu den marxistischen Arbei- 
Trotz eines gewissen Bemühens der Polizeikräfte, rechtsstaatliche Verhältnisse zu wahren, war auch in diesem Fall ihre Parteilichkeit unübersehbar. Spöttisch schrieb die ganz und gar nicht radikale Difesa popolare: „Es wurden sehrviele Personen durchsucht, ausgenommen diejenigen, die mit dem faschistischen Abzeichen geschmückt waren, weil sie als den Guardie regie zugehörig betrachtet werden, von denen sie sich auch tatsächlich nicht unterscheiden. ${ }^{43}$ Den Faschisten gelang es, in der folgenden Nacht trotz starker Polizeipräsenz in das an der zentralen Piazza Alberica gelegene sozialistische Parteilokal einzudringen, es zu verwüsten und Akten sowie Fahnenstangen mitzunehmen ${ }^{44}$, weil die Carabinieri-Patrouille, die die Vorgänge bemerkt hatte, angeblich erst noch Verstärkung in der Kaserne holen mußte, um ihnen entgegentreten zu können ${ }^{45}$.

Nach dem Intermezzo im traditionell ruhigeren Massa verschob sich der Schwerpunkt der Auseinandersetzungen wieder nach Carrara, wo die sozialen und politischen Gegensätze seit jeher stärker waren. In der Woche vom 28. Mai bis zum 3. Juni steigerten sich die gewalttätigen Konflikte zu einem bürgerkriegsähnlichen Zustand: Ausgangspunkt waren ständige kleine Händel zwischen den Anarchisten, hauptsächlich des Germinal-Zirkels, und den Faschisten. Nachdem diese am 26. Mai in der angemaßten Rolle einer Ersatzpolizei eine Gruppe von Anarchisten nach Waffen durchsucht und dann nach Hause geschickt hatten, provozierten jene sie zwei 'Tage später mit Pöbeleien vor dem Fascio-Lokal ${ }^{46}$. Die Faschisten eilten auf die Straße und ergriffen Romualdo Del Papa, den Sohn des verstorbenen charismatischen Anarchistenführers Ugo Del Papa, rissen ihm die rote Nelke aus dem Knopfloch und verletzten ihn mit mehreren Stockschlägen ${ }^{47}$. Die Anarchisten konterten am nächsten Tag mit einem Überfall auf den Faschisten Aldo Bezzi, den sie ebenfalls mit Stockschlägen traktierten. Wiederum als Reaktion darauf überfielen die Faschisten den Circolo Germinal, es kam dort zu einer Schießerei, bei der der Anarchist Paride Barattini eine Schußverletzung am Fuß erlitt ${ }^{48}$. Wenig später wurde eine Gruppe Faschisten überfallen und dabei der Marmorunternehmerssohn Remo Lagomarsini verletzt ${ }^{49}$.

Die Auseinandersetzungen eskalierten in der Nacht vom 29. auf den 30. Mai, als sich nach der Detonation einer Bombe, die die Polizei als vereinbartes Zeichen der sovversivi deutete, in der ganzen Stadt Schießereien entwickelten ${ }^{50}$. Schüsse, die wahrscheinlich einem Sympathisanten des Fascio, dem 18jährigen Oberschüler Franco Menichelli, gegol-

terparteien war nicht unmaßgeblich durch die Auseinandersetzungen um Krieg und Patriotismus bedingt, die auch wiederum in Massa eine größere Rolle spielten als in Carrara und bis hin zu gewalttätigen Konflikten mit Todesopfern führten. Die Situation in Massa ähnelt so ein wenig den Verhältnissen in der Romagna, wo sich eine starke profaschistische Strömung innerhalb der republikanischen Partei bildete. Siehe Fedele, Repubblicani, S. 189-200.

${ }^{43}$ La Difesa popolare vom 28. 5. 1921.

44 Ebenda und ACS, MI, DGPS 1921, b. 101, f. „Fasci Massa“: Präfekt an Innenministerium vom 26. 5. 1921.

45 Ebenda.

46 ASM, Commissariato Carrara, b. 55: Kommissar an Questore vom 27. 5. 1921.

47 Ebenda: Bericht des Befehlshabenden der Carabinieri-Station von Carrara, Hauptmann Giovanni Benni, vom 31. 5. 1921.

48 Ebenda und Kommissar an Questore vom 29. 5. 1921.

49 Bericht wie Anm. 47.

${ }^{50}$ Ebenda. 
ten hatten, trafen Mutter und Schwester, die ihn begleiteten ${ }^{51}$. Die Verletzung der beiden Frauen offenbart die hysterische Ziellosigkeit in der Aktion der Linken, die nur den Effekt hatte, daß sich die Stimmung gegen die Antifaschisten wendete. Durch eine allgemeine Entrüstung über den Vorfall ermuntert, stürmten die Faschisten zusammen mit Polizeieinheiten unter der Führung des mittlerweile deutlich faschistenfreundlichen Vizekommissars Licata die Casa socialista. Die dort Verbarrikadierten verteidigten sich mit Schußwaffen, doch ihr Widerstand wurde schnell gebrochen. Die Faschisten drangen in das Haus ein und verwüsteten es, während die Polizei die inzwischen über den Hof geflohenen Verteidiger verfolgte und verhaftete ${ }^{52}$. Es folgten polizeiliche Durchsuchungen der Camera del lavoro, des Circolo comunista und der beiden anarchistischen Zirkel Germinal und Bruno Filippi, bei denen aber weder Waffen noch Sprengstoff gefunden wurden ${ }^{53}$. Die Carabinieri sperrten außerdem alle Zugänge in die Stadt und verhängten in der Nacht de facto die Ausgangssperre ${ }^{54}$.

Am folgenden Tag traten die Arbeiter aus Protest gegen die Übergriffe der Faschisten und der Polizei spontan in den Streik. Von seiten der örtlichen Carabinieri-Führung ging jetzt ein Versuch zur Beilegung der Auseinandersetzungen aus, der aber bei Renato Ricci auf entschiedenen Widerstand stieß. Offen bekundete er seine Absicht, mit den gewalttätigen Aktionen fortzufahren und dafür Squadren aus anderen Städten zu Hilfe zu rufen ${ }^{55}$. Die Camera del lavoro dagegen erklärte sich bereit, zur Wiederaufnahme der Arbeit aufzurufen, unter der Bedingung, daß die faschistischen Gewalttätigkeiten aufhörten ${ }^{56}$. Die Carabinieri versprachen, hierfür zu sorgen, und erreichten so den Abbruch des Streiks noch am Nachmittag des gleichen Tages. Auch die Faschisten verpflichteten sich jetzt, die Feindseligkeiten bis zu einer vom Carabinieri-Kommando angeregten Zusammenkunft aller an den Auseinandersetzungen beteiligten Gruppen am nächsten Tag einzustellen, die zu einer Art langfristigem Waffenstillstand führen sollte ${ }^{57}$. In der Zwischenzeit waren allerdings faschistische Squadren aus Massa und Pisa eingetroffen, deren Führer sich zunächst auf die Abmachung einließen, aber schließlich doch nicht willens oder in der Lage waren, ihre Leute zu bremsen. Die örtliche CarabinieriFührung war entschlossen, keine Gefährdung der Übereinkunft durch Individualaktionen einzelner Squadren zuzulassen, doch es gelang ihr nicht ganz, die Faschisten am Zügel zu halten. So verübten sie einen Überfall auf den Circolo Germinal im Vorort Ortomurano und lösten ein Scharmützel mit den Einwohnern von Fossola aus. Als am späten Abend weitere 200 squadristi aus Pietrasanta, Seravezza, Viareggio und Livorno eintrafen, griffen die verantwortlichen Carabinieri-Offiziere zu einer unge-

51 Ebenda, siehe auch die Darstellung von Il Giornale di Carrara vom 4. 6. 1921.

52 Ein Indiz für die schon fortgeschrittene Abkehr des lokalen Bürgertums von liberaldemokratischen Auffassungen ist die Selbstverständlichkeit, mit der Il Giornale di Carrara vom 4. 6. 1921 diese allen rechtsstaatlichen Prinzipien spottende "Arbeitsteilung" $z$ wischen Polizei und Faschisten darstellt.

53 Wie Anm. 47. Eine zusammenfassende Darstellung der Ereignisse findet sich auch in den Berichten des Präfekten vom 30. 5. und 31. 5. 1921 (ASM, MI, DGPS 1921, b. 101, f. „Fasci Massa“).

54 Ebenda.

55 Ebenda.

56 Ebenda.

${ }^{57}$ Ebenda. Il Giornale di Carrara vom 4. 6. 1921 spricht noch von weiteren Überfällen auf Einrichtungen der Arbeiterbewegung, über die sich der Polizeibericht ausschweigt. 
wöhnlichen Maßnahme. Sie eskortierten die Faschisten mit großem Polizeiaufgebot in die Carabinieri-Kaserne von Carrara, wo sie nicht ganz freiwillig festgehalten wurden, bis ihre Führer fest zusagten, keine Aktionen bis zu den geplanten Befriedungsverhandlungen am nächsten Morgen zu unternehmen. Dieses im lokalen wie im nationalen Maßstab vergleichsweise entschiedene Vorgehen gegenüber den Faschisten führte zu einem Konflikt zwischen dem Carabinieri-Major Cenisio Fusi, Kommandant der Division von Massa-Carrara, und den durchwegs faschistenfreundlichen zivilen Polizeifunktionären, vor allem dem Vicequestore Giustiniani und dem Vizekommissar von Carrara Alfredo De Gattis ${ }^{58}$.

Trotz dieser Vorkehrungen des Carabinieri-Kommandos kam die Stadt allerdings noch nicht zur Ruhe. Einige squadristi versuchten noch in der Nacht, in die Camera del lavoro einzudringen, wurden aber von dem dort zur Bewachung abkommandierten Posten abgehalten. Wenig später faßte die Polizei zwei Anarchisten, die im Begriff waren, vor dem Fascio-Lokal eine selbstgebastelte Bombe zu legen, was belegt, daß die versöhnliche Haltung der anarchosyndikalistischen Führer der Gewerkschaftszentrale in den Kreisen der anarchistischen Clubs nicht durchwegs geteilt wurde.

Am folgenden Tag, dem 31. Mai, fand im Rathaus von Carrara die geplante Zusammenkunft der verschiedenen politischen Kräfte zur „sozialen Befriedung“ statt. Die Faschisten hatten ihre Teilnahme davon abhängig gemacht, daß der ihnen wohlgesinnte Vicequestore von Massa Giustiniani die Versammlung leite ${ }^{59}$. Anwesend waren unter anderem Renato Ricci sowie die Squadrenführer aus Pietrasanta, Seravezza, Viareggio und Livorno, respektive Claudio Papini, Giuseppe Silicani, Lino Reggiani und Galliano Baldini, außerdem die Vertreter der Liberalen, Oreste Nori und Emilio Orsini, die Republikaner Gioberto Raffo und Nello Tofanari, der Sozialist Migliario und der Kommunist Giuseppe Bibolotti. Als politische Schirmherren der Initiative nahmen der republikanische Bürgermeister Edgardo Starnuti von Carrara und der ebenfalls republikanische Parlamentsabgeordnete aus Carrara Eugenio Chiesa teil ${ }^{60}$. Anárchisten und Camera del lavoro blieben der Sitzung demonstrativ fern; man kann vermuten, daß sie die Initiative in Verkennung der Rolle der Carabinieri-Führung für ein abgekartetes Spiel zwischen Polizei und Faschisten hielten. Mit Tofanari, der nur im Namen der Republikaner reden konnte, war allerdings ein Mitglied der Exekutivkommission der Gewerkschaftskammer gleichsam als Beobachter anwesend.

Die Versammlung begann gleich mit einer Provokation der Faschisten: Sie forderten die Verbannung der Arbeiterführer aus Carrara, und Giustiniani mußte ihnen die Illegalität dieses Anliegens auseinandersetzen ${ }^{61}$. Nach einer langen heftigen Diskussion wurde dann eine Resolution verabschiedet, mit der sich die Versammelten verpflichteten, die

\footnotetext{
58 ACS, MI, Gabinetto Bonomi, b. 4, f. 43: De Gattis und Giustiniani an Questore vom 31. 5. 1921; ACS, MI, DGPS 1921, b. 101, f. „Fasci Massa“: Untersuchungsbericht des Gruppenkommandos der Carabinieri Florenz vom 2. 12. 1921. Interessant ist in diesem Zusammenhang, daß der Sohn von Giustiniani Mitglied des Fascio von Massa war (Bericht von Trani vom 4. 8. 1921 in Costantini, Sarzana, S. 93).

59 ASM, Commissariato Carrara, b. 55: Vicequestore an Questore und Präfekten vom 31. 5. 1921.

60 Unterschriften unter dem Schlußdokument, abgedruckt in Il Giornale di Carrara vom 4. 6. 1921.

61 Wie Anm. 59.
} 
Anhänger ihrer politischen Gruppierung zur Friedlichkeit und Mäßigung anzuhalten, „so daß sich jedwede Propaganda frei und ungestört entfalten könne, die nicht antiitalienisch sei ${ }^{\text {“62 }}$.

Wenn man sich vor Augen führt, wie inflationär die Faschisten mit dem Stempel des Antiitalienischen alles brandmarkten, was ihnen nicht gefiel, kommt diese Resolution allerdings der Akzeptierung eines Maulkorbs und damit der politischen Kapitulation zumindest der Sozialisten und Kommunisten gleich. Internationalismus, Pazifismus, Klassenkampf, also zentrale politische Inhalte der Linken, wurden von der politischen Rechten seit den Tagen der Kriegspropaganda an der sogenannten „inneren Front“ als fortgesetzter Landesverrat betrachtet, und allein die Zurschaustellung der Parteisymbole, etwa der roten Fahne, galt schon als antiitalienische Propaganda ${ }^{63}$. Die Unterschrift der Vertreter der Arbeiterparteien unter eine Resolution mit dieser eindeutig gegen sie gerichteten Reiz- und Kampfvokabel macht offenbar, daß sie von einer Position der Schwäche aus verhandelt und ihr Heil in einer Appeasement-Haltung gesucht hatten. Sie taten dies, ohne in einer wirklichen Notlage zu sein, denn trotz des Klimas der Einschüchterung, das die Faschisten verbreiteten, war die organisatorische Basis der Arbeiterbewegung noch nicht substantiell angeschlagen, wie der gelungene spontane Generalstreik des Vortages gezeigt hatte. Das Exekutivkomitee des kommunistischen Provinzialverbands reagierte auf diesen Fauxpas prompt mit dem Parteiausschluß von Giuseppe Bibolotti wegen "schweren und unentschuldbaren Akts des politischen Unverständnisses und der Disziplinlosigkeit“ und bezeichnete das Abkommen als „eine grausame Verhöhnung des Proletariats“64.

Die Vereinbarung dokumentiert noch einmal deutlich die politische Schwäche von Sozialisten und Kommunisten in Carrara. Durch die Abwesenheit der anarchosyndikalistischen Führer der Camera di lavoro bei der Sitzung erhielt sie fast den Charakter einer bilateralen Übereinkunft zwischen Faschisten und Republikanern, deren politische Überzeugungen durch den Wortlaut des Resolutionstextes nicht berührt waren. Die aktive Teilnahme von Eugenio Chiesa, einem der führenden Köpfe der Partei auf nationaler Ebene, verweist auf die große politische Bedeutung der Übereinkunft für den PRI. Die Offensive der Faschisten in ihrer Hochburg Carrara beunruhigte die republikanischen Parteiführer. In einem Interview mit dem Giornale d'Italia konstatierte Chiesa eine Tendenz zur Abwanderung von Republikanern zu den Faschisten ,aus jugendlichem Ungestüm" und betonte gleichzeitig, daß die republikanische Partei in keinem Fall Angriffe auf die Errungenschaften der Arbeiterbewegung dulden könne ${ }^{65}$. Als eine Partei mit ideologischen Affinitäten zum Ursprungsfaschismus und starker Verankerung im Mittel-

62 Il Giornale di Carrara vom 4. 6. 1921.

${ }^{63}$ Mit der Verteidigung des Nationalen, der „italianità ", legitimierten sich die Aktionen der Faschisten, die ansonsten auf einem ideologisch wie politisch sehr dürftigen Fundament standen. Der gnadenlose Kampf der „squadristi“ gegen die Linke verstand sich als Aufbruch der Nation gegen die antinationalen und zersetzenden Elemente in der Gesellschaft, auch dann, wenn er nicht viel mehr bedeutete als militante Interessenvertretung von Agrariern und Industriellen. Erfolgreiche Kämpfe gegen „rote" Kommunalverwaltungen wurden mit dem Hissen der Nationalfahne an den Rathäusern zelebriert, die Einschüchterung oder Gleichschaltung von Gewerkschaften und Genossenschaften durch das Anbringen von trikoloren Bändern an die Vereinsfahne.

${ }_{64} \mathrm{La}$ Battaglia comunista vom 4. 6. 1921.

${ }^{65}$ Das Interview wurde auszugsweise abgedruckt in La Sveglia repubblicana vom 4. 6. 1921. 
stand, die aber gleichzeitig traditionelle Bindungen zur Arbeiterbewegung besaß, war sie durch die gewalttätige faschistische Polarisierungsstrategie in ihrem Kern bedroht, ohne schon zu ihrer direkten Zielscheibe geworden zu sein ${ }^{66}$.

Nach der Bekanntgabe des Abkommens durch öffentliche Plakatierung reisten die Squadren aus Pietrasanta, Seravezza, Viareggio und Livorno, deren Führer es unterschrieben hatten, $a b^{67}$. Es ist äußerst unwahrscheinlich, daß sie die ausgehandelte „Befriedung" wirklich ernst nahmen, doch wollten sie wohl nicht als offensichtliche Vertragsbrecher erscheinen. Auch die einheimischen Faschisten hielten sich zunächst ruhig, und es ist kein Zufall, daß der nächste schwere Zwischenfall zwei Tage später von einer verspätet eingetroffenen Florentiner Squadra unter der Führung des berüchtigten Amerigo Dumini ausgelöst wurde. Es ist wahrscheinlich, daß sie mit der Absicht der Sabotierung der Befriedungsbemühungen in Carrara blieb, war doch die Übereinkunft im Direktorium des Florentiner Fascio, das sich für die gesamte Toskana verantwortlich fühlte, auf völlige Ablehnung gestoßen ${ }^{68}$.

Eine Gruppe dieser squadristi stieß am 2. Juni bei einem ihrer „Patrouillengänge“ auf die junge Clara Lazzeri, die eine rote Blume am Kleid trug. Die Faschisten fühlten sich von dem gegnerischen Symbol so provoziert, daß sie das Mädchen zwangen, die Blume wegzuwerfen. Als der Bruder Remo Lazzeri aus dem nahegelegenen Haus der Familie ihr zur Hilfe kam, prügelten sie auf ihn ein und entrissen ihm die Manschettenknöpfe mit eingeprägten Hammer und Sichel. Wutentbrannt eilte jetzt auch der ältere Bruder Renato Lazzeri, ein kriegsversehrter Kommunalarbeiter, herunter und schoß mit seinem Revolver mehrmals auf die Faschisten. Am Kopf schwer getroffen brach der squadrista Gastone Miniati zusammen. Renato Lazzeri wurde ebenso wie seine Mutter, die ebenfalls aus dem Haus gestürzt war und sich verzweifelt vor ihren Sohn geworfen hatte, augenblicklich von den Faschisten erschossen ${ }^{69}$. Diese Todesschüsse werden in der Literatur durchwegs dem späteren Matteotti-Mörder Amerigo Dumini zur Last gelegt, obwohl es in den Quellen dafür keine wirklichen Anhaltspunkte gibt ${ }^{70}$. Die Justiz sparte sich jegliche Anklageerhebung wegen Mordes oder Totschlags und beschränkte sich lediglich darauf, dem Verletzten Miniati und einem weiteren Faschisten aus Florenz, Raf-

${ }^{66}$ Nachdem die "fatti di Marina“ zunächst die Republikaner in vorderster Front in die Auseinandersetzungen mit den Faschisten hineingezogen hatten, bemühten sich beide Seiten jetzt um Zurückhaltung. Bei den Aktionen der letzten Maitage wurden weder republikanische Einrichtungen noch Anhänger der republikanischen Partei von den Faschisten angegriffen.

67 Wie Anm. 59.

${ }^{68}$ ACS, MI, DGPS 1921, b. 101, f. „Fasci Massa“: Präfekt von Massa an Innenministerium vom 9.6. 1921 .

${ }^{69}$ Die Rekonstruktion des Tathergangs basiert auf den Berichten von Il Giornale di Carrara und La Sveglia repubblicana, beide vom 4. 6.1921, sowie auf dem Bericht des Präfekten vom 2. 6. 1921 (ACS, MI, DGPS 1921, b. 101, f. „Fasci Massa“) und dem tabellarischen Überblick des Polizeikommissariats Carrara ohne Datum(ASM, Commissariato Carrara, b. 55). Der von Bianchi, Lotte sociali, S. 166, zitierte Bericht des Polizeikommissariats Carrara konnte an der angegebenen Stelle nicht gefunden werden.

70 Die These der Täterschaft von Dumini fand vor allem durch E. Lussu, Marcia su Roma e dintorni, Rom 1945, S. 165 f., Verbreitung. Ebenso Bianchi, Lotte sociali, S. 166, und Bernieri, Carrara moderna, S. 191. 
faele Talamini, die bewaffnete Nötigung und Gewaltanwendung gegenüber Clara und Remo Lazzeri vorzuwerfen ${ }^{71}$.

Es ist aufschlußreich für die selbstgerechte Psychologie der Faschisten, daß sie sich, obwohl sie selbst den Vorfall provoziert und diesmal auch das Leben einer wehrlosen Frau auf dem Gewissen hatten, als die Opfer des Zusammenstoßes gebärdeten, denen jetzt auch noch Rache zustand. Unmittelbar nach dem Vorfall drangen einige squadristi in das Haus des exponierten Anarchisten und ehemaligen Vizesekretärs der Camera del lavoro, Umberto Pedruzzi, ein und verbrannten den gesamten Hausrat ${ }^{72}$. Andere Faschisten durchstreiften provozierend das Arbeiterviertel Grazzano, verfolgten den Anarchisten Vittorio Pasquini, der in seinem Laden Zuflucht suchen mußte, und jagten mehrere Pistolenschüsse durch die verschlossene Tür, ohne ihn allerdings zu treffen ${ }^{73}$. In der Nacht suchten Florentiner squadristi den vorwiegend von Steinbrucharbeitern bewohnten Bergort Torano heim, wo sie in den Circolo comunista einbrachen und die Einrichtung verwüsteten. Sie fanden dort Sprengstoff, Bombenhülsen und Zündschnur, was sie dazu bewog, kurzerhand den Hausmeister des Vereinslokals in seiner Wohnung zu überfallen und ihn nach Carrara zu verschleppen, um ihn dort an der Carabinieri-Kaserne abzuliefern ${ }^{74}$. Die Kidnapper blieben selbstverständlich auf freiem Fuß, so wie auch jene selbsternannten Ersatzpolizisten, die am gleichen Tag den populären sozialistischen Anwalt Vico Fiaschi zu „einem Verhör“ im Fascio-Lokal „vorübergehend festnahmen“. Das gleiche wiederfuhr dem Sekretär des kommunistischen Ortsvereins von Carrara, Lamberto Bonci ${ }^{75}$.

Die Aktionen wurden zwar jetzt hauptsächlich von den einheimischen Faschisten getragen, doch war die Scharfmacherrolle der Florentiner squadristi auch von außen so deutlich erkennbar, daß sich der $\mathrm{Haß}$ der sovversivi von Carrara ganz gegen sie und ihren Führer Dumini richtete. Nachdem den Florentinern von einer Gruppe junger Anarchisten auf theatralische Weise die Fehde erklärt worden war, wurde Dumini am 7. Juni von Unbekannten niedergeschossen, als er auf der Suche nach den „Herausforderern“ um ein Uhr nachts die zentrale Via Carriona entlangging ${ }^{76}$. Dumini erlitt nur eine leichte Schußverletzung am Oberschenkel und wurde am folgenden Tag in ein Krankenhaus nach Florenz überführt. Unmittelbar nach dem Attentat wiederholte sich das mittlerweile gewohnte Schauspiel der faschistischen Amtsanmaßung. Parallel zu den zahlreichen Hausdurchsuchungen der Polizei veranstalteten die squadristi in den Häusern am Tatort ihre eigene Razzia, ohne daß die Ordnungshüter eingriffen. Weder die einen noch die anderen konnten allerdings irgendwelche Waffen oder gar Tatverdächtige aufspüren ${ }^{77}$.

71 ASM, Tribunale di Massa, Sentenza penale 1922/263 (30. 12. 1922). Die Angeklagten wurden aufgrund der Amnestie vom 22. 12. 1922 freigesprochen, da es das Gericht als erwiesen ansah, daß die Tat ${ }_{n}$ mit nationalem Ziel ${ }^{\alpha}$ begangen worden war.

72 Il Giornale di Carrara vom 4. 6. 1921 und ACS, MI, DGPS 1921, b. 101, f. „Fasci Massa“: Präfekt von Massa an Innenministerium vom 18. 6. 1921.

73 ASM, Commissariato Carrara, b. 55: „Cenno sommario“ ohne Datum.

${ }^{74}$ Ebenda.

75 Il Giornale di Carrara vom 4. 6. 1921.

76 ASM, Commissariato Carrara, b. 55: Kommissar an Questore von Massa vom 7. 6. 1921 und Il Giornale di Carrara vom 11. 6. 1921. Sowohl der Polizei-als auch der Zeitungsbericht sprechen von dieser etwas merkwürdigen "Verabredung " nach Western-Manier.

77 Il Giornale di Carrara vom 11.6.1921. 
Auf den ersten Monat der faschistischen Aktivitäten in der Marmorregion zurückblickend, erkennt man keine geradlinige politische Gewaltstrategie. Die Aktionen, die oft fast den Charakter von spontanen Auseinandersetzungen hatten, zielten allerdings darauf ab, dem Gegner „die Straße $e^{\alpha}$ streitig zu machen, das heißt seinen Bewegungsspielraum in der Öffentlichkeit zu beschränken. Das öffentliche Bekunden der politischen Anschauungen wurde für die Linke immer schwieriger; die Faschisten behandelten dieses von vornherein als Provokation, auch wenn es sich dabei nur um das Tragen von Parteiabzeichen oder anderen Gesinnungssymbolen handelte. Trotz der militanten Antwort von seiten der Anarchisten gelang es den noch gar nicht zahlreichen Faschisten Carraras, mit Hilfe von wiederholten Konzentrationen auswärtiger squadristi in der Stadt das politische Klima in dieser relativ kurzen Zeitspanne entscheidend zu ihren Gunsten zu verändern. Die Arbeiterführer verzichteten auf eine eigentlich unverzichtbare Demonstration und waren bereit, eine gemeinsame Resolution mit dem Gegner zu unterschreiben, die noch vor kurzem als absolut demütigend empfunden worden wäre. Das Sprachrohr des etablierten Bürgertums, der Giornale di Carrara, machte sich ganz zum Interpreten des jungen lokalen Fascio; ohne Scham und bar jeglicher rechtsstaatlicher Empfindlichkeiten berichtete er von den faschistischen Übergriffen und verschwieg auch meistens die polizeiliche Duldung nicht, so als ob sie eine Selbstverständlichkeit wäre. Der politische Gewinn der nicht abreißenden Kette von mehr oder minder erfolgreichen faschistischen Kraftproben bestand so hauptsächlich darin, daß sich jetzt die sympathisierenden Kreise im Bürgertum und im Staatsapparat, aber auch bei Teilen der Republikaner und der Arbeiterschaft herauszuschälen begannen. Auf einmal erschien das denkbar, woran eigentlich niemand geglaubt hatte: die völlige Ausschaltung des sovversivismo im rebellischen Carrara nach dem Muster der schon faschisierten Provinzen der Emilia und der Toskana.

\section{Politische Vorstöße und Gewaltoffensiven}

Im Frühsommer 1921 wurde parallel mit dem Auftreten der faschistischen Squadren eine deutliche Verschlechterung der Absatzlage für Carrara-Marmor sichtbar. Der Marmorabsatz aus dem Gemeindegebiet von Carrara, der 1920 nach der schlimmen Krise während des Ersten Weltkriegs mit Mühe und Not wieder auf knapp 70 Prozent der Vorkriegszeit gestiegen war, erlebte 1921 wieder einen deutlichen Einbruch um 25 Prozent ${ }^{1}$. Im Frühsommer 1921 ließen die Betriebe nur noch an zwei, drei oder höchstens vier Tagen in der Woche arbeiten, einige kündigten sogar schon die Entlassung der Arbeiter en bloc an ${ }^{2}$. Die Camera del lavoro, durch die Beschäftigungskrise naturgemäß geschwächt und durch die gewalttätigen Aktionen der Faschisten in ihrer Handlungsfähigkeit behindert, reagierte nur matt mit dem Appell an die Kommune, die anstehenden öffentlichen Bauvorhaben, vor allem den jahrelang geplanten Ausbau des Hafens, zügig in Angriff zu nehmen, um die Arbeitslosigkeit zu lindern ${ }^{3}$.

\footnotetext{
1 Zur Gesamtentwicklung des Marmorabsatzes in Carrara siehe Anhang, S. 287.

2 Il Cavatore vom 25. 6. 1921.

${ }^{3}$ Ebenda.
} 
Die Faschisten erkannten die Rekrutierungschancen, die sich durch das Anwachsen eines Heeres von demoralisierten Unterbeschäftigten und Arbeitslosen ergaben. Wahrscheinlich durch einen gewissen Zulauf aus den Kreisen der Arbeiterschaft bestärkt, ging der Fascio von Carrara Anfang Juni zu einem politischen Frontalangriff auf die Camera del lavoro über. Am 5. Juni wurde der Gewerkschaftssekretär Alberto Meschi in das Fascio-Lokal bestellt. Unheil ahnend informierte er die Polizei. Auf Vermittlung des Carabinieri-Chefs von Carrara, Hauptmann Giovanni Benni, fand daraufhin im Rathaus ein Treffen zwischen dem Gewerkschaftsführer und Renato Ricci im Beisein Bennis und unter Hinzuziehung des Bürgermeisters Starnuti statt. Ricci unterbreitete dabei folgenden Forderungskatalog ${ }^{4}$ :

1. politische Neutralität der Camera del lavoro;

2. Gleichstellung der Arbeiter mit Ausweis der Camera del lavoro und des Fascio;

3. Anbringung von trikoloren Bändern an allen Ligenfahnen;

4. Übernahme der Nationalfahne als Fahne der Camera del lavoro;

5. Anerkennung des Fascio und Erläuterung des faschistischen Programms in der Arbeiterschaft.

Wenn die Forderungen nicht erfüllt würden, so ließen die Faschisten durchblicken, käme es zur gewaltsamen Besetzung der Camera del lavoro. Meschi betonte zu Punkt eins, daß die Gewerkschaftszentrale von jeher politisch neutral gewesen sei, bei den restlichen Punkten behielt er sich eine Entscheidung durch die Exekutivkommission der Organisation vor. Angesichts des Ernstes der Situation steuerte die Gewerkschaftsführung aber eine breitere Legitimierung etwaiger Beschlüsse an und berief kurzfristig für den 12. Juni eine Delegiertenkonferenz aller Ligen ein. Meschi seinerseits trat formell zurück und verließ Carrara, um die „Aufmerksamkeit “ der Faschisten von seiner Person wegzulenken. Diegeschlossene Haltung der Gewerkschaftsführung und ihre geschickte und standfeste Reaktion überzeugten die Faschisten wohl davon, daß ihr Anschlag dabei war zu mißlingen. Wahrscheinlich hatten sie gehofft, daß ihr Vorstoß bei den republikanischen Gewerkschaftern auf mehr Sympathie stoßen würde und daß sich mit ihrer Hilfe eine Bresche in die Front des gewerkschaftlichen Antifaschismus schlagen ließe $e^{5}$. Als diese politisch etwas naive Hoffnung verraucht war, nahmen sie Zuflucht zu der Verbreitung von Korruptionsvorwürfen gegen die Leitung der Camera del lavoro, mit der Absicht, wenigstens an der Gewerkschaftsbasis noch ein wenig Mißtrauen zu schüren. Am Tag vor der Konferenz erschienen Plakate an den Wänden Carraras, die die Arbeiter dazu aufforderten, von der Gewerkschaftsleitung „vor jeglicher anderen Diskussion Rechenschaft über die Spenden für die Ausgesperrten der Versilia“ zu verlangen ${ }^{6}$. Die Unterstellung, daß die Unterstützungsgelder für den langandauernden Arbeitskampf des Frühjahres 1921 in den Marmorbrüchen der benachbarten Versilia veruntreut worden seien, war zwar vollständig aus der Luft gegriffen; aber aus der Behauptung, die Gewerk-

${ }^{4}$ ACS, MI, DGPS 1921, b. 101, f. „Fasci Massa“: Präfekt von Massa an Innenministerium vom 9. 6. 1921.

5 In Polizeikreisen kursierten sogar Gerüchte über die bevorstehende Übernahme der Camera del lavoro durch die Faschisten ,in Zusammenarbeit oder mit moralischer Unterstützung der Republikaner"; ASM, Commissariato Carrara, b. 55: Questore von Massa an Polizeikommissar Barcucci vom 9. 6. 1921.

6 Ebenda: Kommissar an Questore vom 11.6. 1921, $17^{40}$.

7 ACS, MI, DGPS 1921, b. 101, f. „Fasci Massa“: Präfekt von Massa an Innenministerium vom 13. 6. 1921 . 
schaftsfunktionäre würden sich am hart erarbeiteten Geld der einfachen Arbeiter schadlos halten, so dachten wohl die Faschisten, ließ sich allemal politisches Kapital schlagen. Doch hatten sie auch hiermit wenig Glück: „Das Plakat blieb ohne Echo“, kabelte der Präfekt nach Rom ${ }^{7}$. Ihre politische Schwäche gegenüber der Gewerkschaft muß den Faschisten zum Schluß ziemlich klar gewesen sein, denn sie verzichteten auf jeden direkten Druck auf die Delegiertenversammlung. Am Tag der Konferenz zogen die Carrareser Squadren ins 40 Kilometer entfernte Pontremoli zu einer schon länger geplanten Großaktion des toskanischen Squadrismus.

Die Versammlung am 12. Juni 1921, bei der die Vertreter von 51 Mitgliedsorganisationen anwesend waren, konnte so in relativer Ruhe diskutieren und verabschiedete einstimmig eine Resolution, in der sie die politische Neutralität der Camera del lavoro bekräftigte, die, so der Wortlaut, „die unumgängliche Bedingung ihrer Existenz und ihres Funktionierens" sei, "da die Arbeitermassen von Carrara bekanntermaßen unterschiedlichen politischen Bekenntnissen" anhingen und so keine Richtung der gemeinsamen Arbeit ihren Stempel aufdrücken dürfe. Weiter stellte sie fest, daß die Kammer nur der Linie folgen könne, die durch die Beschlüsse ihrer Kongresse vorgezeichnet sei, und „Einmischungen oder Auflagen von welcher Seite auch immer" nicht dulden könne. Sollte diese Freiheit, die durch die "Grundgesetze, die uns regieren" garantiert sei, beeinträchtigt werden, so wäre sie gezwungen, die staatlichen Stellen und die Industriellenklasse dafür verantwortlich zu halten, und könne deshalb keine Verantwortung für eventuelle Konsequenzen übernehmen ${ }^{8}$.

Die Resolution stellt eine bemerkenswerte Mischung zwischen defensiver und offensiver Reaktion auf die Anmaßungen der Faschisten dar. Auf der einen Seite zieht sie sich auf das Bekenntnis der politischen Neutralität oder gar der "Apolitizität“, wenn man versucht, den italienischen Begriff wörtlich zu übersetzen, zurück, die eine Gewerkschaft, zumal wenn sie sich als Klassengewerkschaft versteht, nicht haben kann und die die Camera del lavoro auch nie hatte, wie man an ihren diversen Aufrufen zu politischen Streiks und Demonstrationen in der Vergangenheit sehen kann. Auf einem anderen Blatt steht, daß sie parteipolitisch im wesentlichen immer neutral geblieben war, was den Wahlabstinenz predigenden Anarchisten in der Gewerkschaftszentrale auch nicht schwerfiel. Die Betonung der politischen Neutralität war also ohne Zweifel ein taktischer Rückzug angesichts der Eroberungsgelüste der Faschisten, deren Ziele, soweit sie erkennbar waren, allem, was die Camera del lavoro bisher vertreten hatte, diametral entgegengesetzt waren. Die offensichtliche Unterstützung des Squadrismus durch einen Teil der maßgebenden Marmorunternehmer sowie das Beispiel des Agrarfaschismus in der restlichen Toskana und der Emilia entlarvten die squadristi in der organisierten Arbeiterschaft so eindeutig als „weiße Garde der Bourgeoisie“, daß das Neutralitätsbekenntnis, gerade den Faschisten gegenüber, den Charakter einer politischen Notlüge bekam, die niemand wirklich ernst nehmen konnte. Ein weiteres Indiz für die defensive Haltung der versammelten Gewerkschafter ist die Bezugnahme auf "die Grundgesetze, die uns regieren“, aus der der Giornale di Carrara genüßlich die Anerkennung der monarchistischen Konstitution Italiens, des albertinischen Statuto, herauslas" und die zum „staatsfeindlichen "Ver-

\footnotetext{
${ }^{8}$ ASM, Commissariato Carrara, b. 55: Abschrift der Resolution vom 12. 6. 1921, die auch als Plakat und im Cavatore vom 25.6.1921 veröffentlicht wurde.

9 Il Giornale di Carrara vom 18.6. 1921.
} 
balradikalismus, den die Anarchosyndikalisten in der Vergangenheit gepflegt hatten, in einem denkbar scharfen Kontrast stand.

Auf der anderen Seite waren die Gewerkschafter aber auch nicht bereit, die Waffen zu strecken, und drohten denen mit Konsequenzen, die sie nicht zu Unrecht verantwortlich hielten für das Ausufern der faschistischen Gewaltstrategie: den staatlichen Stellen in der Provinz und der Marmorunternehmerschaft. Doch die einzige Konsequenz, die hier in Frage kam, nämlich der Generalstreik - nachdem an die Organisation einer militanten Abwehr im Rahmen der Gewerkschaft nie ernsthaft gedacht wurde -, war in der Situation der herrschenden schweren Absatzkrise eine stumpfe Waffe, wenn man von seiner demonstrativen Wirkung einmal absieht. Ein anderes Zeichen des noch vorhandenen Selbstbewußtseins der Gewerkschafter ist in der unterbliebenen personellen Anpassung der Gewerkschaftsleitung an den von der faschistischen Gewalt hervorgebrachten patriotischen „Zeitgeist“, etwa durch die Hereinnahme von weiteren Republikanern, zu sehen. Zwar wurde die Versammlung von Alberto Meschi gemeinsam mit dem Republikaner Nello Tofanari geleitet, als Demonstration der republikanischen Präsenz innerhalb der Camera del lavoro, doch die Zusammensetzung der Exekutivkommission wie des Sekretariats blieben unangetastet und letzteres somit weiterhin in der Hand der Anarchisten; es bedarf kaum der Erwähnung, daß natürlich auch der Rücktritt Meschis rückgängig gemacht wurde ${ }^{10}$. Die Loyalität der führenden republikanischen Gewerkschaftsfunktionäre war zu keiner Zeit in Frage gestellt. Die einzige Konzession, die sie im Unterschied zur Kongreßmehrheit bereit waren zu machen, wenn damit eine Besetzung der Camera del lavoro hätte abgewendet werden können, war die Anbringung von trikoloren Bändern an die Ligenfahnen ${ }^{11}$. Im großen und ganzen erlitten die Faschisten Carraras somit bei ihrem ersten Versuch, „sich mit Arbeiterbewegung zu befassen", so die spöttische Formulierung des Cavatore ${ }^{12}$, Schiffbruch. Anders als in der Emilia hatte es in Carrara nie ein Zwangssystem der Ligen gegeben, das zu schweren Ressentiments von bestimmten Gruppen innerhalb der Gewerkschaften selbst geführt hätte ${ }^{13}$, und so konnten die Faschisten nirgendwo den Hebel ansetzen, um die Position der traditionellen Führungsgruppe ins Wanken zu bringen.

Wie schon erwähnt, befanden sich die Faschisten Carraras am Tag des Gewerkschaftskongresses auf einer spedizione in Pontremoli. Den Anlaß für die vom segretario politico regionale der Toskana, Marchese Dino Perrone Compagni, angeführte Zusammenkunft der Squadren aus der gesamten Toskana bildete die Einweihung des Wimpels des lokalen Fascio. Dieser tat sich trotz seiner Erstgeborenenstellung in der Provinz recht

${ }^{10}$ Am 24. 4. 1921 waren in die "commissione esecutiva" der Camera del lavoro gewählt worden: 4 Anarchisten (Andrea Giandalasini, Paride Barattini, Ercole Cargioli, Armando Pardini), 3 Republikaner (Corinto Pisani, Nello Tofanari, Domenico Fabbricotti), 3 Sozialisten (Enrico Salvini, Eugenio Lencioni, Antonio Bardi), 3 Kommunisten (Lamberto Bonci, Giuseppe Pasquini, Giuseppe Bibolotti) und 2 Parteilose (Dario Dolfi, Vincenzo Vincentini); ACS, MI, DGPS 1921, b. 79, f. 54: Präfekt an Innenministerium vom 4. 5. 1921. Das Sekretariat bestand aus 5 Anarchisten: Alberto Meschi, Eugenio Girolo, Arturo Fellini, Gino Petrucci und Umberto Petruzzi (La Battaglia comunista vom 12. 2. 1921).

11 ASM, Commissariato Carrara, b. 55: Kommissar an Questore vom 11. 6. 1921, $16^{40}$.

12 Il Cavatore vom 25.6.1921.

${ }^{13}$ Zum Unmut der bessergestellten Bauern- und Landarbeitergruppen gegenüber dem System der roten Ligen in der Emilia siehe oben, S. $23 \mathrm{f}$. 
schwer, aus seinem Schattendasein herauszutreten, und dem sollte mit einer großen Machtdemonstration abgeholfen werden. Vor der Veranstaltung hatten verschiedene Arbeitervereine in Erwartung der üblichen Übergriffe versucht, der Sottoprefettura die Schlüssel ihrer Lokale zu übergeben, um sie so für ihren Schutz verantwortlich zu machen. Doch diese hatte die Annahme mit der Begründung abgelehnt, sie könne sich für einen friedlichen Ablauf verbürgen ${ }^{14}$.

Es kam anders: Schon zum Auftakt drohte Perrone Compagni den lokalen Sozialisten und vor allem den Eisenbahnern des örtlichen Depots, er habe eine Proskriptionsliste in der Tasche, von deren Umsetzung in die Tat er nur vorläufig absehen wolle. Nach dem „Festakt“ durchkämmten die Squadren unter Drohungen aller Art die Stadt, doch aufgrund der starken Zurückhaltung der einheimischen sovversivi kam es nicht zum wohl erhofften $Z$ wischenfall. Trotzdem wurde am Nachmittag die vorgesehene Gewaltaktion entfesselt, an der sich anscheinend Perrone selbst mit gezücktem Revolver beteiligte ${ }^{15}$. Die Faschisten überfielen den Circolo ferrovieri und plünderten die Einrichtung; gleichzeitig drangen sie in die Büroräume des Bahnhofs und in das Eisenbahndepot ein und bedrohten die anwesenden Beamten und Arbeiter mit Messern und Revolvern, so daß die meisten ihren Arbeitsplatz verließen, um sich in Sicherheit zu bringen; erwähnenswert ist hierbei, daß die betroffenen Beamten gar keine sovversivi waren. Die squadristi konnten bei ihrer Aktion mit einem Wohlwollen von seiten der Polizeikräfte rechnen, das selbst im Vergleich mit Carrara und Massa außergewöhnlich war. Nach Stunden der faschistischen Bahnhofsbesetzung, die den Eisenbahnverkehr der ganzen Region lahmlegte, fanden sie sich erst zu einem halbherzigen Eingreifen bereit, als ein eigens aus La Spezia angereister Inspektor der Staatsbahnen sie dazu aufforderte.

Nach diesen Ausschreitungen konnte Perrone Compagni in aller Ruhe an der „Porta Fiorentina " eine zweite, wieder von Drohungen und verbaler Gewalt strotzende Kundgebung halten, die den Auftakt für eine Hetzjagd im Arbeitervorort Annunziata bildete. Auf der Suche nach exponierten Aktivisten der Arbeiterorganisationen überfielen und verwüsteten die Faschisten dort neben dem Circolo operaio zahlreiche Privatwohnungen. Einige ortsbekannte sovversivi, denen man mit Hilfe einheimischer Faschisten habhaft werden konnte, wurden übel zusammengeschlagen.

Doch der schlimmste Vorfall ereignete sich, nachdem die Squadren Pontremoli wieder verlassen hatten. Auf dem Heimweg kamen die Carrareser squadristi unter der Führung von Renato Ricci unvermeidlich durch die sozialistisch-kommunistische Hochburg Sarzana, die sie, wohl wissend, daß sie sich auf „feindlichem Gebiet“ befanden, wild schießend durchquerten, wobei sie wahllos Personen mit dem Revolver bedrohten und durchsuchten; inwieweit das Vorgehen der Faschisten durch provozierendes Verhalten von seiten lokaler sovversivi ausgelöst wurde, ist unklar, weil sich die Aussagen in den

${ }^{14}$ Die Darstellung der Ereignisse in Pontremoli folgt in erster Linie dem Bericht der Battaglia vom 25. 6. 1921. Außerdem ACS, MI, DGPS 1921, b. 101, f. „Fasci Massa“: Bericht eines Augenzeugen vom 13. 6. 1921 (Unterschrift unleserlich) und ACS, MI, Gabinetto Bonomi, b. 4, f. 4: Memorandum des sozialistischen Abgeordneten Giuseppe Modigliani ohne Datum.

15 APC, b. B 10, Bd. IV, S. 58: Perrone an Buttini vom 27. 1. 1922. Perrone Compagni wurde jedenfalls vom Rechtsanwalt und gemäßigten Sozialistenführer von Pontremoli, Pietro Bologna, wegen „Drohung mit der Waffe“ (minaccia a mano armata) angezeigt. Daß die entsprechenden Zeugen im Januar 1922 ihre Aussage widerriefen, ist kein Beweis für ihre Unrichtigkeit, sondern wahrscheinlich Folge der zu diesem Zeitpunkt herrschenden Angstatmosphäre. 
Quellen stark widersprechen ${ }^{16}$. Ohne erkennbaren Grund erschossen sie den alten Arbeiter Luigi Castardelli auf der Schwelle seines Hauses, während er im Begriff war, im Innern Zuflucht zu suchen. Die brutale Kraftdemonstration, die den wenigen einheimischen Faschisten wohl den Rücken stärken sollte, erreichte genau das Gegenteil. Noch in der gleichen Nacht beschloß der gerade erst gegründete lokale Fascio seine Auflösung und die Übergabe der Vereinskasse an die Angehörigen des Opfers. In einer öffentlichen Begründung dieses Schritts stellte das Direktorium fest, daß „unangebrachte, weder angeforderte noch angekündigte Einfälle von Pseudofaschisten das Werk der moralischen Erhebung zunichte machen, die der Fascio von Sarzana sich zur Aufgabe gesetzt hatte, und ihn in die Verantwortung für Vorfälle verwickeln, die er verabscheut und mit denen er nichts zu tun hat "17. Wahrscheinlich konnte der Auflösungsbeschluß mit der Distanzierung von der blutigen Aktion nicht rechtzeitig publik gemacht werden, denn am folgenden Tag versammelte sich ein große Menschenmenge drohend vor dem Haus des lokalen Fascio-Sekretärs Tancredi Revelli, der die Nerven verlor, mit dem Gewehr wild um sich schoß und dabei mehrere Personen verletzte ${ }^{18}$.

Die weder mit den einheimischen Faschisten noch mit dem hier eigentlich zuständigen Sekretär der ligurischen Fasci, Mastromattei, koordinierte Aktion in Sarzana hatte weitreichende Folgen. Die lokale Rechte bekam jetzt erst recht politisch keinen Fuß mehr auf den Boden. Als profaschistisch gebrandmarkt und von den Trauerfeierlichkeiten für den ermordeten Arbeiter ausgeschlossen, zog sie sich aus dem Stadtrat zurück ${ }^{19}$. Bei der Linken führte der Faschisteneinfall zu einem heilsamen Schock, denn man ging sofort an den Aufbau einer effizienten Selbstschutzorganisation, in die große Teile der Bevölkerung einbezogen wurden und mit der auch die Polizeikräfte wohl oder übel zusammenarbeiten mußten. So war der Grundstein gelegt für die große politisch-militärische Niederlage, die der sonst so siegesgewohnte toskanische Squadrismus hier gut einen Monat später erlebte.

Man kann nur darüber mutmaßen, ob bei dem brutalen Verhalten der Carrareser Faschisten in Sarzana Frustrationen über ihren heimischen Mißerfolg in der Sache Camera del lavoro mitgespielt haben. Sicher ist, daß sie in ihrer Heimatstadt ein ungleich größeres politisches Fingerspitzengefühl bewiesen. So scheint ihnen an sich klar gewesen zu sein, daß mit Terror allein die Loyalität der Arbeiter gegenüber ihren verdienten Führern nur sehr schwer gebrochen werden konnte, solange den Faschisten ein so eindeutig arbeiterfeindliches Image anhaftete. Es ist in den Quellen nicht direkt nachzuweisen, doch hat es an Sympathiebekundungen des Fascio von Carrara gegenüber der Arbeiter-

${ }^{16}$ Der Polizeibericht (ASM, Commissariato Carrara, b. 55: Kommissar an Questore von Massa vom 13. 6. 1921) spricht von Drohungen und Stockschlägen von seiten der lokalen "sovversivi“, während die Battaglia comunista vom 18.6. 1921 schrieb, es sei „nicht die geringste Provokation " vorausgegangen.

17 Abdruck des Plakats des Fascio di combattimento von Sarzana in La Battaglia comunista vom 18.6.1921.

${ }_{18}$ APC, b. B 9, Bd. I, S. 208: Perrone an Bellugi vom 17. 6. 1921. Mastromattei und wohl auch Teile des Zentralkomitees und der Parlamentsfraktion der Fasci waren verärgert über das Vorgehen der Squadren, so daß Perrone als Genugtuung den Ausschluß der beteiligten "squadristi“ von allen Aktionen für zwei Wochen anordnen mußte, was vor Ort mit größter Wahrscheinlichkeit ignoriert worden ist.

19 Vgl. Bianchi, Lotte sociali, S. 176, Anm. 63. 
schaft wohl nicht gefehlt, denn in der lokalen Arbeiterpresse taucht schon sehr früh für die Faschisten die ironische Umschreibung „die Freunde der Arbeiter“ auf.

Unmittelbar nach der mißlungenen politischen Offensive gegenüber der Camera del lavoro lancierte Renato Ricci jedenfalls eine Kampagne zur Preissenkung für die wichtigsten Konsumgüter. Das war ein nicht ungeschickter Schachzug in einer Zeit, wo vielen Arbeiterfamilien das Wasser bis zum Hals stand. Am 13. Juni zog eine Gruppe von Faschisten von Laden zu Laden und überreichte den Händlern Papierstreifen mit einem Aufdruck, der eine allgemeine Preissenkung von zehn Prozent ankündigte. Angeblich war diese Maßnahme zwischen dem Fascio und der örtlichen Einzelhändlervereinigung ausgehandelt worden, mit wieviel Druck von seiten der Faschisten ist nicht klar ${ }^{20}$. Die Preissenkungen wurden auch den ambulanten Händlern des örtlichen Gemüsemarktes aufgezwungen, mit der Folge, daß am nächsten Tag so viele Händler wegblieben, daß die angebotene Ware nicht mehr für die Versorgung der Bevölkerung ausreichte. Die Auswirkungen der Aktion, die bei vielen der einkaufenden Hausfrauen zunächst auf lautstarke Zustimmung gestoßen war, drohten sich jetzt gegen die Initiatoren zu richten. Doch die Faschisten reagierten blitzschnell: Sie ließen Plakate drucken und noch am gleichen Vormittag kleben, auf denen für den nächsten Tag ein von ihnen organisierter Gemüseverkauf auf dem Marktplatz angekündigt wurde ${ }^{21}$. In der Nacht fingen sie auf der Landstraße bei Avenza die für La Spezia bestimmten Obst- und Gemüsetransporte ab und dirigierten sie nach Carrara um. Dort veranlaßten sie den Verkauf der Ware zu Großhandelspreisen, was dem Polizeibericht zufolge sowohl die Käufer als auch die nicht ganz freiwilligen Verkäufer zufriedengestellt haben soll. Jedenfalls hat der Frischwarenverkauf auf dem örtlichen Markt noch eine Weile unter der Regie der Faschisten stattgefunden ${ }^{22}$.

Auch das Verhalten der Ladenbesitzer scheint nicht ganz nach dem Geschmack der Faschisten gewesen zu sein, denn am 17. Juni 1921 ließen sie ein ungewöhnlich scharf formuliertes Plakat in den Druck gehen mit der Aufforderung an ihre Adresse: „Zum letzten $\mathrm{Mal}$ - [...] Verzichtet auf die übermäßigen und halsabschneiderischen Gewinne. “ Der Fascio di combattimento, so der Wortlaut, „verlangt, daß innerhalb von 48 Stunden nach dem Erscheinen dieses Plakates bei allen lebensnotwendigen Gütern (Öl, Wein, Fleisch, Schuhe, Stoffe und Wäsche) eine angemessene Senkung der derzeitigen Ver-

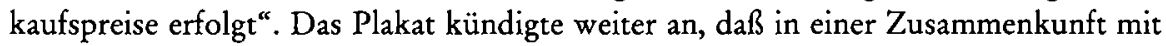
dem Einzelhändlerverband, an der von den Faschisten benannte Sachverständige teilnehmen sollten, endgültige Höchstpreise festgelegt würden. Den stadtbekannten Wucherern, die „in den letzten Jahren leichte und widerrechtliche Gewinne zum Schaden des Volkes" gemacht hätten, wurde im Falle mangelnder Einsicht "gnadenlose Vergeltung" versprochen ${ }^{23}$. In den Verhandlungen zwischen Faschisten und der Unione esercenti, die politisch völlig isoliert dastand, da sich nicht einmal die Liberalen für sie stark machen wollten, wurden die Preise für Wurst, Schinken, Käse, Olivenöl und Wein festgelegt, während für die restlichen Lebensmittel die erwähnte allgemeine Preissenkung von 10

20 ASM, Commissariato Carrara, b. 55: Kommissar an Questore vom 14. 6. 1921.

21 Ebenda: Kommissar an Questore vom 15. 6. 1921.

22 Ebenda: Kommissar an Questore vom 16. 6. und 20. 6. 1921.

23 Ebenda: Das Plakat vom 17.6. 1921 ist mit "Il segretario politico" (Renato Ricci) unterschrieben. 
Prozent gelten sollte. Außerdem einigte man sich auf erhebliche Preissenkungen bei Schuhen und Hüten ${ }^{24}$.

Es ist schwer zu sagen, ob diese „verbraucherfreundlichen“ Aktionen den Faschisten nennenswerten Zulauf von seiten der Arbeiterschaft eingebracht haben; sicher hat es geholfen, ihr Image aufzupolieren. Die Härte des Vorgehens zeigt aber in aller Deutlichkeit, daß der gewerbliche Mittelstand im Faschismus von Carrara keine gute Position besaß, ein charakteristischer Unterschied zu den Faschismen anderer Gegenden.

Im Kampf der Faschisten um die politische Kontrolle der Arbeiterschaft spielte die Behinderung der linken Presse, die sich in der Marmorregion noch vor dem Marsch auf Rom bis zu ihrer weitgehenden Ausschaltung steigerte, eine große Rolle. Zumindest im Bereich der Lokalzeitungen hatte die stampa sovversiva in der Provinz Massa-Carrara traditionell eine beherrschende Stellung, und so galt es, ihre fundamentale Rolle in der politischen Kultur der Region zu beseitigen ${ }^{25}$. Vielleich noch deutlicher als bei seinen Angriffen auf Personen oder seinen Vandalenakten wird hier die "totalitäre“ Zielsetzung des Faschismus sichtbar, der von Anfang an auf eine erzwungene politische und ideologische Uniformität hinsteuerte und dabei von den Gralshütern des lokalen Liberalismus auf erkennbare Weise nicht gebremst wurde. Der erste aktenkundige faschistische Anschlag auf die Pressefreiheit vollzog sich schon am 2. Juni in der Endphase der ersten bürgerkriegsähnlichen Auseinandersetzungen in Carrara, als zwei Faschisten die Druckerei der sozialistischen Wochenzeitung La Battaglia aufsuchten und kategorisch verlangten, daß vor dem Erscheinen des Blattes ein Probeabzug dem Fascio zur Zensur vorzulegen $\operatorname{sei}^{26}$. Die Redaktion weigerte sich, auf die Anmaßung der Faschisten überhaupt einzugehen, und erklärte, eher würde sie die Zeitung gar nicht erscheinen lassen, was bei der nächsten, am 4. Juni fälligen Ausgabe tatsächlich geschah. Danach erschien die Battaglia wieder regelmäßig, doch ist von jetzt an gerade bei der Berichterstattung aus Massa und Carrara eine gewisse Selbstzensur zu erkennen ${ }^{27}$.

Am 9. Juni beorderte die Fascio-Führung von Carrara dann vier Faschisten an den Bahnhof von Avenza mit dem Auftrag, sich bei dem dortigen Kiosk die Exemplare der überregionalen kommunistischen Zeitung Ordine nuovo aushändigen zu lassen und zu verbrennen ${ }^{28}$. Am 14. Juni zwang eine andere Gruppe von Faschisten einen Zeitungsverkäufer, die Exemplare des $I l$ Comunista und des Avanti! herauszugeben ${ }^{29}$. Außer

${ }^{24}$ Ebenda: Plakat mit den ausgehandelten Preisen.

25 Nach Aufstellungen der lokalen Polizeibehörden (ASM, Commissariato Carrara, b. 72 und Questura Massa, b. 21) bestanden folgende Größenverhältnisse: Il Cavatore (anarchosyndikalistisch), Aufl. 3300; Il'94 (anarchistisch, sehr unregelmäßiges Erscheinen), Aufl. 2000; La Battaglia (sozialistisch), Aufl. 1500; La Sveglia repubblicana, Aufl. 2000; La Difesa popolare (politischer Katholizismus), Aufl. 500; Il Giornale di Carrara (liberal, später philofaschistisch), Aufl. 1500. Die Angaben für die Battaglia comunista fehlen.

${ }^{26}$ ASM, Commissariato Carrara, b. 55: Kommissar an Questore von Massa vom 2. 6. 1921.

${ }^{27} \mathrm{Z}$. B. schweigt sie sich regelmäßig über Gewaltaktionen der Faschisten aus, gerade auch dann, wenn Sozialisten davon betroffen waren. Möglicherweise sollte diese "Vogel-Strauß-Haltung“ auch den Zweck erfüllen, die Demoralisierung der eigenen Anhängerschaft geringzuhalten.

28 ASM, Commissariato Carrara, b. 55: Überblicksbericht des Polizeikommissars von Carrara ohne Datum. In einem anderen Bericht vom 9. 6. 1921 ist statt der kommunistischen Zeitung Ordine nuovo die anarchistische Zeitung Umanità nova angegeben.

29 ASM, Commissariato Carrara, b. 55: Kommissar an Questore von Massa vom 14. 6. 1921. 
diesen in den Polizeiakten vermerkten Übergriffen muß man in diesem Zeitraum noch weitere Behinderungen der Linkspresse annehmen. Ohne die Ausnahmesituation, die der Squadrismus in Carrara geschaffen hatte, ist zum Beispiel nicht zu erklären, warum mehr als einen Monat lang, vom 21. Mai bis zum 25. Juni, keine Ausgabe des Cavatore erschien; die Zeitung der Camera del lavoro war sonst wenigsten alle 14 Tage herausgekommen.

Die Beseitigung der Pressefreiheit in der Region war ein Prozeß, der sich in Etappen noch über viele Monate hinzog. Schritt für Schritt wurde die „subversive“ Sublultur aus dem Bereich der Öffentlichkeit verdrängt, bis am Ende nur noch das gedruckt und verteilt werden konnte, was zu den Auffassungen der Faschisten nicht im Gegensatz stand. Einen ersten Meilenstein auf diesem Weg erreichte die faschistische Gewalt allerdings schon sehr bald, als die Zeitung des kommunistischen Provinzialverbands, La Battaglia comunista, mit der Ausgabe vom 25. Juni ihr Erscheinen einstellen mußte. An diesem Tag schwappte eine Welle der faschistischen Gewalt über Massa hinweg ${ }^{30}$.

Der "Generalstab“ des toskanischen Squadrismus in Florenz hatte einen großangelegten Säuberungsfeldzug in der Region schon länger auf dem Programm. Dies hatte Perrone Compagni ungeschminkt nach der Aktion in Pontremoli vor Polizeifunktionären des Carrareser Kommissariats bekanntgegeben ${ }^{31}$. Als unmittelbarer Anlaß für den Squadrenüberfall vom 25. und 26. Juni auf die Provinzhauptstadt Massa, der erstmals zu einem wirklich substanziellen Verlust von organisatorischer Präsenz und politischen Machtpositionen der Arbeiterbewegung führte, mußte eine äußerst obskure Mordaffäre herhalten: In der Nacht vom 24. auf den 25. Juni wurde der Fiume-Kämpfer und Mitbegründer des Fascio di combattimento von Massa Gilberto Ciberti von einem aus nächster Nähe abgefeuerten Pistolenschuß getötet. Die Polizei verhaftete unmittelbar nach der Auffindung der Leiche einige Sozialisten und Kommunisten, die sie als „schwer verdächtig" bezeichnete ${ }^{32}$. Am folgenden Tag veranlaßten die Masseser Faschisten Trauerbeflaggung in der ganzen Stadt, und gegen Abend und in der Nacht versammelten sich etwa 300 squadristi aus Pisa, Viareggio, Pietrasanta, Seravezza, Carrara und La Spezia in der Provinzhauptstadt ${ }^{33}$. Einige Faschisten drangen spät nachts in das Haus des Bäckers Mario Mussi ein, zwangen ihn, das Haus zu verlassen, und exekutierten ihn nicht weit davon entfernt auf einer Wiese. Auch sein Bruder Pietro Mussi entging nur ganz knapp einem Mordanschlag, jedenfalls versuchte die gleiche Gruppe, sein Haus anzuzünden, doch die Ausbreitung der Flammen konnte noch rechtzeitig durch das Eingreifen der Nachbarn verhindert werden. Die Polizei interpretierte den Mord an Mussi als eine Vergeltungsaktion, und um diese These zu untermauern, bezeichnete sie das Opfer in allen ihren Berichten als Kommunisten, obwohl er in Wirklichkeit parteilos war. Es stellte sich später unter dem maßgeblichen Druck der in Massa kursierenden Gerüchte heraus, daß Ciberti aus privaten Motiven von einem anderen Faschisten, dem Maurer Massimo Maltagliati, ermordet worden war. Maltagliati war es auch gewesen, der den Überfall auf die Brüder Mussi angeführt hatte. Anscheinend sollten damit zwei unbequeme Zeugen aus-

${ }^{30}$ Vgl. dazu auch Bertozzi, Stampa, S. 168.

31 ASM, Commissariato Carrara, b. 55: Kommissar an Questore von Massa vom 14. 6. 1921.

${ }^{32}$ ASM, MI, DGPS 1921, b. 101, f. „Fasci Massa“: Präfekt an Innenministerium vom 25. 6. 1921.

${ }^{33}$ Ebenda: Präfekt an Innenministerium vom 26. 6. 1921. 
geschaltet werden, die das Pech gehabt hatten, in der fraglichen Nacht am Tatort vorbeigekommen zu $\operatorname{sein}^{34}$.

Die wirklichen Hintergründe kamen allerdings nur nach und nach ans Tageslicht. Maltagliati wurde erst am 14. Juli verhaftet, und so konnte der Ciberti-Mord als Legitimation für die folgenden „Strafaktionen“ dienen. Es ist bezeichnend für die Art und Weise, wie faschistische Märtyrerlegenden geschaffen wurden, daß nach dem Geständnis Maltagliatis seine angebliche kommunistische Vergangenheit an die große Glocke gehängt und darüber hinweggegangen wurde, daß er seit Mai, daß heißt praktisch seit der Gründung, Mitglied des Fascio di combattimento von Massa war und daß er sich bei den Aktionen in Carrara und Pontremoli als squadrista hervorgetan hatte. Trotz der Verurteilung von Maltagliati wegen der Morde an Ciberti und Mussi am 11. Dezember 1922 durch das Schwurgericht Massa hielt die faschistische Regimegeschichtsschreibung später zum Teil an der von Polizei und bürgerlicher Presse verbreiteten allerersten Version der Schuldzuweisung fest ${ }^{35}$.

Die Zweifelhaftigkeit der Tatumstände war schon unmittelbar nach der Tat deutlich geworden: Den Stock nämlich, den das Opfer immer bei sich getragen hatte, fand man zerbrochen in dem Haus, wo sich Ciberti mit anderen Faschisten bis spät in der Nacht aufgehalten hatte ${ }^{36}$. Trotzdem brach unmittelbar darauf der faschistische Zerstörungsfeldzug über Massa herein. Am 26. und 27. Juni war die Provinzhauptstadt völlig in der Hand der Squadren, die, von der Polizei wenig behindert, Jagd auf die exponierten Vertreter der sozialistischen und kommunistischen Partei machten, Partei- und Gewerkschaftslokale sowie Cafés und Geschäfte von sovversivi verwüsteten und sogar das Sozialamt der Gemeinde überfielen. Am härtesten traf es die Kommunisten: Ihr Sekretär Aladino Bibolotti wurde angegriffen, geschlagen und mit dem Tode bedroht, später wurde seine Wohnung überfallen und verwüstet. Ebenso erging es dem Drucker und dem Geschäftsführer der Battaglia comunista, die gekidnappt, in das Fascio-Lokal gebracht und dort mit vorgehaltener Waffe gezwungen wurden zu erklären, daß sie ihre Tätigkeit nicht weiterführen würden, was zur erwähnten Einstellung des Blattes führte. Der Terror war so systematisch und die Gegenseite so hilflos, daß nahezu die gesamte Führungs-

${ }^{34}$ Die Rekonstruktion des Tathergangs stützt sich auf verschiedene Dokumente: ACS, MI, DGPS 1921, b. 101, f. „Fasci Massa“: Präfekt an Innenministerium vom 27. 6. 1921 und Antwort auf die parlamentarische Anfrage des sozialistischen Abgeordneten Giuseppe Mingrino aus der Feder des Staatssekretärs im Innenministerium Antonio Teso vom 23. 7. 1921. Aufschlüsse über die eigentlichen Hintergründe der Morde liefert das Memorandum des sozialistischen Abgeordneten Giuseppe Modigliani ohne Datum (ACS, MI, Gabinetto Bonomi, b. 4, f. 43). Siehe außer$\operatorname{dem}$ ASM, Corte d'assise Massa, Fascicoli processuali, b. 146, f. „M. Maltagliati“: Urteil im Vorverfahren vom 5. 1. 1922. Maltagliati tischte verschiedene widersprüchliche Geschichten auf, die alle einen privaten Hintergrund hatten. Schon zehn Tage nach dem Mord waren die Faschisten darüber im Bilde, wer der wirkliche Täter war. Maltagliati wurde daraufhin plötzlich zum eingeschleusten „sovversivo“, der angeblich von Anfang an mit der Absicht, Faschisten zu ermorden, dem Fascio beigetreten war (APC, b. B 3, f. 3: Bellugi an Perrone vom 6. 7. 1921). Doch das Bemühen der Faschisten, eine politische Verschwörung aufzudecken (Giovinezza vom 10. 12. 1922), mißlang. Maltagliati wurde als Einzeltäter verurteilt (ASM, Corte d'assise, Sentenza 1922/27, 11. 12. 1922).

35 Vgl. Chiurco, Rivoluzione fascista, Bd. 3, S. 373.

36 So jedenfalls die Angaben im Modigliani-Memorandum, siehe Anm. 34. 
gruppe der kommunistischen und der sozialistischen Partei aus der Stadt fliehen muß$\mathrm{te}^{37}$.

Die schlimmsten Übergriffe erfolgten nach der Beerdigung von Ciberti am Abend und in der Nacht des 26. Juni. Während sich die Carabinieri-Führung in der Befürchtung, die Aktionen könnten völlig ausarten, bemühte, die Situation unter Kontrolle zu bringen, rührten die zivilen Beamten der Questura keinen Finger ${ }^{38}$. Es erwies sich, daß die Questura in Massa noch parteilicher war als ihre Außenstelle in Carrara mit dem schwächlichen Kommissar Barcucci. Wohl unter dem Eindruck der von den Faschisten geschickt gelenkten öffentlichen Empörung über den Ciberti-Mord, die ihren Ausdruck in den Trauerfeierlichkeiten fand, an denen 3000 Personen, unter ihnen die gesamte bürgerliche Stadtnotabilität, teilnahmen, gaben die zivilen Polizeiverantwortlichen den Faschisten grünes Licht für diesen regelrechten Feldzug.

Bezeichnend für die Haltung der Beamten ist, daß nachweislich unter ihren Augen das von einem Sozialisten geführte Ristorante degli Aranci geplündert und verwüstet wurde, ohne daß sie sich veranlaßt sahen einzugreifen. Als der Carabinieri-Major Fusi etwas später den ranghöchsten der anwesenden Beamten, den Vizekommissar Iori, zur Mithilfe bei der Verfolgung der Täter aufforderte, entgegnete dieser, daß er das nur auf Befehl des Questore könne, der schon schlafe und nicht gestört werden wolle ${ }^{39}$. Die Carabinieri verhafteten noch in der Nacht zwei der faschistischen Plünderer, bei denen Geld, Spirituosen und Süßigkeiten aus dem Ristorante degli Aranci und dem ebenfalls geplünderten Café della Posta gefunden wurden. Peinlicherweise handelte es sich bei einem der Verhafteten um den kriegsversehrten und hochdekorierten Leutnant Dario Vitali aus Lucca. Die Faschisten konnten natürlich nicht dulden, daß ausgerechnet eines ihrer frontkämpferischen Aushängeschilder festgehalten wurde, noch dazu mit diesen ehrenrührigen Anschuldigungen. Sie drohten mit dem Marsch aller toskanischen Squadren auf Massa und dem Sturm auf das Gefängnis ${ }^{40}$. Überstürzt wurde Vitali daraufhin vom Questore von Massa wieder freigelassen, obwohl das rechtlich nur durch den Staatsanwalt nach vorangegangener Vernehmung möglich gewesen wäre ${ }^{41}$.

${ }^{37}$ Es ist bezeichnend, daß detaillierte Polizeiberichte zu den Vorfällen nicht vorhanden sind, und daß die wenigen, die es gibt, die Ereignisse in unglaublicher Weise herunterspielen; ACS, MI, DGPS 1921, b. 101, f. „Fasci Massa": Präfekt an Innenministerium vom 27. 6., 28. 6. und 17. 7. 1921.

38 ACS, MI, DGPS 1921, b. 101, f. „Fasci Massa“: Untersuchungsbericht des Brigadegenerals der Carabinieri, Leopoldo Ferrè, vom 2. 12. 1921, S. 26 f. Aber auch den Carabinieri-Major Cenisio Fusi, der sich in dieser Situation als Wahrer von Recht und Ordnung profilierte, schienen die spät nachts einsetzenden Plünderungen von Cafés und Restaurants sehr viel mehr zu beunruhigen als die vorangegangenen Terroraktionen gegen sozialistische und kommunistische Funktionäre, von denen die meisten immerhin auch Gemeinderäte waren.

${ }^{39}$ Ebenda. Interessant ist in diesem Zusammenhang, daß der Sohn von Iori wohl aktiver Faschist war. ACS, MI, Gabinetto Bonomi, b. 4, f. 43: Savini an Präfekten von Massa vom 26. 11. 1921.

40 ACS, MI, DGPS 1921, b. 101, f. "Fasci Massa“: Präfekt an Innenministerium vom 29. 6. 1921. Der aus Lucca stammende Vitali blieb nach den Vorfällen in Massa und wurde Squadreninspekteur der Zone von Massa. Er war Inhaber der "medaglia d'oro al valore militare“. Kurzlebenslauf bei Missori, PNF, S. 289.

${ }^{41}$ Siehe die Beschwerde des für die Kontrolle der Staatsanwaltschaft von Massa zuständigen Generalstaatsanwalts beim Appellationsgericht Genua; ACS, MI, DGPS 1921, B. 101, f. „Fasci Massa": Justizministerium an Innenministerium vom 14. 7. 1921. 
Trotz der galoppierenden Selbstauflösung des Rechtsstaates in der Provinz, die durch die beschriebene Episode erhellt wird, ist es nicht ohne weiteres einsichtig, wie es den Faschisten in nur zwei Tagen gelingen konnte, auf einen Schlag die scheinbar gut verankerte Macht der Sozialisten und Kommunisten und mit ihr die gesamte organisatorische Struktur der Arbeiterbewegung in Massa weitgehend auszulöschen. Sowohl vor als auch nach dieser Großaktion der Squadren war es in Massa ganz unvergleichlich „ruhiger“ als etwa in Carrara, wo die Faschisten fast ein Jahr brauchten, um in einem beständigen Kleinkrieg das gleiche Ergebnis zu erzielen. In Massa erwies sich wie schon in der Emilia und in anderen "roten Zonen “ die enorme Verletzlichkeit der sozialistisch-kommunistischen Machtpositionen. Der Verbalradikalismus der maximalistischen Nachkriegsströmung, dem die Mehrheit der Masseser Sozialisten wie auch die Kommunisten gleichermaßen anheimgefallen waren, fand keine Entsprechung in ihrer konkreten Politik, die sich zumindest bei den Sozialisten weiterhin in den reformistischen Bahnen der Vorkriegszeit bewegte. Er schnitt ihnen aber den Weg zu politischen Verständigungen mit bürgerlichen Kräften und den in Massa zunehmend an Bedeutung gewinnenden popolari ab, ohne sie gleichzeitig für den von den Faschisten entfesselten Bürgerkrieg wappnen zu können. Hinzu kommt, daß die Unione socialista massese trotz ihres Erfolgs bei den Kommunalwahlen 1920, der bemerkenswerterweise durch einen deutlichen Einbruch bei den nationalen Wahlen in Frage gestellt wurde, und trotz einer im toskanischen Maßstab guten Mitgliederquote im Grunde eine lethargische Organisation war, die zum Beispiel dem Vergleich mit dem Aktivismus der Masseser popolari in keiner Weise standhalten konnte ${ }^{42}$. Als die sozialistische Gemeindeverwaltung nach dem Faschisteneinfall die Waffen streckte und zurücktrat, war sie schon durch eine monatelange Kampagne der popolari gegen die kommunale Sondergrundsteuer, in deren Verlauf die "weiße" Unione del lavoro Tausende von Kleinbauern mobilisiert hatte, politisch in die Defensive gedrängt worden.

Ob der gerade erst drei Monate alte kommunistische Ortsverein unter der energischen Leitung von Aladino Bibolotti auf Dauer das unfruchtbare Erbe des Maximalismus hätte überwinden können, ist schwer zu sagen. Tatsache ist, daß die Kommunisten trotz ihres Achtungserfolgs bei den nationalen Wahlen, wo sie auf Anhieb 12,4 Prozent der Stimmen erringen konnten, noch zu schwach waren, um den Faschisten politisch oder gar militärisch etwas entgegensetzen zu können. Auch für sie gilt, daß sich hinter einer abstrakten revolutionären Rhetorik die Unfähigkeit verbarg, konkret auf den Angriff zu reagieren ${ }^{43}$. Die mangelnde Vorbereitung auf den aufgezwungenen Bürgerkrieg und vielleicht auch der Mangel an persönlichem Mut bei einzelnen sozialistischen und kommunistischen Führern führten während der faschistischen Aktion zu einem Schauspiel, das die beiden Arbeiterparteien nachhaltig diskreditierte. Wie schon erwähnt, flohen die meisten überstürzt, während einige der Verbliebenen sich den üblichen faschistischen Unterwerfungsritualen unterziehen mußten, bei denen sie, in Todesangst gehalten, öffentlich ihren politischen Überzeugungen abschworen ${ }^{44}$. So tat sich die Difesa popolare leicht mit

42 Vgl. die Ausführungen weiter unten, S. 163.

43 Die Beiträge der Battaglia comunista zum Problem Faschismus spiegeln jedenfalls keine fruchtbare Auseinandersetzung wider. Anfangs sind sie großspurig und völlig abstrakt, und ganz zum Schluß gehen sie in einen merkwürdigen Fatalismus über. Positiv heben sich in ihrer Konkretheit bezeichnenderweise die Korrespondentenberichte aus Sarzana ab.

44 La Difesa popolare vom 2. 7. 1921. 
der höhnischen Bemerkung: „Mit gewissen Volksführern, da können wir beruhigt sein, sind Revolutionen nicht möglich. ${ }^{\text {"45 }}$ Die Wirkung solcher Szenen auf die Arbeiterschaft sollte nicht unterschätzt werden: Der brutale und gleichzeitig psychologisch geschickte Anschlag auf das Ansehen von Arbeiterführern, ein vielfach von den Faschisten eingesetztes Mittel, hat in Massa seine Wirkung wohl nicht verfehlt und dazu beigetragen, dem Wiederfußfassen von Sozialisten und Kommunisten nach dem "großen Sturm“ der spedizione punitiva die Basis zu entziehen.

Die Auswirkungen der Masseser Ereignisse waren in Carrara erstaunlich gering. Die Faschisten beschränkten sich darauf, den Vizesekretär der Camera del lavoro, Eugenio Girolo, gefangenzunehmen und ihm bei einem „Verhör" im Fascio-Lokal die Beteiligung am Ciberti-Mord vorzuwerfen ${ }^{46}$. Girolo kam durch das sofortige Eingreifen der Polizeiführung wieder frei, ein doch bemerkenswerter Vorgang, wenn man ihn mit dem polizeilichen Laissez-faire in Massa vergleicht, der sich nur mit dem anhaltenden Respekt vor der Macht der Gewerkschaftszentrale erklären läßt. Zu weiteren Aktionen kam es nicht. Die Faschisten verzichteten entgegen ihrer eigentlichen Planung darauf, ihre Aktionen von Massa auf das sieben Kilometer entfernte Carrara auszudehnen, wo sie bei dieser Gelegenheit ursprünglich auch gleich den Widerstand der Camera del lavoro niederringen wollten ${ }^{47}$. Wahrscheinlich waren die zur Verfügung stehenden 300 squadristi dazu kräftemäßig nicht in der Lage, zumal sie in Carrara nach den vergangenen Erfahrungen damit rechnen mußten, auf bewaffneten Widerstand zu treffen. Nach dem Ausarten der Aktion und der Verhaftung der beiden Plünderer konzentrierte sich dann ohnehin die ganze Aufmerksamkeit der Faschisten auf das Gefängnis von Massa.

Die Führung der Camera del lavoro wurde sich des Ernstes der Lage sehr schnell bewußt. Schon am 25. Juni, also noch bevor sich in Massa die schlimmsten Übergriffe ereignet hatten, berief ihre Exekutivkommission für den folgenden Tag eine Versammlung der Sekretäre aller Mitgliedsligen ein, die allerdings nur eine Protestresolution und den Plan für eine Kundgebung produzierte, der nie in die Tat umgesetzt wurde ${ }^{48}$. Meschi äußerte gegenüber dem Vicequestore Giustiniani, daß „die Geduld der Arbeiter auf eine harte Probe gestellt“ werde und er sie „auf Dauer nicht mehr bremsen“ könne. Allerdings wolle er weiterhin für den Frieden wirken und sich, soweit es in seiner Macht stehe, dafür einsetzen, daß auf „Provokationen“ nicht geantwortet werde ${ }^{49}$. Diese lammfrommen Bekundungen gegenüber einem der faschistenfreundlichsten Polizeifunktionäre der Provinz kommen fast einer Ohnmachtserklärung gleich. Die Masseser Ereignisse hatten gezeigt, daß es fünf Minuten vor zwölf war und auch die defensivste Haltung der Linken die Polizeiverantwortlichen nicht einmal dazu bewegen konnte, wirksame Maßnahmen wenigstens zum Schutz ihrer gewählten Vertreter in den kommunalen Institutionen zu ergreifen. Zurückhaltung um des Friedens willen war in dieser Situation sicher nicht mehr angebracht, aber wahrscheinlich waren andere Optionen kaum mehr möglich. Für den Aufbau und die politische Absicherung eines wirkungsvollen Selbstschutzes war es wohl schon zu spät.

\footnotetext{
45 Ebenda.

${ }_{46}$ ASM, Commissariato Carrara, b. 55: Vicequestore Giustiniani an Questore vom 25. 6. 1921.

47 Ebenda: Vicequestore Giustiniani an Questore vom 26. 6. 1921.

48 Ebenda: Vicequestore Giustiniani an Questore vom 26.6. 1921 (weiteres Phonogramm).

${ }^{49}$ Ebenda.
} 
Nach der relativ mühelosen „Säuberung“ von Massa, an der die Carrareser Squadren einen wesentlichen Anteil hatten, gingen die Faschisten Carraras an die Bereinigung der Stituation in der eigenen Gemeinde. Trotz des systematischen Terrors der letzten Wochen und des wachsenden Zulaufs auch aus Randbereichen der Arbeiterschaft war die Position der Faschisten gerade in den vielen Vororten von Carrara noch ziemlich prekär. In Nazzano beispielsweise hatte eine Gruppe von jungen sovversivi, in ihrer Mehrzahl Anarchisten, am 19. Juni den Spieß umgedreht und nach einer Tanzveranstaltung den Faschisten Italo D'Este bedroht und die Abzeichen heruntergerissen ${ }^{50}$. Die Einschüchterungsaktion war sofort in Auseinandersetzungen mit den Carabinieri der Station von Avenza gemündet, die dem Faschisten zu Hilfe geeilt waren. Die Gruppe junger sovversivi, unter ihnen der Anarchist und spätere Partisanenführer Ugo Mazzucchelli, war den Carabinieri mit gezückten Revolvern entgegengetreten und hatte sich damit der Durchsuchung und Verhaftung entzogen.

In der Nacht eskalierten die Auseinandersetzungen: Die Anarchisten befürchteten einen faschistischen Revancheakt und suchten D'Este in der Wohnung seiner Eltern auf, um ihn zu "verhören“. Als sie ihn nicht antrafen, stellten sie sich auf eine faschistische spedizione ein. Sie spannten Drahtseile über die Straße, um heranfahrende Lastwagen stoppen zu können, und gingen zwischen den Blöcken eines Marmordepots in Stellung. Statt der squadristi kam eine Carabinieri-Patrouille, der die Anarchisten ein regelrechtes Feuergefecht lieferten ${ }^{51}$. Obwohl die meisten Beteiligten bald verhaftet wurden, scheinen diese Vorfälle die Faschisten Carraras stark beunruhigt zu haben, hatten sich doch hier im Kleinen genau die Befürchtungen bewahrheitet, die in bürgerlichen Kreisen anfangs zu Vorbehalten gegenüber der Fascio-Gründung geführt hatten: Die Linke hatte sich an die faschistischen Gewaltmethoden angepaßt und war von antifaschistischen Aktionen zu aufständischen Handlungen übergegangen.

Die Reaktion der Faschisten ließ nicht lange auf sich warten. Zwei Tage später, am 21. Juni 1921, überfielen und verwüsteten squadristi aus Carrara spät nachts die Lokale der örtlichen Lega cavatori e segatori und der Lega contadini, wo sie sogar eine Bombe zündeten ${ }^{52}$. Die Schonfrist für Gewerkschaftsorganisationen war offensichtlich vorbei. Die Faschisten wußten, daß sich die Gruppe um Mazzucchelli im Circolo della lega cavatori e segatori formiert hatte. Außerdem war in der anarchistischen Hochburg Nazzano, wo die mächtige Organisation der Marmorsägewerkarbeiter auch politisch das Zentrum der Arbeiterbewegung bildete und Ortsvereine der Sozialisten und Kommunisten fehlten, ohnehin keine andere Zielscheibe zu finden.

Nach den Zerstörungsaktionen in den Gewerkschaftslokalen drangen die Faschisten in zwei Privatwohnungen ein und verletzten die völlig unschuldigen Besitzer mit Stockschlägen schwer. Bei ihrer Rückkehr nach Carrara suchten sie dann noch, wohl in einer Art Rausch befangen, die beiden am Weg liegenden Orte heim: In Raglia überfielen sie

50 Darstellung der Auseinandersetzungen in ASM, Tribunale di Massa, Sentenza penale 1921/272 (10. 12. 1921); außerdem bei Bertolucci, Anarchia, S. 42 - 45. Einzelheiten wurden in einem Interview mit Mazzucchelli am 23. 5. 1989 präzisiert.

51 ASM, Commissariato Carrara, b. 55: Kommissar an Questore vom 20. 6. 1921.

52 Ebenda: Carabinieri der Station Avenza an Kommissariat von Carrara vom 22. 6. 1921; Kommissar an Questore vom 22.6. 1921; Vicequestore an Questore vom 23. 6. 1921. 
eine Privatwohnung und den unpolitischen Circolo economico, in Fossola den Circolo socialista ${ }^{53}$.

Zum ersten Mal waren die Faschisten Carraras in ihrer eigenen Gemeinde zur rücksichtslosen Zerstörung von Gewerkschaftseinrichtungen übergegangen. In den Räumen der Ligen war nichts heil geblieben, die Organisationsakten, die Möbel und sogar Türen und Fenster wurden herausgerissen und verbrannt, der Rest der Einrichtung kurz und klein geschlagen. Nach der klaren Absage des Gewerkschaftskongresses an die Adresse der Faschisten ging Renato Ricci zur üblichen Praxis des toskanischen Squadrismus über, dessen "unpolitisches“, aber erfolgreiches Rezept darin bestand, mit „flächendeckenden" Gewaltaktionen in der Arbeiterschaft ein Höchstmaß an Einschüchterung und Demoralisierung zu erzeugen. Ihm blieb auch gar nicht anderes übrig, denn gerade die großen Ligen der Marmorarbeiter waren in der Regel fest in der Hand der Anarchisten, ja sie hatten, aus einer langen politischen Tradition heraus, weitgehend den Charakter anarchosyndikalistischer Organisationen, in denen die "reformistische" Praxis der alltäglichen Gewerkschaftsarbeit nicht widerspruchsfrei, aber untrennbar mit der revolutionären Utopie einer egalitären und herrschaftsfreien Gesellschaft verbunden war. Der weltanschauliche Graben zum aggressiven Nationalismus und zu den hierarchisch-autoritären Ordnungsvorstellungen der Faschisten war zu groß, als daß eine einfache „Übernahme" der Organisationen vorstellbar gewesen wäre, auch wenn die Faschisten ihre Unabhängigkeit von den „Marmorbaronen“ hätten glaubhaft machen können.

Neben der festverwurzelten anarchistischen Arbeiterkultur stellte der ebenfalls gut verankerte linksrisorgimentale Patriotismus der Republikaner einen zweiten Hemmschuh für die faschistische Expansion dar. Der politische Monopolanspruch der Faschisten gründete sich wesentlich auf ihr Selbstverständnis als nationale Aufbruchsbewegung, der alle "gesunden" Kräfte der Nation wie selbstverständlich zu folgen hätten. Die mißtrauische bis feindselige Haltung der Republikaner in ihrer Hochburg Carrara ließ aber hier jene Atmosphäre der patriotischen Einigkeit nur sehr unvollständig aufkommen, die anderswo die Basis für den bedingungslosen Kampf gegen die "Vaterlandsver-

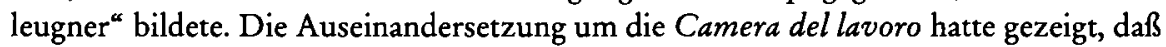
die republikanische Führung nicht bereit war, den Faschisten die Gewerkschaftsbewegung zu überlassen; und auch an der Basis hatte es ganz den Anschein, als sei die Loyalität innerhalb der „subversiven“ Subkultur, die die Republikaner mit Anarchisten, Kommunisten und Sozialisten verband, stärker als ihre Bindungen zu den anderen "nationalen Kräften“. Die Liberalen, von den Republikanern abschätzig „Monarchisten“ genannt, waren ihre traditionellen politischen Gegner, und das faschistische Hauptquartier bestand $j a$ in der Mehrheit aus ehemaligen Liberalen, deren politische Vergangenheit wenig mit den nationalrevolutionär-republikanischen Traditionen der Ursprungsfaschismen anderer Gegenden zu tun hatte.

So wie schon der Jahrestag des italienischen Kriegseintritts in Massa zu einer "patriotischen" Kraftprobe den Anlaß geliefert hatte, wurde jetzt in Carrara von den Faschisten und den mit ihnen mittlerweile eng verbundenen Liberalen der Solferino-Tag benutzt, um eine artifiziell-übersteigerte patriotische Zeremonie in Szene zu setzen ${ }^{54}$.

${ }^{53}$ Ebenda.

54 ASM, Commissariato Carrara, b. 55: 2 Phonogramme des Vicequestore an Questore vom 24. 6. 1921. 
Wenn man dem Bericht des faschistenfreundlichen Vicequestore Giustiniani halbwegs glauben kann, hatten die Faschisten erreicht, daß nahezu die gesamte Stadt die Nationalfahne geflaggt hatte, was sicher nicht ohne massiven Druck abgegangen war, zumal sich die Republikaner geweigert hatten, an den Feierlichkeiten teilzunehmen. 200 uniformierte Faschisten in Marschkolonnen führten den Festzug an und demonstrierten damit ihren Avantgardeanspruch. Auch die Reihenfolge der Kundgebungsredner - erst die beiden Liberalen Nori und Tenerani, dann ein Vertreter der Organistation der Heimkehrer aus den Einigungskriegen und zum Schluß der Sekretär des Fascio di combattimento Renato Ricci - verdeutlicht die führende Stellung, die den Faschisten mittlerweile durch ihren militanten Aktivismus zugefallen war.

Die Solferino-Feier wäre für den Carrareser Faschismus ein ungetrübter politischer Erfolg geworden, wenn es nicht am Abend zu einem unangenehmen $Z$ wischenfall gekommen wäre. Als bei einem feierlichen Konzert auf dem Hauptplatz die faschistische Hymne Giovinezza gespielt wurde, sang eine Gruppe von Republikanern den Text eines ihrer Kampflieder mit, der mit dem Refrain „Krieg dem König“ endet. Augenblicklich drangen Faschisten, die wahrscheinlich auf etwas Derartiges gefaßt waren, mit Stockschlägen auf die „Störer“ ein. Die Schlägerei löste in der Menge eine allgemeine Panik aus, und das Konzert mußte längere Zeit unterbrochen werden ${ }^{55}$.

Mit dieser kleinen Provokation hatten die Republikaner in eine offene Wunde gestochen. Ausgerechnet bei der Feier, die die neue Geschlossenheit des nationalen Lagers unter der Führung des Faschismus demonstrieren sollte, hatten sie mit ihrer antimonarchistischen Demonstration die Stimmung verdorben und den Faschisten ihre eigenen inneren Auseinandersetzungen über die tendenzialità repubblicana schmerzlich ins Bewußtsein zurückgerufen. Um gar keinen Zweifel über ihre Gesinnung aufkommen zu lassen, durchzogen die Faschisten bis spät abends unter Hochrufen auf den König die Straßen der Stadt ${ }^{56}$. Dieses in solcher Deutlichkeit vielleicht nicht erwartete Bekenntnis des Fascio von Carrara zur Monarchie stellte zwar die Harmonie mit dem lokalen Establishment wieder her, war aber natürlich nicht geeignet, bei potentiellen Sympathisanten im republikanischen Lager Propagandaerfolge zu erzielen.

Nach diesen Vorfällen erreichte die Spannung zwischen Faschisten und Republikanern einen Höhepunkt. Die Faschisten warfen der republikanischen Kommunalverwaltung die Nichtteilnahme an den Solferino-Feierlichkeiten und die Provokation beim abendlichen Konzert vor und verlangten auf einem Plakat die öffentliche Klärung ihrer Position gegenüber der faschistischen Bewegung. Der Bürgermeister Starnuti versammelte daraufhin die republikanische Mehrheitsfraktion des Gemeinderates, um über eine Antwort an die Faschisten zu beraten ${ }^{57}$. Mit großer Mehrheit wurde eine Resolution verabschiedet, mit der sie verzweifelt versuchte, eine neutrale Stellung zu bewahren. Neben der klaren Absage an die faschistische Gewalt gegenüber den Organisationen der Arbeiterschaft enthält das Papier Formulierungen, die einer nunmehr deutlichen Appeasement-Haltung entsprangen. Dem Vorwurf des mangelnden Patriotismus wurde mit einer Beschwörung der langen patriotischen Tradition der Partei begegnet, und geradezu anbiedernd ist der Text dort, wo er für die Republikaner in Anspruch nimmt, sie

\footnotetext{
${ }_{55}$ Ebenda: Vicequestore an Questore vom 25.6. 1921.

56 Ebenda.

57 ASM, Commissariato Carrara, b. 55: Vicequestore an Questore vom 26. 6. 1921.
} 
seien vor dem Auftreten der Faschisten die einzigen gewesen, die dem „Ausufern der sozialistischen und maximalistischen Illusion in den einfachen und unwissenden Herzen unserer Arbeitermassen " entgegengetreten seien ${ }^{58}$. Es handelte sich hier ohne Zweifel um eine ausgeprägte politische Defensivhaltung, die allerdings angesichts der faschistischen Polarisierungsstrategie in der gegebenen Situation nicht völlig unangemessen war. Die Republikaner konnten damit ihre Unabhängigkeit von den Faschisten wahren, ohne offen in das Lager ihrer Gegner überzugehen, was sie eines Teils ihrer Möglichkeiten beraubt und wahrscheinlich die Partei einer politischen Zerreißprobe ausgesetzt hätte. Nachdem sich herauskristallisiert hatte, daß Polizei und Justiz dem Faschismus in der Region mehr oder minder den Steigbügel hielten, war eine offiziell neutrale und inoffiziell vorsichtig antifaschistische Kommunalverwaltung in Carrara eines der ganz wenigen institutionellen Hindernisse für die hegemonialen Zielsetzungen der Faschisten geblieben $^{59}$.

Der Juni und die ersten Julitage brachten eine bemerkenswerte organisatorische Expansion des Faschismus im Gemeindegebiet von Carrara. Es gelang dem Fascio di combattimento im Laufe dieser Zeit, in acht Vororten Ableger zu gründen. Neben den beiden größten Vororten, der republikanischen Hochburg Avenza und dem Hafenvorort Marina, handelte es sich hierbei um Codena, Miseglia, Torano, Bergiola, Foscalina und Bedizzano und anscheinend auch schon Gragnana ${ }^{60}$, ausgesprochene Steinbrucharbeitersiedlungen im bergigen Hinterland von Carrara. Innerhalb von 14 Tagen, vom 28. Juni bis zum 11. Juli, wurden alle diese Orte, zum Teil wiederholt, von Faschisten heimgesucht ${ }^{61}$. Die spedizioni verliefen überall in etwa nach dem gleichen Schema: Spät nachts oder in den ersten Morgenstunden überfielen squadristi aus Carrara mit Unterstützung einheimischer Faschisten Vereinslokale und exponierte Angehörige der Arbeiterorganisationen. Die Lokale wurden aufgebrochen und vollständig verwüstet, Brauchbares, etwa Lebensmittel und Wein, und die Fahnen der Organisationen als Siegestrophäen meistens mitgenommen. Die Faschisten drangen gewaltsam in die Wohnungen ihrer designierten Opfer ein. Dort vollzog sich das immer gleiche Ritual: Suche nach versteckten Waffen, Terrorisierung des Betroffenen und seiner Familie mit vorgehaltenen Schußwaffen und

${ }^{58} \mathrm{La}$ Sveglia repubblicana vom 2.7.1921.

59 Bezeichnend für den undemokratischen Geist, der unter den höheren Staatsbeamten der Provinz herrschte, ist, daß mittlerweile vom Vicequestore Giustiniani auch die Legitimität der republikanischen Kommunalverwaltung von Carrara in Frage gestellt wurde: Auf die Äußerung des Bürgermeisters hin, die Monarchie hätte am Risorgimento „nur mit Schändlichkeiten und Verbrechen “ teilgenommen, bemerkte er, dieser benutze „sein hohes Amt, um die Gefühle der großen Mehrheit der Bürger zu verletzen“. Angesichts des Wahlergebnisses vom vergangenen Mai, das in Carrara fast 75 Prozent der Stimmen für die antimonarchistischen Parteien verzeichnete, wird deutlich, daß die Bürger („cittadini“) für Giustiniani nicht die Wahlberechtigten waren, sondern eben nur die sich zunehmend faschisierende ehemals liberale Stadtnotabilität, für die die Worte des Bürgermeisters „abends Gegenstand der unnachsichtigsten Kommentare waren“; ASM, Commissariato Carrara, b. 55: Vicequestore an Questore vom 1. 7. 1921.

60 Der Polizeikommissar spricht von insgesamt acht Ortsvereingründungen bis Mitte Juli (ASM, Commissariato Carrara, b. 55: Überblicksbericht ohne Datum), aber bei Gragnana sind Zweifel angebracht. Siehe Anm. 66.

${ }^{61}$ Die synthetische Darstellung der Ereignisse basiert auf den Berichten des Vicequestore Giustiniani und des Kommissars Barcucci im Zeitraum vom 28. 6. 1921 bis zum 12.7. 1921 (ASM, Commissariato Carrara, b. 55); außerdem für die Ereignisse in Bedizzano und Gragnana: ASM, Tribunale di Massa, Sentenze penali 1922/130 und 1922/134. 
schließlich Prügel mit Fausthieben, Tritten und Stockschlägen, die in der Regel zu leichteren bis mitrelschweren Verletzungen führten ${ }^{62}$.

\begin{tabular}{llll}
\hline $\begin{array}{l}\text { Datum } \\
\text { Uhrzeit }\end{array}$ & Ort & $\begin{array}{l}\text { überfallene } \\
\text { Einrichtungen }\end{array}$ & $\begin{array}{l}\text { überfallene } \\
\text { Personen }\end{array}$ \\
\hline $\begin{array}{l}\text { 28. Juni } \\
\text { 1.30 Uhr }\end{array}$ & Codena & $\begin{array}{l}\text { Club anarchico } \\
\text { Lega cavatori }\end{array}$ & $\begin{array}{l}\text { Sekretär der } \\
\text { Lega cavatori }\end{array}$ \\
$\begin{array}{l}\text { 29. Juni } \\
\text { 19.00 Uhr }\end{array}$ & Miseglia & $\begin{array}{l}\text { Club socialista } \\
\text { Lega cavatori }\end{array}$ & \\
$\begin{array}{l}\text { 30. Juni } \\
\text { 3.00 Uhr }\end{array}$ & Gragnana & $\begin{array}{l}\text { Circolo comunista } \\
\text { Club anarchico }\end{array}$ & \\
30. Juni & Sorgnano & Circolo comunista & \\
$\begin{array}{l}\text { 1. Juli } \\
\text { 3.30 Uhr }\end{array}$ & Torano & Circolo socialista & \\
$\begin{array}{l}\text { 3. Juli } \\
\text { 22.00 Uhr }\end{array}$ & Bergiola & Lega cavatori & zwei Anarchisten \\
$\begin{array}{l}\text { 5. Juli } \\
\text { 0.00 Uhr }\end{array}$ & Gragnana & kommunistische & ein Anarchist \\
7. Juli & Kooperative & Kommunist \\
23.00 Uhr & Miseglia & ein Kommunist \\
$\begin{array}{l}\text { 11. Juli } \\
\text { 0.00 Uhr }\end{array}$ & Bedizzano & $\begin{array}{l}\text { Lega cavatori } \\
\text { Club comunista }\end{array}$ & $\begin{array}{l}\text { fünf Personen } \\
\text { (Anarchisten und } \\
\text { Kommunisten) }\end{array}$ \\
\hline
\end{tabular}

Die Faschisten gingen offensichtlich planvoll vor. Es sind keine oder nur nichtige konkrete Anläße für die nächtlichen Einfälle aktenkundig, und so drängt sich die Annahme auf, daß es sich hier um prophylaktische Einschüchterungsaktionen handelte, die einen eventuellen Widerstandswillen der lokalen sovversivi schon im Keim ersticken und so den Weg für die Kontrolle der abgelegenen frazioni durch die lokalen Faschisten frei machen sollten. Tatsächlich scheinen schon die ersten spedizioni im ganzen betroffenen Raum eine außerordentliche Demoralisierung hervorgerufen zu haben, denn auch in den Orten, die später überfallen wurden, trafen die Arbeiterorganisationen keinerlei Vorkehrungen zum Schutz ihrer Vereinslokale, obwohl das weitere Vorgehen der Faschisten zunehmend leichter vorherzusehen war. Auch die Polizei beschränkte sich wie üblich auf das Verfassen von Berichten nach erfolgter Aktion, obwohl in zwei der am stärksten betroffenen Orte, Gragnana und Bedizzano, sogar eigene Carabinieri-Stationen vorhanden waren, von denen aus das Nichtbemerken der Überfälle schon einem Kunststück gleichkam. Auch vom zentral zuständigen Polizeikommissariat von Carrara, in dem der

62 Ebenda: In den Akten ist hinsichtlich der Verletzungen in der Regel von einer Heilungszeit von zwei bis drei Wochen die Rede. 
Vicequestore von Massa Giustiniani in Vertretung des gesundheitlich schwer angeschlagenen Kommissars Barcucci wirkte, ging keinerlei Initiative zum Schutz der bedrohten Einrichtungen und Personen aus. Seine Untätigkeit war diesmal so auffällig gewesen, daß der Präfekt der Provinz Grignolo, der sich selbst nie durch energisches Handeln gegenüber den Faschisten hervorgetan hatte, den Polizeiverantwortlichen von Carrara die mangelhaften Sicherheitsvorkehrungen vorhielt. Bezeichnenderweise sah er sich auch veranlaßt, das Kommissariat von Carrara daran zu erinnern, daß es sich bei den von den Faschisten verübten Taten um „wirkliche Gesetzesübertretungen“ handelt ${ }^{63}$.

Das Übergreifen des Faschismus von der Stadt Carrara auf fast alle größeren ville des Berglandes, ausgespart blieben nur die weit entfernten Orte Castelpoggio und Colonnata, ist eine genauere Betrachtung wert, weil es sich in einem soziologisch und politisch recht gut zu überblickenden Rahmen vollzog und einige Bedingungen offenbart, unter denen es ihm gelang, Fuß zu fassen ${ }^{64}$. Erstaunlich ist auf den ersten Blick, daß es sich durchwegs um Orte handelte, in denen die Steinbrucharbeiter, das eigentliche „Rückgrat" der Arbeiterbewegung in der Region, die große Mehrheit der Bevölkerung stellten; die mehr kleinbäuerlich strukturierten und von der Marmorverarbeitung bestimmten Orte der Ebene erwiesen sich gegenüber dem Faschismus als wesentlich resistenter. Auffällig ist auch die überdurchschnittliche kommunistische Präsenz in einem Großteil der betroffenen Orte, so in Gragnana, Sorgnano, Codena, Miseglia und Torano, die sich allerdings in den letzten beiden Orten nicht organisatorisch, sondern nur im Wahlverhalten ausdrückte. In Gragnana, das einen außergewöhnlich großen kommunistischen Ortsverein hatte, wurden im Abstand von fünf Tagen zwei spedizioni verübt. Es bestätigt sich hier im kleinen, was sich zur Ausbreitung des Provinzfaschismus im allgemeinen konstatieren läßt: Die faschistische Entfaltung setzt das Vorhandensein bedeutender Positionen der Linken voraus.

Trotz des „rebellischen “ Charakters der Orte des Berglands, die neben den Kommunisten vor allem auch durch die Anarchisten sowie durch "Anarcho-Republikaner" und Sozialisten geprägt waren, findet sich hier ein in dieser Größe nicht ohne weiteres zu erwartendes liberal-konservatives Wählerpotential. Die nationalen Wahlen des Mai 1921 brachten dem Blocco nazionale in den Stimmbezirken Torano/Miseglia, Sorgnano/Montia und Codena/Bergiola jeweils circa ein Drittel der abgegebenen Stimmen; das liegt weit über dem Gesamtergebnis in der Gemeinde Carrara und noch weiter über dem der gesamten Provinz. Dieses gute Abschneiden läßt sich nicht allein durch die Wahlentscheidung des lokalen Bürgertums erklären, das bestimmt nicht mehr als zehn Prozent der Bevölkerung ausmachte; man muß folglich davon ausgehen, daß ein nicht zu vernachlässigender Teil der hier ansässigen Steinbrucharbeiter traditionell "monarchistisch“ wählte. In Torano und Bergiola gab es sogar Ortsvereine der Associazione democratica liberale, ein weiteres bemerkenswertes Faktum angesichts der notorischen organisatorischen Schwäche der Liberalen. Bezeichnenderweise erfolgte in Bergiola die Gründung des Fascio-Ortsvereins durch die Brüder Picciati auch aus der liberalen Organisation heraus.

Der Faschismus fand also in den frazioni des Berglands ein ausgeprägt polarisiertes politisches Terrain vor, das sein Eindringen zweifellos wesentlich begünstigt hat. Er

${ }^{63}$ ASM, Commissariato Carrara, b. 55: Präfekt an Kommissar von Carrara vom 7. 7. 1921.

${ }^{64}$ Zur politischen Struktur dieses Gebiets siehe die Übersicht im Anhang, S. $287 \mathrm{f}$. 
konnte bei der Rekrutierung auf ein beträchtliches „antisubversives" Reservoir zurückzugreifen und einen deutlich konturierten Gegner zu seiner Zielscheibe machen. Eine große republikansiche Anhängerschaft, wie sie etwa in Gragnana, Sorgnano und Code$\mathrm{na} /$ Bergiola zu verzeichnen war, konnte dort anscheinend die Tendenz zur politischen Polarisierung nicht entschärfen, wahrscheinlich weil sie keinen Ausdruck in der Tätigkeit politischer Organisationen der Republikaner fand. Ganz anders als etwa in den Talorten Fossola, Avenza und Marina gab es in den Berg-frazioni keine republikanischen Vereine; das ist ein markantes Indiz für die Labilität der dortigen republikanischen Basis. In Gragnana, wo es im Mai ein für die Republikaner geradezu plebiszitäres Wahlergebnis gegeben hatte, war ihr Verhältnis zu den lokalen Sozialisten und Kommunisten in der Vergangenheit alles andere als spannungsfrei gewesen ${ }^{65}$. Nicht zufällig rekrutierte der Faschismus in diesem Ort den harten Kern seiner squadristi aus den Kreisen republikanisch orientierter Jugendlicher ${ }^{66}$.

Die sovversivi des Berglands ertrugen die Offensive der Squadren und die Einnistung von faschistischen Zellen in ihren Orten im allgemeinen ohne nennenswerte Reaktion. Eine Ausnahme bildete Torano, wo eine kleine Gruppe unter der Führung des Anarchisten Paride Barattini am 11. Juli einen bewaffneten Angriff auf die lokalen Faschisten unternahm. Die Brüder Tancredi und Alfonso Rinaldi, ehemalige Sozialisten, die sich dem Fascio angeschlossen hatten, konnten sich nur knapp vor ihren Kugeln in das $\mathrm{Fa}$ scio-Lokal retten, wo sich das Gros der Faschisten schon verschanzt hatte. Die Angreifer belagerten und beschossen das Haus, bis Faschisten aus dem Nachbarort Miseglia, die von dem Vorfall benachrichtigt worden waren, die Gesinnungsgenossen aus Torano aus ihrer mißlichen Lage befreiten. Bei der Schießerei wurde der Squadrenführer und Fascio-Sekretär von Miseglia, Sesto Ganapini, leicht verletzt. Am Ort des Geschehens fand man außerdem die Leiche eines gewissen Ercole Bonvini, dessen Rolle bei den Auseinandersetzungen ebensowenig wie die Verantwortung für seinen Tod vollständig geklärt ist. Im ersten Polizeibericht wurde er den angreifenden sovversivi zugeschlagen und sein Tod mit einer verirrten Kugel aus den eigenen Reihen erklär ${ }^{67}$. Die im ganzen einleuchtendere Tatrekonstruktion des Schwurgerichts Massa ${ }^{68}$, der allerdings angesichts des Datums der Urteilssprechung vom 18. April 1923 auch nicht ganz zu trauen ist,

${ }^{65}$ Der faschistischen Aktion in Gragnana war unmittelbar eine Auseinandersetzung zwischen Republikanern und Sozialisten vorausgegangen, bei der der Republikaner Virginio Pedroni irrtümlicherweise seine eigene Frau mit einem Revolverschuß verletzte (ACS, MI, DGPS 1921, b. 69, f. „Ordine pubblico Massa“: Präfekt an Innenministerium vom 30.6. 1921). Sein Bruder Michele Pedroni wurde wenig später erster Fascio-Sekretär von Gragnana.

${ }^{66}$ Erst am 28. 8. 1921 wurde diese Gruppe, bestehend aus Angelo Piazzi, Ferdinando Zeni, Gisberto Zeni, Tito Bernucci, Amato Bordigoni, Achille Tufarini und Luigi Cricca, auf einer Versammlung der Gioventù repubblicana förmlich aus der republikanischen Organisation ausgeschlossen (La Sveglia repubblicana vom 4. 9. 1921). Dieses Faktum wie auch die Tatsache, daß Daten zu Gragnana erst im November 1921 auftauchen (ACS, MI, DGPS 1923, b. 91, f. „Fasci Massa“, sf. „Costituzione fasci“: Präfekt an Innenministerium vom 5. 11. 1921), könnten auf die Tatsache hinweisen, daß dort der Fascio-Ortsverein deutlich später gegründet wurde als in den übrigen genannten Orten, um auf diesen Ablösungsprozeß Rücksicht zu nehmen.

67 ASM, Commissariato Carrara, b. 55: Kommissar an Questore vom 12. 7. 1921.

${ }^{68}$ ASM, Corte d'assise Massa, Sentenze 1923/8 (18.4 1923) und 1923/37 (16.11. 1923). Auf die Ausführungen im letzteren Urteil basiert im wesentlichen die vorliegende Darstellung des Vorfalls. 
spricht von der unmittelbar vorangegangenen Konversion des Sozialisten Bonvini zum Faschismus. Hiernach hatte er den Antrag für die Aufnahme in den Fascio schon gestellt und sei durch das trikolore Bändchen an der Brust und die Reitpeitsche in der Hand als Faschist zu identifizieren gewesen. Das sei der Grund für seine „Hinrichtung“ durch die Gruppe um Barattini gewesen.

Es ist zweifelhaft, ob die isolierte Terroraktion von Torano irgendeine Wirkung hatte. Die Erfassung der Steinbrucharbeiterorte durch den Faschismus konnte sie jedenfalls nicht aufhalten, auch wenn die vergleichsweise dürftige Mitgliederentwicklung des $\mathrm{Fa}$ scio von Torano ein auffälliges Faktum ist und auf ein für die Faschisten anhaltend ungünstiges Klima schließen läßt. Interessant ist der Fall Torano aber vor allem deshalb, weil hier das Überlaufen von Sozialisten zum Fascio zu einem sehr frühen Zeitpunkt festzustellen ist, als die Freiwilligkeit einer solchen Entscheidung noch völlig außer Frage stand. Bei den Rinaldis kann man wirtschaftliche Not als Beweggrund für diesen Schritt vermuten. Darauf weist wenigstens die aktenkundige Beschimpfung der Familie als "morti di fame" hin ${ }^{69}$.

\begin{tabular}{lccl}
\hline Orte & Einwohner $^{70}$ & Faschisten $^{71}$ & Prozent \\
\hline Bedizzano & 1647 & 50 & 3,0 \\
Bergiola F. & 890 & 60 & 6,7 \\
Codena & 1130 & 50 & 4,4 \\
Miseglia & 938 & 30 & 3,2 \\
Torano & 1924 & 25 & 1,3 \\
Zum Vergleich: & & & \\
Carrara (Stadt) & 24461 & 700 & 2,8 \\
Marina d. Ca. & 4899 & 60 & 1,2 \\
\hline
\end{tabular}

Erstaunlicherweise erreichte der Faschismus in den frazioni des Berglandes auf Anhieb eine höhere Organisierungsquote als in der Stadt und in den Orten der Ebene. Die beachtlichste Mitgliederentwicklung vollzog sich in Bergiola Foscalina, wo den Faschisten neben der erwähnten liberalen Organisation als Startrampe wohl auch die völlige Abwesenheit von politischen Organisationen der Arbeiterbewegung zugute kam. Die faschistische Organisation wurde dort schon am 20. Mai gegründet ${ }^{72}$, also nur eine Woche nach dem Fascio von Carrara, und die hier bisher vorherrschende republikanisch-anarchistische politische Kultur sowie die örtliche Steinbrucharbeitergewerkschaft hatten ihrer Dynamik anscheinend wenig entgegenzusetzen. In kurzer Zeit gelang es ihr, über den

${ }^{69} \mathrm{Zu}$ deutsch: „Hungertote“. Eine noch heute gängige Beschimpfung besonders armer Leute (ebenda).

70 Censimento popolazione 1921, Bd. 7, S. 42.

${ }^{71}$ ACS, MI, DGPS 1922, b. 101 bis „Costituzione fasci“: Überblick über die Provinz Massa ohne Datum; ebenda, DGPS 1923, b. 91, f. „Fasci Massa“, sf. „Costituzione fasci“: Präfektenberichte vom 30. 7. bis 31. 8. 1921. Die Zahlen sind offensichtlich gerundet oder von den örtlichen Carabinieri-Stationen geschätzt, was aber ihre Aussagekraft nicht nennenswert einschränkt. In der Tabelle wurden nur die Zahlen verwendet, die den Stand von circa Ende Juli 1921 widerspiegeln. Daten zu Carrara (Stadt): Alalà vom 20. 8. 1921.

72 ACS, MRF, b. 23, f. 113, sf. 53: ausgefüllter Erhebungsbogen des PNF vom Januar 1922. 
Rahmen der Associazione democratica liberale, die nur 20 Mitglieder hatte, weit hinauszukommen und zur beherrschenden Größe im Ort zu werden ${ }^{73}$. Von den 66 Mitgliedern, die der Fascio von Bergiola am Jahresende zählte, waren 58 Arbeiter, vier Marmorunternehmer und zwei Studenten ${ }^{74}$. Diese bemerkenswerte Dominanz der Arbeiter galt wohl im wesentlichen auch für die anderen faschistischen Ortsvereine des Berglandes. Das Eindringen des Faschismus von Carrara in dieses Gebiet führte so, neben einem deutlichen Mitgliedergewinn von circa 50 Prozent, zu seiner soziologischen Neuzusammensetzung zugunsten des Elements der Steinbrucharbeiter, das ihn in Zukunft charakterisieren sollte. Hinsichtlich der Ursachen und Implikationen dieses bemerkenswerten Phänomens sei auf ein späteres Kapitel verwiesen ${ }^{75}$.

Die erfolgreiche Expansion im Hinterland verleitete den Fascio zu einer neuerlichen Kraftprobe mit der Camera del lavoro von Carrara. In der Nacht vom 6. zum 7. Juli erschienen squadristi vor ihrem Gebäude. Die zur Bewachung abgestellten Carabinieri hielten sie an der Eingangspforte ab, bemerkten aber nicht, daß unterdessen auf der Rückseite andere Faschisten in das Haus einstiegen und Akten entwendeten. Die Nachricht von dem Überfall verbreitete sich schnell, und am folgenden Tag kam es zu spontanen Arbeitsniederlegungen, während die Gewerkschaftsführung die offizielle Ausrufung eines unbefristeten Generalstreiks vorbereitete ${ }^{76}$, eine Maßnahme, die nach der letzten Kraftprobe mit dem Fascio für den vorliegenden Fall praktisch angekündigt worden war. Das Polizeikommissariat von Carrara befürchtete eine unkontrollierbare Eskalation der Auseinandersetzungen. Es forderte deshalb zusätzliche Polizeieinheiten an und berief die Exekutivkommission der Camera del lavoro und das Direktorium des Fascio in das Büro des Bürgermeisters, um auf dem Wege von Verhandlungen die Situation zu entschärfen. Hier machten die Faschisten einen Rückzieher; sie erklärten, daß es nicht ihre Absicht sei, einen Anschlag auf die gewerkschaftliche Tätigkeit der Camera del lavoro auszuüben, und daß sie die entwendeten Akten zurückgeben würden ${ }^{77}$. Wahrscheinlich hatten sie gehofft, in den Unterlagen Kompromittierendes zu finden, das ihnen erlaubt hätte, eine Kampagne gegen die Gewerkschaftszentrale zu entfesseln; ihr Aktenstudium war aber offensichtlich fruchtlos geblieben. Darüber hinaus ließ der laufende spontane Streik vermuten, daß der Generalstreik zu einem großen Erfolg für die Camera del lavoro werden würde. Die Gewerkschaftsführung ihrerseits war sichtlich erleichtert darüber, auf die Konfrontation verzichten zu können. In einem Plakat gab sie ihrer Genugtuung über die Erklärung des faschistischen Direktoriums Ausdruck und rief die Arbeiter dazu auf, die Arbeit wieder aufzunehmen ${ }^{78}$.

Das Ausbleiben des angestrebten strategischen Sieges über die Arbeiterbewegung in Carrara ließ die Faschisten wieder zum täglichen Kleinkrieg zurückkehren, dessen zermürbende Wirkung versprach, auf längere Sicht auch zum Ziel zu führen. Vor allem Marina di Carrara wurde Mitte des Monats zur Bühne verschiedener Angriffe auf einzelne

\footnotetext{
73 Vgl. die Organisationsdaten für Bergiola Foscalina in der Übersicht im Anhang, S. 287.

74 Wie Anm. 72.

75 Siehe weiter unten, S. 157-161.

76 ASM, Commissariato Carrara, b. 55: 2 Berichte des Kommissars an Questore vom 7. 7. 1921.

7 Ebenda.

${ }^{78}$ Ebenda: Abschrift des Plakats der Camera del lavoro vom 7. 7. 1921.
} 
sovversivi und politische Zirkel der Linken ${ }^{79}$, aber auch in Carrara selbst häuften sich jetzt die Prügelaktionen vor allem gegen Anarchisten ${ }^{80}$. Der schwerwiegendste Vorfall ereignete sich am 12. Juli, als einige Faschisten, unter ihnen Umberto Ricci, der Bruder des Fascio-Sekretärs, und das Direktoriumsmitglied Ugo Dell'Amico, den sozialistischen Rechtsanwalt Vico Fiaschi zusammenschlugen ${ }^{81}$. Fiaschi, der durch das Eingreifen der Carabinieri vor Schlimmerem bewahrt wurde, war sicherlich in seiner Qualität als Rechtsberater der Camera del lavoro aufs Korn genommen worden, doch diese verzichtete auf jegliche Reaktion, obwohl hier ganz deutlich wurde, was von der nur fünf Tage alten Erklärung der Faschisten zur Nichtbehinderung der Gewerkschaftstätigkeit zu halten war.

Zieht man Bilanz, so läßt sich sagen, daß die Faschisten im zweiten Monat ihrer gewalttätigen politischen Aktion in der Marmorregion entscheidende Positionsgewinne errangen. Vor allem die Sozialisten erlitten durch den Squadrismus harte Schläge. In ihrer Hochburg Massa verschwanden sie praktisch von der politischen Bildfläche, und auch in Pontremoli, der drittgrößten Stadt der Provinz Massa-Carrara, waren sie nach dem großen Squadreneinfall so geschwächt, daß sie keine nennenswerten Aktivitäten mehr entfalteten. Im sozialistisch-kommunistischen Sarzana hingegen führte die "hautnahe“ Bedrohung durch die faschistische Gewaltoffensive zu einer einheitlichen Abwehrreaktion, die dem Faschismus dort und in der ganzen Region noch große Probleme bereiten sollte.

Eine ganz besondere Situation bildete sich in der Gemeinde Carrara, dem einwohnerreichen wirtschaftlichen Zentrum der Marmorregion, heraus. Hier bemühten sich die Faschisten, durch die Wirkungen des konjunkturellen Einbruchs in der Marmorwirtschaft begünstigt, mit Erfolg um die Rekrutierung in der Arbeiterschaft. Der Carrareser Faschismus bildete "Ableger“ in den meisten frazioni des Gemeindegebietes und wuchs im Laufe des Juli auf die Stärke von 700 Mann an, was weit über die Hälfte der Faschisten in der gesamten Provinz bedeutete ${ }^{82}$. Trotz seiner numerischen Stärke und seiner Gewalttätigkeit, die in ihrer Beständigkeit alles weit in den Schatten stellten, was sich sonst noch in der Provinz ereignete, gelang es den Faschisten nicht, ihre Gegner aus den entscheidenden Positionen zu verdrängen. Die Camera del lavoro blieb fest in der Hand der traditionellen anarchosyndikalistischen Führungsgruppe und büßte noch nicht einmal ihre Streikfähigkeit ein. Entscheidend gestützt wurde sie von den Republikanern, die durch ihre patriotische Tradition und die Verfügung über die Kommunalverwaltung

79 Ebenda: Kommissar an Carabinieri von Marina di Carrara und 2 Berichte der Carabinieri von Marina an Kommissar vom 13. 7.1921.

80 Ebenda: „Cenno sommario“ des Kommissars von Carrara ohne Datum: „bastonatura“ von Primo Giorgi, Guido Maggioli und Ezio Cesrin (9./10./12. 7. 1921). Außerdem Angriff auf Benedetto Angeloni (ASM, Tribunale Massa, Sentenza penale 1922/58, 22. 3. 1922) und die „bastonatura" von Salvatore Franchi durch Renato Ricci (ASM, Tribunale Massa, Sentenza penale 1922/618, 27. 12. 1922).

81 ASM, Commissariato Carrara, b. 55: „Cenno sommario“ des Polizeikommissars ohne Datum; ACS, MI, DGPS 1921, b. 101, f. „Fasci Massa“: Präfekt an Innenministerium vom 13. 7. 1921.

82 Es ist nicht möglich, das numerische Gewicht der Carrareser innerhalb des Faschismus der Provinz genauer anzugeben, denn die Statistik des Innenministeriums hält einer Überprüfung nicht stand und kann nur hier und da durch Modifikationen der Realität angenähert werden. Diese (ACS, MI, DGPS 1922, b. 101 bis "Costituzione fasci“, verwendet bei De Felice, Mussolini il 
für die Faschisten noch weitgehend unangreifbar waren. Das destruktive Potential des Faschismus ließ sich also nicht ohne weiteres gleich in einen positiven politischen Gewinn verwandeln. Die Beherrschung der „Straße“, die Einschüchterung der Aktivisten der Arbeiterbewegung und die Demoralisierung ihrer Basis ebneten jedoch den Faschisten auf lange Sicht den Weg zur gänzlichen Ausschaltung der Linken. Der Eintritt in den Fascio mußte jetzt opportunistischen Elementen, vor allem auch in der Arbeiterschaft, als zunehmend lohnenswerter erscheinen: Das persönliche Risiko nahm ab, Möglichkeiten der gewalttätigen Selbstbehauptung eröffneten sich gerade auch für Personen mit besonders niedrigem Sozialstatus, und die Hoffnung, eine individuelle Lösung des Problems der eigenen Unterbeschäftigung oder Arbeitslosigkeit durch die Hilfe eines faschistenfreundlichen Marmorindustriellen zu finden, war nicht völlig abwegig. So erwies es sich, daß in der zweiten Junihälfte und der ersten Julihälfte der eigentliche Durchbruch des Faschismus in der Region von Carrara stattgefunden hatte. Bei seiner weiteren Machtkonsolidierung konnte er auf eine in dieser Phase geschaffene solide Basis aufbauen. Die relative Unbeschadetheit, mit der er die bevorstehende schwere politisch-militärische Niederlage von Sarzana überstehen wird, ist dafür der beste Beweis.

\section{Die „fatti di Sarzana“: das „Caporetto“ des toskanischen Squadrismus?}

Die fatti di Sarzana vom 21. Juli 1921, neben dem Debakel der Squadren Italo Balbos in Parma im August 1922 die einzige große „militärische“ Niederlage des Faschismus, sind aus den verschiedensten Perspektiven ausgiebig untersucht worden, so daß hier über den Forschungsstand hinaus nur wenig Neues hinzugefügt werden kann' ${ }^{1}$. Mit diesem Ereignis tritt der Faschismus der Marmorregion endgültig ins nationale Blickfeld. Der Verlauf der fatti di Sarzana und die darauffolgende kurze Tätigkeit des vom Innenministerium entsandten polizeilichen Generalinspektors Vincenzo Trani lassen Handlungsalternativen zur üblichen Praxis der Arbeiterorganisationen wie auch der Polizei erkennen, die die unvermeidlich erscheinende Expansion des Faschismus für kurze Zeit in Frage stellten.

fascista 1, S. 8 f.) führt für die Provinz Massa am 31. 8. 1921, zu einer Zeit also, als allein der Fascio von Carrara schon ca. 1400 Mitglieder hatte (vgl. S. 105, Anm. 66), 14 Fasci mit insgesamt 965 Mitgliedern auf. Diese Zahlen beruhen größtenteils auf nicht aktuellen Angaben. Der Fascio von Massa etwa schlägt in dieser Statistik mit nur 48 Mitgliedern zu Buche, was auf eine nicht aktualisierte Angabe vom Mai zurückgeht (ACS, MI, DGPS 1923, b. 91, f. „Fasci Massa“, sf. "Costituzione fasci“ : Präfekt an Innenministerium vom 20. 5. 1921). Das faschistische Lokalblatt Alalà vom 20. 8. 1921 gibt für Ende Juli die Zahl der Fascio-Angehörigen in Carrara mit über 700 an, eine Angabe, die dem kritischen Vergleich mit den Zahlen in den Polizeiakten standhält. Für die gesamte Provinz kann man zu diesem Zeitpunkt die Zahl von circa 1100 Faschisten annehmen, wenn man die für einige Fasci veralteten Angaben der Polizeistatistik extrapoliert.

1 Gregori, Sarzana, passim, und Banchelli, Memorie, S. 60-68, stellen die Ereignisse aus faschistischer Sicht dar. Da beide Autoren beteiligt waren, enthalten die Schriften - neben propagandistischen Verzerrungen - interessante Details. Fundierte und präzise Darstellungen der Ereignisse bei Costantini, Sarzana, passim, und ders. und Ferro, Sarzana, passim. Siehe außerdem vor allem Cantagalli, Fascismo fiorentino, S. 243-255 und Bianchi, Lotte sociali, S. 175 - 192. 
Die fatti di Sarzana vollzogen sich vor dem Hintergund einer besonderen Situation, die sich nach dem Faschisteneinfall vom 12. Juni in der Stadt herausgebildet hatte. Die liberale Stadtnotabilität war durch die Aktion der Faschisten politisch und moralisch völlig an die Wand gedrängt worden und verlor damit einen Großteil ihres traditionellen Einflusses auf die örtlichen Verantwortlichen der Polizei, die in der Folgezeit unter dem Druck der Volksstimmung den Aufbau eines antifaschistischen Selbstschutzes duldeten. Das Bewußtsein von der drohenden Gefahr erzeugte eine spontane politische Einigkeit im Lager der sovversivi, wie sie aus folgendem Aufruf der örtlichen Kommunisten spricht:

„Proletarier, Arbeiter und Bauern! Wenn man bis gestern über die theoretischen Ziele dieser oder jener Partei diskutieren konnte, so halten wir heute ein im Angesicht der gemeinsamen Gefahr und vergessen nicht, daß über jeglicher politischen Tendenz unser Leben, das der Genossen, das unserer Familien und unserer Einrichtungen steht." 2

Wie in La Spezia, aber mit mehr Erfolg als dort, wurde ein Comitato di difesa proletaria gegründet, in dem Sozialisten, Kommunisten, Anarchisten und Republikaner zusammenfanden und den Aufbau von Selbstschutzabteilungen in Angriff nahmen ${ }^{3}$. Als Ende Juni in Rom ein nationaler antifaschistischer Selbstschutzverband mit dem Namen Arditi del popolo aus der Taufe gehoben wurde, benannte man die Abteilungen auch in Sarzana so ${ }^{4}$. Mititärische Führer der Miliz waren zwei ehemalige Offiziere, die Republikaner Silvio Delfini und Isoppo Papirio. Sarzana wurde so für die gesamte Region zum Symbol eines einheitlichen Widerstandswillens und zum Zufluchtsort für Verfolgte aus den Orten, die schon fest in der Hand der Faschisten waren'.

Natürlich waren die Zustände in der Nachbarstadt Sarzana für die zunehmend uneingeschränkter waltenden Faschisten von Carrara eine Provokation erster Ordnung, ein „Säuberungsfeldzug“ von ihrer Seite lag daher gleichsam in der Luft. Anlaß für eine erste großangelegte Strafexpedition der Squadren Carraras ins nördliche Hinterland gab die Ermordung des Fuhrmanns Pietro Procuranti, dessen Leiche am 15. Juli bei Tendola di Fosdinovo an der Landstraße Carrara-Fivizzano gefunden wurde. Procuranti, der als alter Liberaler schon früh Mitglied des Fascio von Carrara geworden war, trug den Beinamen „der Teufel“ und war wegen seines gewalttätigen Charakters bekannt. Nachdem die Polizei am folgenden Tag einen Sympathisanten der popolari als Tatverdächtigen verhaftete, erschien die politische Motivation des Mordes in Frage gestellt. Das hinderte die Faschisten allerdings nicht daran, Carrara mit einem Plakat zu tapezieren, das die The-

${ }^{2}$ La Battaglia comunista vom 25. Juni 1921.

${ }^{3}$ Vgl. Costantini, Sarzana, S. 69.

4 Der nationale Verband der „Arditi del popolo“ wurde am 27. Juni 1921 aus der Heimkehrerorganisation der „arditi “ (der italienischen Stoßtruppenangehörigen des Ersten Weltkriegs) von dem Anarchisten und ehemaligen „ardito“ Ugo Secondari gegründet. Ziel der Organisation war es, der faschistischen Gewalt eine einheitliche Kampforganisation der Linken entgegenzustellen. Zur Geschichte des Verbands siehe Cordova, Arditi, S. 83-111.

${ }^{5}$ Zur Beteiligung von Fabrikarbeitern aus La Spezia siehe Bianchi, Lotte sociali, S. 183. Außerdem wurden die Anarchisten und Aktivisten der „Camera del lavoro“ von Carrara, Ezio Guerra, Andrea Giandalasini (Miglied der Exekutivkommission) und Antonio Balloni identifiziert, die offensichtlich an den Auseinandersetzungen des 21. Juli 1921 beteiligt waren; ASM, Commissariato Carrara, b. 55: Kommissar an Untersuchungsrichter von Massa vom 27. 10. 1921. 
se vom politischen Meuchelmord verbreitete, um die Stimmung für die folgenden Aktionen der Squadren vorzubereiten ${ }^{6}$.

Noch am gleichen Tag überfielen die Squadren aus Carrara den Nachbarort Fosdinovo, wo sieden Circolo socialista, die A potheke und das Haus des sozialistischen Bürgermeisters verwüsteten. Außerdem verprügelten sie den örtlichen Pfarrer, der ihnen zu sozialistenfreundlich war. Am nächsten Tag fand in Tendola die Beerdigung von Procuranti statt. Aus Carrara reisten circa 150 squadristi mit Lastwagen an, die sie einfach mit Gewalt "requiriert“ hatten. Nach der Beisetzung fuhren die Faschisten weiter nach Monzone, einem kleinen Marmorarbeiterort mit starker kommunistischer Präsenz ${ }^{7}$, wo eine gemeinsame Kundgebung der Kommunisten und Anarchisten angesagt war. Das Herannahen der Squadren veranlaßte die Veranstalter, vorerst auf die Kundgebung zu verzichten, doch konnte das die Faschisten nicht besänftigen. In der offensichtlichen Überzeugung, es könne keinen Falschen treffen, schossen die squadristi wahllos auf die Einwohner und ließen zwei Tote und acht Verletzte zurück. Nachdem sie die örtliche sozialistische Kooperative ausgeraubt und verwüstet hatten, fuhren sie nach Aulla weiter, wo sie von den Carabinieri aus Fivizzano beim Mittagessen aufgespürt wurden. Doch obwohl der befehlshabende Leutnant genau über die verübten Bluttaten im Bilde war, ließ er die Faschisten auf die einfache Versicherung hin, sie würden auf dem schnellsten Wege nach Carrara zurückkehren, weiterfahren, ohne auch nur die Personalien festzustellen ${ }^{8}$.

Die anscheinend teilweise angetrunkenen squadristi setzten ihre Fahrt nach Santo Stefano Magra fort, erschossen dort völlig willkürlich einen alten Bauern, der dem Partito popolare nahestand, und verletzten vier weitere Personen. In Ermangelung von Einrichtungen der Arbeiterbewegung fielen sie unter dem Vorwand der Waffensuche über Privatwohnungen und Läden her und erbeuteten Werte von insgesamt 9000 Lire.

Personen, die aus den heimgesuchten Orten nach Sarzana geflohen waren, brachten die Kunde vom faschistischen Amoklauf dorthin. Die Selbstschutzabteilungen der Arditi del popolo mobilisierten, und der befehlshabende Offizier der örtlichen Station, Leutnant Vinci Nicodemi, ließ in der Erwartung schwerer Auseinandersetzungen die Landstraße zwischen Santo Stefano und Sarzana sperren. Die Faschisten machten zunächst Anstalten, die Carabinieri überrennen zu wollen, ließen sich aber dann von einem aufgefahrenen Maschinengewehr von unvorsichtigen Handlungen abbringen. Sie verließen die Lastwagen und schickten sich an, am Flußlauf des Magra entlang über die Felder nach Carrara zurückzukehren. Auf ihrem Weg trafen sie auf den vom Angeln kommenden

6 ACS, MI, DGPS 1921, b. 101, f. „Fasci Massa“: Bericht des entsandten Generalinspektors Vincenzo Trani vom 23. Juni 1921. Auch die weiteren Ausführungen über die „Strafexpedition“ der Faschisten stützten sich auf dieses Dokument und außerdem auf ACS, MI, DGPS 1921, b. 98, f. „Fasci Genova": 2 Berichte des Präfekten von Genua vom 18. 7. 1921 und Abschlußbericht von Trani vom 4. 8. 1921, letzterer abgedruckt bei Costantini, Sarzana, S. 92-100.

7 Der kommunistische Ortsverein von Monzone hatte 110 Mitglieder (ASM, Questura Massa, b. 10: „prospetto statistico“ vom 23. 5. 1921). Bei einer Einwohnerzahl von 993 (Censimento popolazione 1921, Bd. 7, S. 43) heißt das 11,1\% organisierte Kommunisten, was der Spitzenwert in der Marmorregion sein dürfte.

8 Das Verhalten des Carabinieri-Leutnants von Fivizzano Costantino Flavoni wurde von Generalinspektor Trani gerügt und war Gegenstand einer Untersuchung, bei der zu seiner Verteidigung geltend gemacht wurde, daß ihm nur insgesamt 16 Carabinieri zur Verfügung gestanden hätten; ACS, MI, DGPS 1921, b. 98, f. „Fasci Genova“: Generalkommando der Carabinieri an Innenministerium vom 29. 10. 1921. 
Arbeiter Rinaldo Spadaccini, den sie - anscheinend grundlos - mit drei Revolverschüssen töteten. Nicodemi nahm daraufhin die Verfolgung der Faschisten auf, und es gelang ihm die Verhaftung einer Gruppe von zwölf squadristi, unter ihnen die Anführer Renato Ricci und Gualtiero Betti. Die restlichen versuchten, sich nach Carrara durchzuschlagen, gerieten aber auf ihrem Weg wiederholt in das Feuer der Arditi del popolo. Dabei wurde ein faschistischer Arbeiter aus Bergiola, Venanzio Dell'Amico, tödlich getroffen und weitere squadristi verletzt. Mit Mühe und Not erreichten sie das heimatliche Carrara.

Die Reaktion des liberalen Establishments von Carrara auf die Verhaftungen gibt beredten Aufschluß über den Grad der Zerrüttung rechtlicher und moralischer Grundsätze im tonangebenden Teil des Bürgertums der Stadt. Nach fünf weitgehend willkürlichen Morden und einer Aktion, die zeitweise Formen gewöhnlicher Kriminalität angenommen hatte, verabschiedeten die lokalen Führungsgremien der liberalen Partei eine Resolution, in der sie sich ohne Einschränkungen mit den Faschisten solidarisch erklärten. Dem neuen Ministerium Bonomi in Rom wurde vorgeworfen, daß es sich „auf eine Politik der parteilichen Repression und brutalen Reaktion gegenüber den faschistischen und nationalen Kräften“ hinorientiere. Man verurteilte "die Rückkehr zu einer defätistischen Politik“, die die „unversöhnlichen Feinde des Vaterlands“ begünstige, und erklärte vorweg die „vollständige und begeisterte Solidarität “ mit den Fasci im Falle einer „Aktion, die zur Verteidigung der höchsten Interessen des Vaterlands und zum Widerstand gegen jegliche ungerechte Reaktion oder Repression" nötig sei". Mit einem massiven Rekurs auf das Vokabular der Weltkriegspropaganda versuchten die „konstitutionellen" Kräfte die illegale Aktion des Faschismus zu legitimieren, der im Begriff war, vom Vernichtungsfeldzug gegen die sovversivi in einen offenen Aufruhr gegen die Regierung überzugehen. Ein auch nur gradueller Unterschied zwischen den Positionen der Liberalen und denen der Faschisten ist zu diesem Zeitpunkt nicht zu erkennen.

Angesichts des Freibriefs, den das lokale Bürgertum dem Faschismus erteilte, nimmt es nicht wunder, daß die Polizeiverantwortlichen der Provinz Massa-Carrara auch diesmal wieder "versagten “, als es darum ging, den bevorstehenden Marsch der toskanischen Squadren auf Sarzana zu verhindern, obwohl von Anfang an klar war, daß die Aktion unter anderem zum Ziel haben würde, die dort in Haft sitzenden Faschisten zu befrei$e^{10}$. Einige Maßnahmen wurden immerhin getroffen, die über den in der Provinz üblichen Standard hinausgingen. So erließ der Präfekt ein allgemeines Fahrverbot für Lastwagen, von dem nur solche mit einer ausdrücklichen polizeilichen Erlaubnis ausgenommen waren, und sechs Lastwagen, die Faschisten oder Sympathisanten des Fascio gehörten, wurden durch die Konfiszierung der Zündspulen unbrauchbar gemacht ${ }^{11}$. Außerdem ließ der Polizeikommissar von Carrara an alle Zufahrtsstraßen nach Sarzana

9 ASM, Commissariato Carrara, b. 55: Rundbrief des politischen Sekretariats des Partito liberale democratico italiano, Sezione di Carrara e ville, vom 20.7.1921.

10 Das geht aus dem Hilfeersuchen des Präfekten von Genua an den Präfekten von Massa vom 18. 7. 1921 hervor (ebenda).

11 Ebenda: Plakat mit der Verordnung des Präfekten vom 19. 7. 1921; Aktennotiz über die fahruntüchtig zu machenden Lastwagen vom 19. 7. 1921. Betroffen ist die Firma des Präsidenten des Fascio, Ghino Faggioni, mit drei Lastwagen, ferner mit je einem Lastwagen: Avv. Pellini, Almo Lazzetti, Ettore Manfredi und Marchese Patrizi. 
Polizeieinheiten postieren ${ }^{12}$. Als sich aber im Laufe des 20. Juli Hunderte von squadristi aus der gesamten Toskana in Marina di Carrara versammelten, verfiel die Polizei wiederum in das übliche Laissez-faire. Obwohl in Carrara insgesamt fast 300 Mann für den Polizeieinsatz bereitstanden, gelang nur die Festnahme von 13 Faschisten ${ }^{13}$. Der Vizekommissar De Gattis und der Carabinieri-Hauptmann Benni, die in Marina im Einsatz waren, bekamen vom Vicequestore Giustiniani telefonisch die Anweisung, die Faschisten ziehen zu lassen, falls sie sich in kleinen Gruppen entfernten ${ }^{14}$. Solchermaßen begünstigt sickerten die Squadren über Feldwege und durch die macchia ins Gemeindegebiet von Sarzana ein, und De Gattis beließ es dabei, die dortigen Polizeifunktionäre darüber in Kenntnis zu setzen ${ }^{15}$.

Wohl zwischen 400 und 500 Faschisten unter dem Oberbefehl der Squadrenführer Amerigo Dumini aus Florenz, Bruno Santini aus Pisa und Goffredo Corsi aus Carrara marschierten an der Bahnlinie entlang auf Sarzana. Es handelte sich aber keineswegs um eine disziplinierte Truppe, die nach einem durchdachten Konzept vorging, sondern um einen bunt zusammengewürfelten Haufen, in dem noch nicht einmal die capi squadra wußten, was sie erwartete. Der beteiligte Squadrenführer Umberto Banchelli schreibt darüber in seinen Memoiren: „Der Aktionsplan konnte den Squadrenführern weder vorgelesen noch erklärt werden; es war ihnen im übrigen auch einerlei, denn was die taktischen Richtlinien angeht, wollten fast alle nach ihren eigenen vorgehen. ${ }^{\text {"16 }}$ Als ein Güterzug vorbeikam, wollten einige squadristi aufsteigen und beschossen ihn, um ihn zum Halten zu bringen. Dies gelang natürlich nicht, aber die Eisenbahner brachten die Kunde vom Herannahen der Faschisten nach Sarzana, wo jetzt auch die Arditi del popolo über die spedizione im Bilde waren ${ }^{17}$.

Eine andere Episode verdeutlicht die Desorganisation und die völlige Unvorbereitetheit der Faschisten auf die besondere Situation, die sie in Sarzana erwartete. Eine kleine Squadra von circa 20 Faschisten aus La Spezia gelangte schon am Morgen des 20. Juli, also viel zu früh, in die Nähe der Stadt. Durch die feindselige Haltung der Bevölkerung nervös gemacht, erschossen sie einen Landarbeiter und wurden daraufhin von Gruppen bewaffneter Bauern durch die campagna gejagt ${ }^{18}$. Als sie ihre mißliche Lage erkannt hatten, schickten sie zwei der Ihren nach La Spezia zurück, um Verstärkung zu holen. Die beiden jungen squadristi erreichten allerdings ihr Ziel nie. Auf ihrem Weg wurden sie von der Bevölkerung als Faschisten erkannt, gefangengenommen und nach einiger Zeit umgebracht $^{19}$. Die übrigen Angehörigen der Gruppe konnten sich nur mit Mühe und Not nach La Spezia zurückretten.

12 Ebenda: Anordnungen des Polizeikommissariats Carrara vom 18. und 19. 7. 1921.

13 Ebenda: Vizekommissar De Gattis an Questore und Präfekt von Massa vom 21. 7. 1921.

14 Abschlußbericht von Generalinspektor Trani vom 4. 8. 1921, in Costantini, Sarzana, S. 93.

15 ASM, Commissariato Carrara, b. 55: De Gattis an Vizekommissar Gioia vom 21. 7. 1921, $2^{35}$.

16 Banchelli, Memorie, S. 62.

17 Ebenda, S. 63.

18 Die Darstellung folgt dem Abschlußbericht von Trani vom 4. 8. 1921 (Costantini, Sarzana, S. 95); siehe auch Bianchi, Lotte sociali, S. 184.

19 Der Fund der entstellten Leichen der beiden Faschisten gab später Anlaß zu zügellosen Phantasien in der faschistischen und profaschistischen Presse über die Art, wie sie wohl zu Tode gekommen seien. In Gregori, Sarzana, S. 57 - 73, sind alle Greuelphantasien zusammengefaßt, die damals kursierten. Es ist die Rede von Abhacken der Hände mit einer Axt, Ausbrennen der Augen mit glühenden Eisen, Eintauchen in kochendes Wasser, Entmannung und ähnlichem. Gregori zitiert 
Die Faschistenkolonne erreichte am frühen Morgen des 21. Juli den Bahnhof von Sar$\mathrm{zana}^{20}$, und die squadristi stellten sich erst mal in Reih und Glied auf dem Bahnhofsvorplatz auf. Als wäre er von ihrer Ankunft völlig überrascht worden, eilte der Carabinie$r i$-Hauptmann Guido Jurgens ihnen mit nur neun Carabinieri und vier weiteren Soldaten, die er zufällig auf seinem Weg aufgelesen hatte, entgegen. Offensichtlich meinte er, die Faschisten durch gutes Zureden vom Eindringen in die Stadt abhalten zu können. Doch Dumini und Santini unterbreiteten dem Offizier einen unglaublichen Forderungskatalog. Sie verlangten die Auslieferung des mittlerweile zum Buhmann der Faschisten avancierten Carabinieri-Leutnants Nicodemi, von dem sie behaupteten, er habe Renato Ricci bei der Festnahme geohrfeigt. Außerdem forderten sie die Freilassung der gefangenen Faschisten und freien Zugang zur Stadt, „um mit den Roten aufzuräumen“. Jurgens antwortete, daß er auf die erste Forderung nicht eingehen könne, solange auch nur „ein einziger Carabiniere aufrecht stehe“. Was die Freilassung der Gefangenen angehe, könne er zugestehen, daß zwei von ihnen zum Staatsanwalt gingen, um mit ihm darüber zu verhandeln. Den Zugang der squadristi in die Stadt könne er nicht zulassen, weil er diesbezüglich kategorische Anweisungen habe.

Während sich die Verhandlungen hinzogen, wurden die squadristi ungeduldig und begannen vorzurücken. Jurgens ließ daraufhin die Carabinieri in Schießstellung antreten, und als aus dem Pulk der Faschisten Schüsse abgegeben wurden, antworteten diese sofort, ohne noch seinen ausdrücklichen Befehl abzuwarten. Vier Faschisten wurden tödlich getroffen und sechs verletzt, von denen einer wenig später starb. Auf der Gegenseite fiel ein Soldat, und ein Carabiniere trug leichtere Verletzungen davon. Ein nicht unbeträchtlicher Teil der Faschisten flüchtete Hals über Kopf aus der Stadt in die campagna und lief so direkt den Arditi del popolo und bewaffneten Bauern in die Arme. Weitere neun Faschisten fanden so den Tod; zum Teil kam es zu regelrechten Lynchungen von seiten aufgebrachter Menschenmengen. Ein anderer Teil der Faschisten bestieg den nächsten Zug in Richtung Carrara. Während der Fahrt beschossen diese squadristi die an der Bahnlinie liegenden Häuser und verletzten dabei einen Schrankenwärter und einen Bauern schwer. Die Bauern ihrerseits antworteten auf das Feuer und trafen den jungen Carrareser Faschisten Pietro Gattini, der neben dem Zugführer Platz genommen hatte, tödlich. Insgesamt forderte so die Strafexpedition nach Sarzana auf der Seite der Faschisten 16 Tote und circa 30 Verletzte.

Die Ereignisse trafen die faschistische Bewegung völlig unerwartet, obwohl von vornherein absehbar gewesen war, daß es sich in Sarzana nicht um eine Kraftprobe in den üblichen Dimensionen handeln würde. In gewisser Weise hatten die Initiatoren der Aktion der besonderen Situation immerhin Rechnung getragen, indem sie die Squadren der gesamten Toskana mobilisierten, doch waren sie trotz der vorangegangenen unmißverständlichen Zeichen auf die harte Haltung der Carabinieri nicht vorbereitet gewesen; zu

auch aus Justizakten, welche allerdings die erwähnten Horrorbeschreibungen widerlegen. Hier wird der Tod der beiden Faschisten auf Erwürgen oder Aufhängen zurückgeführt und lediglich drei bzw. zwei Messerstiche „post mortem“ festgestellt. Außerdem ist eine außerordentlich fortgeschrittene Verwesung der Leichen erwähnt, die die Ursache für ihren unschönen Zustand gewesen sein dürfte.

20 Die Darstellung folgt dem Abschlußbericht von Trani vom 4. 8. 1921 (Costantini, Sarzana, S. $95 \mathrm{f}$.). 
oft waren ihre Aktionen, auch wenn sie in schwerste Delikte mündeten, von der wohlwollenden Zurückhaltung der Polizeikräfte begleitet gewesen. Das Geschehen offenbart eine grundsätzlich widersprüchliche Haltung der Squadrenführer: Einerseits wurde anscheinend die Losung ausgegeben, es solle in keinem Fall auf die Polizei geschossen werden ${ }^{21}$, eine Verhaltensmaxime, die der bewährten Taktik entsprach, ein mögliches Einvernehmen nicht von vornherein zunichte zu machen. Auf der anderen Seite hatte das auch in der Vergangenheit schon ungewöhnlich energische Verhalten der verantwortlichen Carabinieri-Offiziere von La Spezia und Sarzana schon so viel böses Blut bei den solches nicht gewohnten squadristi gemacht ${ }^{22}$, daß ein vorsichtiges Vorgehen durch die Eigendynamik der faschistischen Radikalisierungstendenzen verunmöglicht wurde. Übertriebene Nachrichten von der angeblichen Kumpanei von Carabinieri und Arditi del popolo und das frei erfundene Gerücht, Leutnant Nicodemi, der befehlshabende Offizier der Station von Sarzana, habe Renato Ricci bei der Verhaftung geschlagen, hatten die Bereitschaft zur Konfrontation mit den Polizeikräften gefördert. Unmißverständlicher Ausdruck dieser Konfrontation war die unglaubliche Forderung von Dumini und Santini an den Carabinieri-Hauptmann Jurgens, den ihm unterstellten Leutnant Nicodemi auszuliefern. Angesichts dieser kaum zu überbietenden Provokation der Carabinieri durch die beiden „Befehlshaber" der "Strafexpedition", denen als Reserveoffizieren die Ungeheuerlichkeit ihres Anschlagsversuchs auf den Korpsgeist der Arma vollständig bewußt gewesen sein mußte, ist es nicht so verwunderlich, daß aus der Masse der notorisch nicht von taktischen Rücksichten geplagten einfachen squadristi das Feuer auf die kleine Polizeiformation eröffnet wurde, die man mit Leichtigkeit überrennen zu können glaubte.

Die beteiligten Faschisten haben nach den Vorfällen zunächst steif und fest behauptet, die Polizeikräfte hätten zuerst geschossen. Von seiten gemäßigter faschistischer Kreise wurde später dann allerdings die These favorisiert, die ersten Schüsse seien von Heckenschützen der Arditi del popolo ausgegangen ${ }^{23}$. Diese Version, die sich auch in einer Darstellung des faschistenfreundlichen Kommandeurs der Guardie regie-Legion

${ }^{21}$ Dies ist jedenfalls nach den Ereignissen von faschistischer Seite durchwegs behauptet worden. Am weitesten geht Cesare Lodovici, Chefredakteur von Alalà, der Zeitung des Fascio von Carrara: „Die Faschisten hatten den Befehl, nicht auf die Polizei zu schießen. Wir hatten unseren Anhängern den eindeutigen und kategorischen Befehl gegeben, nicht anzugreifen [. . .], und ihnen erklärt, daß unser Kampf sich nur gegen die Kommunisten richte, daß wir nicht, ohne unser Wesen zu verleugnen, die Staatsorgane angreifen könnten, wenn diese diszipliniert die ihnen erteilten Befehle befolgten" (Alalà vom 30.7. 1921). Diese Version von Lodovici, der nach der Verhaftung von Ricci interims der politische Leiter des Fascio von Carrara war, ist in sich einigermaßen schlüssig. Seine etatistisch-gemäßigte Haltung ist allerdings nicht typisch für das Gros der toskanischen „squadristi“ und eine Zuwiderhandlung angesichts der notorischen Disziplinlosigkeit gerade der Florentiner und Carrareser Faschisten nicht verwunderlich.

22 Neben der Polizei von Sarzana unter der Führung von Nicodemi hatte auch Jurgens schon den Unwillen der "squadristi" und ihrer Sympathisanten erregt, als er in seiner Funktion als Carabinieri-Chef von La Spezia in Portovenere 16 Faschisten verhaftet hatte, die dort eingefallen waren und einen Anarchisten getötet hatten (vgl. Costantini, Sarzana, S. 67 f.).

${ }^{23}$ Im Giornale di Carrara vom 23. 7. 1921 wird noch behauptet, daß nach Augenzeugenberichten die Carabinieri auf Befehl ihres Hauptmanns als erste geschossen hätten, während die faschistische Lokalzeitung, Alalà vom 30.7. 1921, schon die Version enthält, die dann später von der faschistischen Regimegeschichtsschreibung kanonisiert wurde. Vgl. Chiurco, Rivoluzione fascista, Bd. 3, S. 460. 
von Genua findet ${ }^{24}$, diente dazu, die Verantwortung für die Ereignisse ganz den örtlichen sovversivi zuzuschieben und dem Überhandnehmen der Ressentiments zwischen Faschisten und Carabinieri, die durch die gegenseitigen Schuldzuweisungen gespeist wurden, entgegenzuwirken. Es galt zu vermeiden, daß das Thema „Sarzana“ zum Ausgangspunkt für einen Entfremdungsprozeß zwischen den Faschisten und den peripheren Polizeiorganen wurde, der für die weitere Aktion des Squadrismus ein gefährlicher Hemmschuh hätte werden können.

„Sarzana" war für den toskanischen Faschismus eine Niederlage auf der ganzen Linie. Seinen vereinigten Squadren war es nicht gelungen, eine Gemeinde von knapp 13300 Einwohnern zu „erobern“, es war zu einem politisch unwillkommenen Schußwechsel mit der Polizei gekommen, und die Arditi del popolo hatten vor der nationalen Öffentlichkeit bewiesen, daß die Organisation eines erfolgreichen „militärischen“ Widerstands möglich war. Es handelte sich um eine ganz besondere Niederlage für die Faschisten Carraras, die in ihren Reihen vier Tote zu beklagen hatten. Sie hatten die Ereignisse durch taktische Unvorsichtigkeit und politische Instinktlosigkeit provoziert, und nun schien es, als würden die Folgen ihre Stellung plötzlich gefährden: Unmittelbar nach den Auseinandersetzungen gab es Anzeichen für ein spontanes Übergreifen des Phänomens der Arditi del popolo von Sarzana auf das Umland von Carrara und Massa.

Die squadristi von Carrara zögerten nicht und demonstrierten mit einer brutalen Vergeltungsaktion, daß sie nicht gewillt waren, sich die Initiative aus der Hand nehmen zu lassen. Gleich am 22. Juli, dem Tag nach den fatti di Sarzana, überfiel eine Gruppe von circa 15 Carrareser Faschisten den Vorort Fossola. Sie durchkämmten die Siedlung mit einer Namensliste in der Hand und exekutierten zwei Arbeiter, ein dritter überlebte trotz schwerer Schußverletzungen. Bei den Opfern handelte es sich keineswegs um Aktivisten der Arbeiterparteien; nur einer, der Arbeiter Cesare Chiappini, war früher Mitglied der sozialistischen Partei gewesen, die anderen beiden hatten anscheinend nie einer Partei angehört ${ }^{25}$. Durch diesen „Racheakt" in dem Vorort Carraras, der sich bisher gegenüber der faschistischen Rekrutierung als besonders renitent erwiesen hatte ${ }^{26}$, sollte das durch „Sarzana“ beeinträchtigte System der Einschüchterung wieder aufgerichtet werden. Auf das äußerst aufschlußreiche strafrechtliche Nachspiel dieser spedizione wird noch genauer einzugehen sein.

Die fatti di Sarzana hatten Auswirkungen, die weit über den lokalen und regionalen Rahmen hinausgingen. In Mailand, Padua, Bologna, Genua, Florenz und vermutlich auch noch in anderen Städten versuchten die Faschisten, den Bürgern „Nationaltrauer“ aufzuerlegen ${ }^{27}$. Die faschistischen Abgeordneten in Rom bombardierten die neue Regierung Bonomi mit parlamentarischen Anfragen, hinter denen sich neben propagandistischen Absichten die Angst verbarg, das Ministerium orientiere sich auf eine antifaschistische Linie hin. Mussolini wertete „Sarzana“ als Symptom einer atmosphärischen Wende, die

24 Costantini, Sarzana, S. 61.

${ }^{25}$ Dies geht aus der Aussage von Augusto Colombini, als „Maresciallo“ Ausbilder an der Carabinieri-Schule in Rom und Bruder des von den Faschisten schwer verletzten Gino Colombini, hervor (Il Cavatore vom 20. 8. 1921).

${ }^{26}$ Fossola ist ein gutes Beispiel dafür, wie das Vorhandensein solider politischer Organisationen der Republikaner und Sozialisten das Fußfassen der Faschisten wesentlich behindern konnte. Vgl. die Übersicht im Anhang, S. 288.

27 Bianchi, Lotte sociali, S. 190; De Felice, Mussolini il fascista 1, S. 139. 
dem Faschismus zum Verhängnis werden könne, wenn er auf dem Weg der Gewalt fortfahre, und intensivierte gegen den verbissenen Widerstand der meisten faschistischen Provinzführer der Po-Ebene und der Toskana die schon Anfang Juli begonnenen Verhandlungen mit den Sozialisten, um zu einem „Befriedungspakt“ auf nationaler Ebene zu kommen. Unmittelbar nach den Ereignissen von Sarzana hatte er das consiglio nazionale in Rom einberufen und ihm unter Einsatz seiner ganzen Autorität eine Entscheidung in diesem Sinn abgerungen. Außerdem setzte er einen Maßnahmenkatalog durch, der eine erhöhte Kontrolle und Disziplinierung des Provinzfaschismus ermöglichen sollte und der etwa die spedizioni punitive gegen Gewerkschaftseinrichtungen ganz untersagte $^{28}$.

Die politische Strategie Mussolinis, die auf eine graduelle Annäherung des Faschismus an die Massenparteien, das heißt an die popolari und an eine zum Reformismus bekehrte sozialistische Partei, hinauslaufen sollte, wurde von den toskanischen Faschisten, in denen extrem gewalttätige und an agrarische und kleinindustrielle Interessen gebundene Elemente vorherrschten, nicht verstanden. Am 24. Juli veranstalteten toskanische Squadren unter der Führung des berüchtigten Hauptmanns a. D. Dino Castellani und seiner Florentiner Disperata ein Blutbad in Roccastrada, einem kleinen Ort in der Provinz Grosseto ${ }^{29}$. Die Aktion, bei der 13 Personen willkürlich ermordet wurden, war als "Rache für Sarzana“ gemeint und sollte den "Weichlingen“ im Zentralkomitee der Fasci und in der Parlamentsfraktion die unter den „Toskanern“ herrschende Stimmung vor Augen führen ${ }^{30}$.

Es war keine leichte Arbeit für den Generalsekretär Umberto Pasella, die Vertreter der toskanischen Fasci bei ihrer Zusammenkunft am 31. Juli in Florenz auf eine Linie einzuschwören, mit der Mussolini einstweilen leben konnte. Die Versammlung verabschiedete nach härtesten Auseinandersetzungen und Tumulten aller Art eine Resolution, die dem Zentralkomitee zwar formale Gefolgschaft auf dem Weg zum patto di pacificazione versprach, gleichzeitig aber einem prinzipiellen Mißtrauen gegenüber der „Befriedung“ Ausdruck gab und ankündigte, beim nächsten nationalen Kongreß der faschistischen Bewegung würden „die jeweiligen Verantwortlichkeiten“ für diese grundsätzlich unerwünschte politische Orientierung festgestellt. Daß es nicht zu einer offenen Revolte der Toskaner kam, was durchaus der Stimmung „an der Basis“ entsprochen hätte, war wohl dem Umstand zu verdanken, daß der segretario politico regionale, Perrone Compagni, sich auf die Seite Pasellas geschlagen hatte, um mit Hilfe der Führungsorgane der Bewegung seine Rivalen im Direktorium des Florentiner Fascio, Dumini und Banchelli, zwei der Hauptverantwortlichen für das Debakel von Sarzana, auszubooten $^{31}$. Der patto di pacificazione wurde am 5. August 1921 unterzeichnet, hat-

28 Vgl. ebenda, S. $139-142$.

29 Im einzelnen siehe Cantagalli, Fascismo fiorentino, S. 259-262.

30 Eine aufschlußreiche Quelle für die Stimmung an der Basis des toskanischen Squadrismus ist das Tagebuch des Mitglieds der Florentiner "Disperata“ Mario Piazzesi. Zur Nachgeschichte von „Sarzana" und zum "patto di pacificazione" siehe S. 185-193. "Quei rammoliti del Comitato Centrale“ (ebenda, S. 197).

${ }^{31}$ Cantagalli, Fascismo fiorentino, S. 263 - 266. Hier handelte es sich aber nicht um reinen machtpolitischen Opportunismus von Perrone, wie Cantagalli unterstellt, sondern um eine politische Konzeption, die darauf zielte, die skrupellosen Draufgänger im Florentiner Fascio zu neutralisieren. 
te aber in der Toskana und den anderen Gebieten, in denen er in erster Linie hätte wirksam werden müssen, einen nur sehr begrenzten Effekt. Das lag daran, daß nach der im Provinzfaschismus vorherrschenden Mentalität „Frieden“ nur nach der vollständigen Ausschaltung des politischen Gegners denkbar war. Mit dieser „totalitären“ Gesinnung war er der noch vergleichsweise demokratischen politischen Kategorien verhafteten „Mailänder“ Führungsgruppe um Mussolini einen Entwicklungsschritt voraus.

Für den Faschismus in der Marmorregion von Carrara bildete "Sarzana“ den Endpunkt der Durchbruchsphase. Paradoxerweise besiegelte das „faschistische Caporetto ${ }^{\text {“32 }}$ die Etablierung der Faschisten als der entscheidenden politischen Kraft der Region; gerade in der Gefährdung erwiesen die von den Faschisten geschaffenen politischen Verhältnisse ihre Stabilität. Wie im folgenden darzustellen sein wird, sprangen die Marmorunternehmerschaft en bloc und die Liberalen aller Schattierungen in die Bresche, um eine drohende antifaschistische Tendenzwende in der Region zu verhindern; zu keinem anderen Zeitpunkt war die Anerkennung des Faschismus durch das lokale Bürgertum als ihrer Klassenmiliz deutlicher als in dieser kurzen Krisenphase.

Die Hauptgefahr für das System des Provinzfaschismus in der Region ging unmittelbar nach „Sarzana" von Rom aus. Alarmiert vom Ausufern der faschistischen Gewalt und von der Untätigkeit der örtlichen Polizeiorgane, vor allem im Verwaltungsbereich der Provinz Massa-Carrara, entsandte die Regierung Bonomi den Generalinspektor der Polizei Vincenzo Trani, einen Mann, der politisch als linksliberaler nittiano ${ }^{33}$ galt und der daher wenig Nachsicht gegenüber den Faschisten erwarten ließ. Anscheinend gab man ihm Richtlinien mit auf den Weg, die auf den Versuch hinausliefen, die Begünstigung der Faschisten durch die lokalen Beamten und Notabeln zu kompensieren ${ }^{34}$. Trani wurde die Leitung der Polizei im gesamten „Krisengebiet “ um Sarzana und Carrara übertragen, außerdem war er mit der Untersuchung der blutigen Ereignisse und der politischen „Befriedung“ der gesamten Gegend beauftragt. Seine Tätigkeit wich von der bisher geübten polizeilichen Praxis stark ab. In seinen Berichten an das Innenministerium und in seinen öffentlichen Erklärungen betonte er den verbrecherischen Charakter der faschistischen Aktionen, eine Lesart, die normalerweise von den verantwortlichen Beamten, beeinflußt von der Stimmung bei den „staatstragenden Kräften“, so gut es ging, vermieden wurde ${ }^{35}$.

${ }^{32}$ Dieser Ausdruck bei Banchelli, Memorie, S. 61.

33 Die Anhänger des ehemaligen Ministerpräsidenten Francesco Saverio Nitti (1919/20) galten im allgemeinen zu Recht als besonders sozialistenfreundlich und antifaschistisch. Die ihm nahestehende Zeitung, Il Paese, war 1921 das einzige deutlich antifaschistische überregionale bürgerliche Blatt. Nitti und seine politischen Freunde wurden sogar verdächtigt, die „Arditi del popo10 “ zu finanzieren, was allerdings nicht zutrifft (Cordova, Arditi, S. 100 f.).

${ }^{34}$ Die politischen Richtlinien für die Tätigkeit Tranis sind nirgends überliefert. Aus seinen Berichten ist allerdings zu erkennen, $\mathrm{daß}$ sie ziemlich eindeutig antifaschistisch ausgerichtet gewesen sein mußten, so daß er nach seiner Ausbootung durch Bonomi von einer "Veränderung der Richtlinien in profaschistischem Sinne" reden konnte; Trani-Bericht vom 4. 8.1921 in Costantini, Sarzana, S. 100.

35 Bezeichnend ist in diesem Zusammenhang, daß die Faschisten von Carrara jetzt auch gegen überregionale bürgerliche Zeitungen vorgingen, weil sie sich bei ihrer Berichterstattung auf Erklärungen Tranis gestützt hatten. Der Mailänder Corriere della sera wurde mindestens einmal „beschlagnahmt“ und verbrannt, und der Redaktion der Turiner Stampa wurde die „Beschlagnahmung“ 
Ganz gegen den im lokalen Bürgertum herrschenden Common sense und gegen den Ratschlag des Präfekten von Genua, Cesare Poggi, verzichtete er auf die gewaltsame „Säuberung“ der Ebene von Sarzana und der Berggebiete um Carrara von Arditi del popolo und anderen „bewaffneten Banden“36. Er nahm mit Hilfe von Mittelsmännern Kontakt zu den Wortführern einiger versprengter Gruppen auf, die sich im Zuge der letzten faschistischen Aktionen im Raum von Carrara und Massa gebildet hatten, und versuchte, sie durch Verhandlungen zur Niederlegung der Waffen und zur Heimkehr zu bewegen. Trani interpretierte das Phänomen der bande armate als spontane und defensive Reaktion auf den faschistischen Terror und trat den künstlich-hysterischen Klagen über die angebliche Unsicherheit der campagna entgegen, die, wie er erkannte, die Funktion hatten, von der eigentlichen Gefahr für die öffentliche Sicherheit, dem Squadrismus, abzulenken und die ersten Ansätze für einen Selbstschutz der sovversivi im Keim zu ersticken. So schreibt er in seinem Abschlußbericht: „Der Wille der Hintermänner der Faschisten, jener, die den finanziellen Bedarf der faschistischen Organisation decken, um mit Hilfe dieser Organisation uneingestehbare Ziele zu verfolgen, ist es, nicht zuzulassen, daß die Organisationen und die Individuen, die man vernichten will, der Vernichtungstätigkeit, die von ihnen über das Mittel der Fasci entfesselt wird, Widerstand entgegensetzen können. “37

Die bewaffneten Gruppen, die Ende Juli 1921 im Hinterland von Carrara und Massa auftauchten, waren eigentlich keine Erscheinung, von der schon eine echte Bedrohung für den Faschismus ausging. Es handelte sich vor allem um die sogenannte banda Valsega, die in der Ebene von Carrara operierte, die banda Pedruzzi, die vom Vizesekretär der Camera del lavoro und Sekretär der Unione anarchica della Lunigiana, Umberto Pedruzzi, angeführt wurde und in den Bergen zwischen Carrara und Vinca di Fivizzano herumstreifte, und eine recht konsistente Gruppe um die Anarchisten Ernesto Andreazzoli und Luigi Del Fiandra im Bergland von Massa ${ }^{38}$. Alle drei Gruppen beschränkten sich im wesentlichen auf die "Requisition“ von Waffen. Die banda Valsega trat daneben auch mit verschiedenen recht ziellosen Aktionen gegen einzelne Faschisten und die Carabinieri der Station von Fossola sowie Eigentumsdelikten hervor. Politisch ernster zu nehmen war sicherlich die Gruppe um Pedruzzi, der mit dem Mitglied der Exekutivkommission Andrea Giandalasini ein weiteres Führungsmitglied der Gewerkschaftszentrale von Carrara angehörte. Auf diese konzentrierten sich die vertrauensbildenden Kontakte von Trani, der mit der Zusicherung, die Polizei würde in Zukunft für ihren Schutz sorgen, ihre Rückkehr in die Stadt und die Ablieferung der Waffen erreichte ${ }^{39}$.

der Zeitung in der gesamten Toskana angedroht; ACS, MI, DGPS 1921, b. 101, f. „Fasci Massa“: Präfekt Grignolo an Innenministerium vom 28. 7. 1921 und b. 98, f. „Fasci Genova“: Savini an Trani vom 30. 7. 1921.

${ }^{36}$ Zur Einschätzung des Problems siehe den Trani-Bericht vom 4. 8. 1921 in Costantini, Sarzana, S. 97.

37 Ebenda.

${ }^{38}$ Zusammensetzung und Tätigkeit dieser Gruppen sind durch die ausführlichen Urteilsbegründungen in den betreffenden Strafprozessen rekonstruierbar. Für die „banda Valsega“ siehe ASM, Tribunale Massa, Sentenza penale 1922/3 (10.1. 1922), für die „banda Pedruzzi“ ebenda, Sentenza penale 1922/93 (13. 5. 1922), und für die "Arditi del popolo“ von Massa ebenda, Sentenza penale $1922 / 9$ (30.1.1922).

39 Trani-Bericht vom 4. 8. 1921 in Costantini, Sarzana, S. 97 f. Trani ging sogar soweit, die Gruppe Pedruzzi, solange sie sich noch in den Bergen befand, mit nicht unbeträchtlichen Geldsum- 
Im wesentlichen war das Phänomen der bande armate in der Region auf den Zeitraum von ungefähr zwei Wochen nach den Ereignissen von Sarzana beschränkt, und der Erfolg des "weichen" Vorgehens von Trani bestätigte seine Einschätzung, daß die Bandenbildung in erster Linie das Ergebnis einer akuten persönlichen Bedrohung der Beteiligten war. Sicherlich spielte auch die Vorstellung eine Rolle, in Nachahmung der erfolgreichen Arditi del popolo von Sarzana den Faschisten einen bewaffneten Widerstand entgegensetzen zu können, doch erwiesen sich die logistischen Schwierigkeiten unter den Bedingungen der absoluten Illegalität, die anscheinend in keiner Weise durch Unterstützung von Sympathisanten in der Bevölkerung gemildert werden konnte, als so unüberwindlich, daß auch nur der halbe Glaube an das Versprechen des hohen Funktionärs aus Rom ausreichte, sie zur Aufgabe zu bewegen ${ }^{40}$.

Eine etwas langlebigere Gruppe von Arditi del popolo bildete sich an der Grenze zur Versilia im Gemeindegebiet von Montignoso auf Initiative des kommunistischen Arbeiters Balilla Grillotti und der anarchistischen Steinbrucharbeiter Gino Del Freo und Giuseppe Raffaelli ${ }^{41}$. Diese Gruppe, der circa 40 bis 60 meist jugendliche Kommunisten, Sozialisten und Anarchisten angehörten, konnte im sozialistisch verwalteten Montignoso zunächst relativ unbehelligt überleben. Im Herbst 1921 ging sie dann zu nicht sehr erfolgreichen bewaffneten Aktionen gegen besonders berüchtigte squadristi über und wurde erst im Januar 1922 durch zahlreiche Verhaftungen aufgerieben ${ }^{42}$.

Für den Gang der Dinge in der Region hatten diese rudimentären Ansätze eines bewaffneten Widerstands gegen den schon fest verankerten Faschismus keine großen Auswirkungen mehr. Ohne eine Kehrtwendung der Sicherheitsorgane und der Justiz, die die Faschisten weitgehend gewähren ließen, während sie die sovversivi, wenn sie auf die Angriffe reagierten, unnachsichtig verfolgten, war der Prozeß der Faschisierung der lokalen Verhältnisse zu diesem Zeitpunkt nicht mehr reversibel. Ein gewisser legaler Spielraum für den antifaschistischen Selbstschutz, so wie er de facto in Sarzana oder ein Jahr später in Parma ${ }^{43}$ existierte, und ein Mindestmaß an Rechtsstaatlichkeit bei der Prävention und Verfolgung faschistischer Straftaten wären unabdingbar Grundlage für die Selbstbehauptung der Arbeiterbewegung gewesen. Trani, der die Aushöhlung der beste-

men zu unterstützen (in der Quelle ist die Rede von insgesamt 10000 Lire), um zu verhindern, daß sie sich die Lebensmittel durch Überfälle besorgten, was ihre polizeiliche Verfolgung und damit das Scheitern seiner „weichen“ Strategie zur Folge gehabt hätte; ACS, MI, Gabinetto Bonomi, b. 3, f. 35: Trani an Innenministerium vom 31. 7. 1921.

40 Selbst wenn man die Wirklichkeitsverzerrung in Rechnung stellt, die sich im Klima des Mai 1922, als der Prozeß gegen die „banda Pedruzzi“ geführt wurde, unvermeidlich in die gerichtliche Rekonstruktion einschleichen mußte, bleibt der Eindruck zurück, daß eine massive Unterstützung durch die Bevölkerung ausgeblieben ist; ASM, Tribunale Massa, Sentenza penale 1922/93, 13. 5.1922.

41 ASM, Questura Massa, b. 10: Vizeinspektor Podda an Questore von Massa vom 22. 7. 1921 und Carabinieri von Montignoso an Questore von Massa vom 25. 7. 1921.

42 ASM, Tribunale Massa, Sentenze penali 1922/4 (11. 1. 1922) und 1922/87 (5. 5. 1922). Die Behauptung Bianchis, diese Gruppe hätte die Faschisten in den apuanischen Bergen „zwei Jahre lang in Schach gehalten “, ist wohl auf eine romantisierende Jugenderinnerung von Giuseppe Raffaelli zurückzuführen (Bianchi, Lotte sociali, S. 181). Sie findet in den Quellen keinerlei Bestätigung. Interessant ist hier, wie schon im Fall von Ugo Mazzucchelli, die frühe antifaschistische Aktivität von Balilla Grillotti, eines späteren Partisanenführers (ebenda).

${ }^{43}$ Zur Rolle der "Arditi del popolo“ in Parma siehe Squeri, Parma, S. 134-136 und 160-162. 
henden staatlichen Ordnung durch die Bürgerkriegsoffensive des Provinzfaschismus erkannte ${ }^{44}$, war entschlossen und zunächst anscheinend dazu auch autorisiert, einige Schritte in diese Richtung zu tun, doch schon nach kurzer Zeit hatte er mit seinem in der Provinz so ganz und gar ungewohnten Stil die gesamte "konstitutionelle“ Notabilität gegen sich aufgebracht. Schon am 23. Juli intervenierte der nationale Industriellenverband Confindustria auf Drängen der Marmorindustriellen von Carrara beim Innenministerium, um auf die "Notwendigkeit aufmerksam zu machen, daß - mit angemessenen Polizeimaßnahmen - die Freiheit und Ruhe der Arbeitstätigkeit und das Eigentumsrecht garantiert werden, die durch die Unruhe im Volke und noch mehr durch die Banden, die die campagna durchstreifen, bedroht sind ${ }^{\alpha 5}$. Das war eine klare Kritik am Vorgehen des Generalinspektors, der eine einseitige Entwaffnungsaktion, ohne Einbeziehung der Faschisten, entschieden ablehnte. Am 24. Juli, nach einer teilweise turbulent verlaufenen Versammlung für die pacificazione, die vom Bürgermeister von Carrara Starnuti einberufen worden war, unternahm auch der an sich den Faschisten relativ distanziert gegenüberstehende Marmormagnat Carlo Andrea Fabbricotti, Vorsitzender der Marmorunternehmervereinigung von Carrara, einen Vorstoß gegen Trani in Rom. Er schrieb an einen einflußreichen Freund, der den Brief gleich an das Innenministerium weiterleitete: "Ich bin der festen Überzeugung, daß man, um die Befriedung der Geister zu fördern, an der Stelle des Commendatore Trani eine für den Zweck sehr viel geeignetere Person entsenden müsse, die wirklich in der Lage ist, Vertrauen in das Werk der Regierung zu schaffen. ${ }^{40}$

In der Versammlung, an der außer Kommunisten und Anarchisten alle bedeutenden politischen und gesellschaftlichen Gruppen der Stadt teilnahmen, hatte Trani die Ergebnisse seiner Untersuchung über die Ereignisse von Sarzana dargelegt und war den aufgebauschten Nachrichten von einer allgemeinen Unsicherheit in der campagna entgegengetreten, beides unter den wütenden Protesten von seiten der Rechten. Es ist bezeichnend, daß Trani von Fabbricotti als der einzige Störenfried dargestellt werden konnte. Offensichtlich waren die ebenfalls anwesenden Republikaner, Sozialisten und Vertreter der Camera del lavoro schon nicht mehr in der Lage, Positionen zu formulieren, die den Faschisten und ihren liberalen fiancheggiatori eine wirkliche politische Auseinandersetzung auferlegt hätten. Als Trani betonte, die Polizei werde in Zukunft gegen alle - ohne Ansehen der Partei - vorgehen, die Gewalttaten verübten, konterte der Wortführer der Faschisten Cesare Lodovici: „So, wie die Soldaten an der Front nicht gewalttätig gegen

44 Trani sprach von „der langsamen Revolution, auf die die Anstifter der Fasci hinarbeiten. Diese können nicht ehrlich die Waffen niederlegen, weil die faschistische Bewegung anwachsen muß, bis sie in die Diktatur mündet, die D'Annunzio übertragen werden soll, der mit der Treue der Legionari fiumani eine Art Generalstab in jedem Fascio besitzt. In der Zwischenzeit läßt man die Aktion der Fasci sich solchermaßen entfalten, daß sie die besonderen Anliegen derjenigen verwirklicht, die sie finanzieren: Agrarier und Industrielle“ (Bericht vom 4.8.1921 in Costantini, Sarzana, S. 100). Bis auf die völlige Überschätzung der Rolle Gabriele D'Annunzios, der sich gerade mit dem Erstarken des Faschismus immer mehr von ihm absetzte, zeugt diese Passage von einem politischen Weitblick, der sich sonst in den Berichten hoher Polizeifunktionäre nicht findet.

${ }^{45}$ ACS, MI, DGPS 1921, b. 101, f. „Fasci Massa “: Generalsekretär der Confindustria an Innenministerium vom 23. 7. 1921.

46 ACS, MI, DGPS 1921, b. 98, f. „Fasci Genova“: Brief von Carlo Andrea Fabbricotti an einen „carissimo amico" (möglicherweise Schiff Giorgini) vom 24. 7. 1921. 
den äußeren Feind waren, so könne man die Faschisten wirklich nicht als gewaltätig bezeichnen, die heute gegen den inneren Feind und für das Heil Italiens kämpfen. " ${ }^{47}$

Ohne Umschweife und vom aktiven Einverständnis der nur noch dem Namen nach liberalen Vertreter begleitet, meldeten die Faschisten den Anspruch an, ihren „Krieg“ unbehelligt von den Paragraphen des Strafgesetzbuches führen zu können, und das in einer Versammlung, die am Ende ein lokales Befriedungsabkommen und ein Komitee hervorbrachte, das seine Einhaltung überwachen sollte. Kein Wunder, daß Trani zu dem Schluß kam, daß man in Carrara „in ehrenhaftesten Worten von Befriedung redet, tatsächlich aber tiefen $\mathrm{Haß}$ nährt und alles macht, um den Zustand der Unruhe zu erhalten und zu verstärken, der verübte Straftaten rechtfertigen soll“48. Doch neben der allgemeinen Solidarisierung des bürgerlichen Lagers mit den Faschisten wird nun im Ansatz auch ein Differenzierungsprozeß erkennbar. Eine von den extremistischen Elementen in der Marmorunternehmerschaft gewollte Protestaussperrung gegen die Tätigkeit von Trani wurde verworfen, und einige Vertreter der Industriellen signalisierten ihm gegenüber sogar eine gewisse Kooperationsbereitschaft ${ }^{49}$.

Trotz des zweifelhaften Charakters der Befriedungsbemühungen in Carrara arbeitete Trani an einer ähnlichen Initiative in La Spezia, dem Hauptort des Verwaltungsbe$\operatorname{zirks}^{50}$, zu dem Sarzana gehörte. Doch hier, wo die Konfrontation noch in keiner Weise zugunsten der Faschisten entschieden war, scheiterte das Projekt schon im Ansatz. Die Arbeiterorganisationen von La Spezia und Sarzana lehnten die Teilnahme an einer Zusammenkunft mit den Faschisten und den bürgerlichen Kräften mit der Begründung $\mathrm{ab}, \mathrm{da} ß$ bei dieser Gelegenheit ohnehin nur Anlässe gesucht würden, um gegen sie vorzugehen. In der Tat verwandelte sich die vom Bürgermeister von La Spezia einberufene Versammlung „in eine Kundgebung“, bei der unter anderem der Sturz der Regierung, die Absetzung des obersten Polizeichefs in Rom, Linares Bonfanti, und die Versetzung des örtlichen Carabinieri-Kommandanten Jurgens gefordert wurde, was Trani dazu bewog, zusammen mit dem Sottoprefetto von La Spezia den Saal zu verlassen ${ }^{51}$. Es sollte hier demonstriert werden, welche Formen der bürgerliche Protest gegenüber der Regierung annehmen würde, wenn sich ihre Politik definitiv auf den von Trani vorgeführten antifaschistischen Kurs hinorientieren sollte.

Die Abberufung von Trani wurde für das lokale Bürgertum zunehmend zum politischen Prüfstein für die Politik der Regierung. Die bürgerlichen Abgeordneten von La Spezia intervenierten in diesem Sinn beim Präfekten von Genua, Cesare Poggi, und direkt beim Ministerpräsidenten Bonomi ${ }^{52}$. Sehr schnell machte sich Poggi selbst, ein Beamter, der politisch wohl als giolittiano eingeordnet werden muß $\aleph^{53}$, zum Wortführer dieser Gruppe; er lieferte seinem Duz-Freund Oliviero Savini, Kabinettschef von Bonomi, die

\footnotetext{
47 Il Giornale di Carrara vom 30. 7. 1921.

48 ACS, MI, Gabinetto Bonomi, b. 3, f. 35: Trani an Präfekten von Genua Poggi vom 27. 7. 1921.

49 ACS, MI, DGPS 1921, b. 98, f. „Fasci Genova“: Trani an Innenministerium vom 26. 7. 1921.

${ }^{50}$ La Spezia war damals noch Hauptort eines „circondario“ mit einem „sottoprefetto “ und gehörte zur Provinz Genua. Im Jahre 1923 wurde das Gebiet zur Provinz erhoben.

51 Trani-Bericht vom 4. 8. 1921 in Costantini, Sarzana, S. 99.

${ }^{52}$ Costantini, Sarzana, S. 84-86.

${ }^{53}$ Vgl. ebenda, S. 62, Anm. 3 bis.
} 
nötige Munition gegen den unbequemen Generalinspektor ${ }^{54}$, und so wurde dieser schließlich am 6. August 1921 durch einen Beschluß des Ministerpräsidenten abberufen und durch den Vizepräfekten von Genua, Francesco Rossi, ersetzt ${ }^{55}$.

Mit dem Abgang von Trani war die Gefahr einschneidender polizeilicher Maßnahmen gegen den Squadrismus in der Provinz abgewendet. Für spektakuläre Aktionen der Faschisten blieb die Situation zwar nach wie vor ungünstig, das lokale und das nationale Befriedungsabkommen waren ja gerade erst unterschrieben worden. Die „Routine“ der „kleinen" alltäglichen Gewalt reichte aber mittlerweile aus, die sovversivi psychologisch in Schach zu halten, ohne großes Aufsehen zu erregen. Außerdem bemühten sich die Polizeiverantwortlichen nunmehr, schwere Bluttaten der Faschisten herunterzuspielen und zu vertuschen. Der frischgebackene Sonderbeauftragte Rossi kabelte am 16. August nach Rom, daß die öffentliche Ordnung in der Region ungetrübt sei, abgesehen von der Verletzung eines Faschisten in Torano ${ }^{56}$, schwieg sich aber über die wüste Schießerei von Faschisten gegen den Arbeiterfreizeitverein in Molino di Sorgnano zwei Tage vorher aus, die zu einer viel ernsteren Verletzung eines sovversivo geführt hatte ${ }^{57}$. Über die Auffindung der Leichen von drei arditi del popolo bei Bergiola Foscalina, die dort Ende Juli von Faschisten erschossen worden waren, war dem Innenministerium nur ganz lückenhaft berichtet worden, und die im gleichen Ort am 23. August aus einem völlig nichtigen Anlaß erfolgte Ermordung des Anarchisten Giovanni Lombardini fiel in den Präfektenberichten ganz unter den Tisch ${ }^{58}$.

Trotz des anhaltend hohen Gewaltniveaus in Carrara ist nicht zu übersehen, daß „Sarzana" und das Befriedungsabkommen innerfaschistisch zu einer Verschiebung des Kräfteverhältnisses zugunsten der Befürworter einer vorläufigen Konsolidierungsstrategie

${ }^{54}$ Einer der Hauptanklagepunkte von Poggi war bezeichnenderweise, daß „Trani weder vor den Beamten noch leider vor den Vertretern der, sovversivi' seine Absicht verheimlicht, die Bauern solange nicht zu entwaffnen, wie die faschistische Bedrohung anhält". ACS, MI, Gabinetto Bonomi, b. 3, f. 35: Poggi an Savini vom 3. 8. 1921.

55 ACS, MI, DGPS 1921, b. 98, f. „Fasci Genova“: Bonomi an die Präfekten von Massa und Genua vom 6. 8. 1921. Die Aufgaben von Rossi sollten zunächst nur die Koordinierung der „Befriedungs" polizeilichen Maßnahmen. Er erkannte aber an dem Entzug dieses politisch zentralen Aufgabenbereichs, daß die gegen ihn gesponnenen Intrigen ihre Wirkung gehabt hatten, und kehrte überstürzt nach Rom zurück, woraufhin Rossi auch die polizeilichen Befugnisse übertragen bekam.

56 ACS, MI, DGPS 1921, b. 101, f. „Fasci Massa“: Rossi an Innenministerium vom 16. 8. 1921. Die Hintergründe der Verletzung des Faschisten in Torano sind aufschlußreich für die Art, wie solche Alltagskonflikte abliefen: Der wohl exponierteste „squadrista“ des Ortes, Ottaviano Roppa, mit dem bezeichnenden Spitznamen „palo di ferro“ (Eisenpfosten) hatte bei einer traditionellen Festlichkeit des Ortes gefordert, daß von der Kapelle die „marcia reale“, der Königsmarsch, gespielt werden sollte. Diese kleine Kraftprobe mit der in großer Mehrheit antimonarchistischen lokalen Bevölkerung, die typisch ist für die Art, wie die Faschisten immer wieder ihre Dominanz zu bestätigen suchten, schlug diesmal fehl. Es kam zu einer Massenschlägerei und in der Folge zu drei Revolverschüssen auf Roppa, der eine leichte Kopfverletzung davontrug (Il Cavatore vom 20. 8. 1921).

57 Il Cavatore vom 14. 8. 1921 und ASM, Tribunale Massa, Sentenza penale 1922/109 (27. 5. 1922).

${ }^{58}$ Das Ministerium erfährt nur ganz lakonisch von der Ermordung Arturo Michelinis. Von den anderen beiden Toten wird Rom offenbar erst im Zusammenhang mit der Verhaftung der mutmaßlichen Täter im folgenden Jahr und der dadurch ausgelösten faschistischen Mobilisierung informiert (ACS, MI, DGPS 1922, b. 134, f. „Fasci Massa“, sf. „Carrara I“). 
führten ${ }^{59}$. Die Heißsporne innerhalb der Bewegung, zu denen wohl auch Renato Ricci gehörte, mußten ihre Pläne eines baldigen Rachefeldzuges gegen Sarzana fallenlassen ${ }^{60}$. Die nationale pacificazione war zwar auch in Carrara nicht nach dem Geschmack der meisten Faschisten, dies drückte sich aber - anders als in anderen Hochburgen des Provinzfaschismus - zunächst noch nicht in öffentlichen Mißfallenskundgebungen aus. Das Lokalblatt des Fascio von Carrara Alalà tat sich allerdings sichtlich schwer, die pacificazione politisch zu vertreten. Auf einer Position des formalen Gehorsams schrieb hier Lodovici:

„Wenn unser Führer, den wir nicht verleugnen und nie verleugnen werden, in dieser Hinsicht kategorische Anordnungen gegeben hat, werden wir uns an diese Anordnungen streng und geschlossen halten, denn unsere Disziplin ist das Zeichen dafür, daß unsere Jugendlichkeit Reife erlangt hat. [... Glauben. Nicht diskutieren. Wie im Krieg die guten Verbände." ${ }^{\text {"61 }}$

Das Aufbegehren der mächtigen faschistischen Organisationen der Po-Ebene auf ihrem Kongreß in Bologna am 16. August ${ }^{62}$ führte dann zu einer kleinen Wende. Die Absage an die pacificazione durch die in Bologna versammelten Fasci und der darauffolgende Rücktritt Mussolinis brachten die zurückgehaltenen Stimmungen im Carrareser Faschismus an das Tageslicht. Es kam zu einem offenen Bekenntnis gegen den „Pakt“ und vor allem gegen die allgemeine politische Neuorientierung, die der Duce damit verfolgt hatte. Ein politischer Ausgleich mit der Linken war für den Provinzfaschismus, dessen Erfolg politische Polarisierung und Gewaltausübung erfordert hatte und dessen Macht sich längerfristig nur durch die völlige Ausschaltung der Arbeiterbewegung in ihren traditionellen Ausformungen erhalten ließ, völlig abwegig. In eklatantem Gegensatz zu den nur eine Woche vorher verbreiteten Gehorsamsbekundungen schwenkte Alalà jetzt ins AntiMussolini-Lager über. In einem anonymen Leitartikel zum Kongreß von Bologna, der vermutlich aus der Feder von Gualtiero Betti stammt, hieß es nun:

„Alle haben, ohne viel zu protestieren, um schmerzliche Spaltungen zu vermeiden, die vielen großen und kleinen Kröten heruntergeschlungen, die er [Mussolini] fast jeden Tag geruhte zu verabreichen. Als aber der sklavische Gehorsam gegenüber Beschlüssen, die mit den Gefühlen der übergroßen Mehrheit der Fasci nicht im Einklang waren, die Liquidierung, ja den Selbstmord des Faschismus hervorzubringen drohte, mußte man aufbegehren. ${ }^{\text {"63 }}$

Dieser ohne Zweifel von Ricci abgesegnete Artikel wagte sich allerdings weiter vor, als es den Gemäßigten im Fascio lieb war, denn in der folgenden Ausgabe des Alalà erschien ein engagiertes Plädoyer zugunsten Mussolinis, wieder aus der Feder von Lodovici: Mussolini habe dem Frieden nicht den Faschismus opfern wollen - er hätte ihn, wenn es nötig gewesen wäre, Italien zuliebe geopfert -, vielmehr habe er bei seinem Tun die

${ }^{59}$ Meinungsverschiedenheiten zwischen Radikalen und Gemäßigten sind zwar, außer in der Marmorindustriellenvereinigung und anhand divergierender Leitartikel in Alalà, quellenmäßig nirgendwo exakt dingfest zu machen, lassen sich aber erahnen. Sie sprechen aus den relativ gemäßigten Alalà-Leitartikeln von Cesare Lodovici und der öffentlichen Zurückhaltung von Ricci, der in der Befriedungsversammlung nicht als Wortführer der Faschisten auftrat.

${ }^{60}$ Auf dem Kongreß der Fasci der Toskana soll Ricci ausgerufen haben: „Solange in Sarzana nicht die Fahne der Faschisten weht, werden wir die Waffen nicht niederlegen. “ Vgl. Cantagalli, Fascismo fiorentino, S. 265 (leider ohne Beleg).

${ }^{61}$ Alalà vom 13. 8. 1921.

${ }^{62}$ Im einzelnen: De Felice, Mussolini il fascista 1, S. $152 \mathrm{f}$.

${ }^{63}$ Alalà vom 20. 8. 1921. 
„höchsten Erfordernisse des Vaterlands“ im Auge gehabt. Wenn man ihm etwas vorwerfen könne, dann höchstens ein „Übermaß an Vaterlandsliebe" ${ }^{64}$. Hier meldeten sich die Kräfte im Carrareser Faschismus zu Wort, die das Erreichte nicht aufs Spiel setzen wollten und die Zeit für eine „Normalisierung“ als gekommen ansahen. Hinter ihnen stand mit großer Wahrscheinlichkeit ein guter Teil der Marmorindustriellen, die mit der gegebenen Situation schon zufrieden sein konnten und keine weitere Unruhe mit ihren negativen Rückwirkungen auf die Produktion wünschten.

Diese Kräfte, denen wohl das Gros der squadristi mit gründsätzlich friedensfeindlichen Positionen gegenüberstand, erlangten in der gegebenen Situation einen überproportionalen Einfluß, zumal sie die Rückendeckung der „Mailänder“ Führungsgruppe und von Perrone in Florenz hatten ${ }^{65}$. Das war der Preis, den die Radikalen für den unüberlegten Aktivismus, der zum Debakel von „Sarzana“ geführte hatte, und die auch nicht ganz kostenlose anschließende Solidarität der etablierten Kreise zahlen mußten. Das Gewicht der Gemäßigten zeigte sich auch daran, daß der Fascio von Carrara weiterhin Mitglied im lokalen Befriedungskomitee blieb, welches sich in der folgenden Konsolidierungsphase als ein nützliches Instrument erwies, um auf ungenehme Entwicklungen politisch einwirken zu können, ohne daß es in entscheidenden Situationen die Aktion des Faschismus wirklich behinderte.

Die relative Ruhephase nach „Sarzana“ brachte dem Faschismus der Region einen nochmaligen abrupten Mitgliederzuwachs. Allein in Carrara verdoppelte sich der Mitgliederstand im Laufe des August ${ }^{66}$. Eine zweite Welle des Zustroms aus den Kreisen der Sympathisanten, die sich in der rauhen und gefährlichen Durchbruchsphase noch nicht zum Eintritt entschließen konnten, ergoß sich in die Organisation, als sie begann, sich in sichereren und ruhigeren Gewässern zu bewegen. So erwies sich „Sarzana“ für den Faschismus der Region nicht als der Anfang einer Katastrophe, sondern als der Beginn einer neuen Phase, in der er seine Position konsolidieren konnte.

Im August 1921 verhielt sich der Fascio von Carrara relativ ruhig. Er hatte die Folgen der fatti di Sarzana zu verdauen und wollte nicht als der Störenfried der zwar etwas unehrlichen, aber dennoch das öffentliche Leben beherrschenden Befriedungsbemühungen erscheinen. Seine Mitarbeit in den Unterkomitees des Comitato di pacificazione, die vor allem auf Initiative der Republikaner in allen frazioni von Carrara wie Pilze aus dem Boden schossen, war freilich weniger als halbherzig. Hier übernahmen häufig die Liberalen oder andere bürgerliche Vertreter den Gegenpart zu den sovversi$v i$, während sich die Faschisten bei der Mitarbeit in diesen Organen auf das Minimum beschränkten, das zur Wahrung ihrer Interessen und zur Demonstration ihrer Friedensbereitschaft notwendig war. Das Engagement der Liberalen und diverser Unternehmer im Comitato di pacificazione sociale zeigt, daß diese mit dem Status quo schon

64 Alalà vom 27. 8. 1921.

${ }^{65}$ APC, b. B 3, f. 4: Brief von Pasella an Perrone vom 18. 8. 1921, in dem dieser Initiativen der toskanischen Fasci gegen die Resolution von Bologna anregt, um Mussolini von seinem Rücktritt abzubringen.

${ }^{66}$ Hinsichtlich der Mitgliederentwicklung des Fascio von Carrara ergibt sich folgendes Bild: Juni: 350 Mitglieder (ACS, MI, DGPS 1923, b. 91, f. „Fasci Massa“, sf. "Costituzione fasci“: Präfekt an Innenministerium vom 17. 6. 1921); Ende Juli: 700 Mitglieder (Alalà vom 20. 8. 1921); Anfang September: 1474 (APC, b. B 3, f. 3: Aufstellung vom 19. 9. 1921); Ende September: 1608 (ACS, wie oben: Präfekt an Innenministerium vom 1. 10. 1921). 
ganz zufrieden waren und sich von einem Anhalten der gewalttätigen Auseinandersetzungen nicht sehr viel versprachen ${ }^{67}$. Die Arbeiterorganisationen waren ja mittlerweile schon so geschwächt, daß sie mittelfristig keine ernstzunehmenden Initiativen ergreifen konnten. Ihre völlige Ausschaltung konnte den unternehmerischen Handlungsspielraum nicht mehr erweitern, mußte aber zwangsläufig dazu führen, daß die Faschisten die verlassenen Positionen besetzten und so den traditionell tonangebenden Kreisen im Bürgertum Carraras gefährlich werden konnten. Auch in der faschistischen Organisation selbst gab es durchaus Stimmen, die die Zeit für eine „Normalisierung“ für gekommen hielten: In einem Leitartikel in Alalà vom 10. September 1921 schrieb Cesare Lodovici, in gewisser Weise der Wortführer der "Gemäßigten“ im Fascio, zum Problem der Umwandlung der faschistischen Bewegung in eine politische Partei, die Voraussetzung hierfür sei „vor allem [... ] das Ende der Gewaltphase".

Die erwähnte Gewichtsverschiebung zugunsten der Gemäßigten in den Wochen unmittelbar nach „Sarzana“ führte, wie gesagt, zunächst zu einer gewissen Zurückhaltung der Faschisten. Eine planvolle Gewaltstrategie des Faschismus ist in dieser Zeit nicht zu erkennen; die vereinzelten Gewalttaten von Faschisten scheinen eher spontaner Natur gewesen zu sein. So war der erwähnte Angriff auf den Circolo economico von Molino di Sorgnano am 14. August von der Führung des Fascio nicht abgesegnet. Diese Aktion einer Gruppe von Faschisten aus Gragnana scheint dem Direktorium sogar ziemlich ungelegen gekommen zu sein. Um die Glaubwürdigkeit der faschistischen Organisation in Sachen pacificazione nicht zu stark zu beeinträchtigen, wurde der Anführer dieses politisch ziemlich überflüssigen Unternehmens stehenden Fußes aus dem Fascio ausgeschlossen $^{68}$.

Ähnliches gilt auch für die Ermordung von Giovanni Lombardini am 23. August 1921 in der Faschistenhochburg Bergiola Foscalina, dem schwersten Delikt nach den Vorkommnissen von Ende Juli. Der Anlaß dieser Bluttat ist charakteristisch für den nichtigen Ursprung gar nicht weniger Auseinandersetzungen zwischen Faschisten und sovversivi: Das Opfer hatte einige Jugendliche des Ortes, die auf seinem Grund spielten, aufgefordert, diesen sofort zu verlassen, weil sie Faschisten seien. Die Herrschaft des Fascio sei jetzt vorüber. Der 24jährige Steinbrucharbeiter Gualtiero Dell'Amico zückte daraufhin seinen Revolver und streckte ihn mit drei Schüssen nieder. Anschließend wurden $i h m$ noch drei Messerstiche unterhalb der linken Achselhöhle zugefügt $t^{69}$. Die Leiche wurde erst am Morgen des nächsten Tages gefunden, und den Tätern gelang es zunächst, völlig unentdeckt zu bleiben, was ihnen von der Polizei, die ganz offensichtlich sehr schleppend ermittelte, sehr leicht gemacht wurde.

${ }^{67}$ Zur Zusammensetzung der einzelnen Unterkomitees siehe: Il Giornale di Carrara vom 6. 8., 13. 8. und 17. 8. 1921. Die breite Dokumentation der Arbeit dieser Komitees im liberalen Lokalblatt ist ein deutliches Zeichen für das Engagement der Liberalen. Alalà dagegen ignoriert sie nahezu vollständig. Außer in der faschistischen Hochburg Bergiola Foscalina, wo die Faschisten nur zögernd und auf die ausdrückliche Aufforderung des „Befriedungsaktivisten“ und republikanischen Gewerkschaftsführers Nello Tofanari hin ihren Sekretär Eugenio Picciati in das Komitee entsandten, gab es in den Unterkomittees keine wirklichen Vertreter der Fasci. In den Komitees von Marina di Carrara und Avenza fungierten die Faschisten Mario Magnani und Umberto Pellini bezeichnenderweise als Unternehmervertreter.

68 Il Giornale di Carrara vom 20. 8. 1921.

${ }^{69}$ ASM, Corte d'assise, Sentenza 1923/28 (26. 6. 1923). 
Es ist deutlich zu erkennen, daß sich die Behörden und die Lokalpresse richtiggehend bemühten, den Mord nicht an die große Glocke zu hängen ${ }^{70}$. Dies gilt auch für die Blätter des linken Spektrums, von denen nur die Sveglia repubblicana die Nachricht überhaupt brachte, allerdings ohne irgendwelche Mutmaßungen über die Täterschaft anzustellen $^{71}$. Eine Mischung aus Einschüchterung und dem Bestreben, den Befriedungsprozeß nicht zu stören, war auf der Linken wahrscheinlich die Ursache für diese Zurückhaltung, die allerdings nur den Effekt hatte, daß die Faschisten ihre propagandistische Überlegenheit ohne Mühe wahren konnten. Die Indizien waren in diesem Fall immerhin so erdrückend, daß die Carabinieri-Station von Bedizzano, die durchaus im Geruch stand, mit den Faschisten in einem sehr freundschaftlichen Verhältnis zu stehen ${ }^{72}$, nicht umhinkonnte, gegen Gualtiero Dell'Amico und sieben andere Faschisten zwei Wochen nach der Tat Anzeige wegen Mordes zu erstatten ${ }^{73}$. Aber sogar nachdem die Polizei gehandelt hatte, blieb die lokale Linkspresse still.

Ganz anders gingen die Faschisten vor, die jeden Angriff auf einen ihrer Leute propagandistisch ausbeuteten. Im Laufe des August waren drei der aktivsten squadristi von Carrara, der Maurer Ottaviano Roppa sowie die beiden Unternehmersöhne Alessandro Manfredi und Francesco Trombella, angegriffen und zum Teil verletzt worden. Alalà ließ es sich nicht nehmen, diese Vorfälle in großer Aufmachung unter dem Titel „Die Befriedung gegen den Frieden“ aufzuzählen und im gleichen Artikel auch die polizeilichen Ermittlungen gegen die Verdächtigen der fatti di Fossola vom 22. Juli anzuprangern, zu denen Roppa und Manfredi gehörten ${ }^{74}$. Es ist aufschlußreich für die Psychologie und das Rechtsverständnis der Faschisten, daß sie die gewalttätige Reaktion der Antifaschisten und die Strafverfolgung von Mordverdächtigen in ihren Reihen mit dem Etikett „friedensfeindlich" auf die gleiche Stufe stellen zu können glaubten. Frieden war in dieser Sicht unmöglich, nicht nur solange die Linke noch in der Lage war zu reagieren, sondern auch solange staatlicherseits nicht wenigstens eine De-facto-Legitimierung der vorangegangenen faschistischen Gewalt mit einem Verzicht auf jegliche Strafverfolgung erfolgte. Hierin waren sich alle im wesentlichen einig, Radikale, Gemäßigte und fiancheggiatori aller Art. „Die staatlichen Stellen sollten sich daran erinnern, daß der Fascio von Carrara vom Vertrauen der besten Bürger getragen wird; das ist eine Stärke und eine Garantie“, schrieb das faschistische Lokalblatt an die Adresse der Regierung in $\operatorname{Rom}^{75}$.

Daß diese Garantie funktionierte, zeigte der Ausgang des Ermittlungs- und Gerichtsverfahren im Fall der Fossola-Morde. Es handelte sich hier um das einzige Mordverfahren vor dem Schwurgericht Massa im Anschluß an eine spedizione punitiva mit klarer

to Vgl. dazu oben, S. 103.

71 La Sveglia repubblicana vom 27. 8. 1921.

72 ACS, MI, Gabinetto Bonomi, b. 4, f. 43: Abschrift des Briefes von Kommissar Barcucci an Carabinieri-Hauptmann Benni vom 27.9. 1921, in dem von Beschwerden über die Kumpanei der Carabinieri von Bedizzano mit den Faschisten von Miseglia die Rede ist.

73 ACS, MI, DGPS 1921, b. 101, f. „Fasci Massa": Gruppenkommando der Carabinieri, Florenz: Liste der Strafanzeigen der einzelnen Carabinieri-Stationen in den Gemeindegebieten von Carrara und Massa vom 2. 12. 1921. Merkwürdig genug bleibt allerdings, daß die wegen Mordes angezeigten Faschisten noch monatelang auf freiem Fuß blieben.

${ }^{74}$ Alalà vom 27. 8. 1921.

75 Ebenda. 
politischer Zielsetzung. Alle übrigen Mord- und Totschlaganklagen gegen Faschisten, die in diesem Justizdistrikt verhandelt wurden, trafen "Schwarzhemden" aus der Unterschicht, die Bluttaten verübt hatten, deren politischer Stellenwert - ähnlich wie im Fall des erwähnten Lombardini-Mordes in Bergiola - niedrig anzusetzen ist ${ }^{76}$.

Die Vorgänge, die im Fossola-Prozeß zum Freispruch aller Angeklagten führten, dokumentieren in aufschlußreicher Weise die Aushöhlung rechtsstaatlicher Verhältnisse in der Provinz Massa-Carrara und sollen daher ausführlicher gewürdigt werden. Am 23. Juli 1921 waren in Fossola, wie schon kurz erwähnt, bei einer faschistischen „Racheaktion " für die Vorfälle vom Vortag in Sarzana drei völlig unbeteiligte Arbeiter kaltblütig „exekutiert" worden, von denen einer seine schweren Schußverletzungen wie durch ein Wunder überlebte. Die Obduktion der Leichen der Ermordeten, Cesare Chiappini und Pietro Piccini, ergab, daß sie von fünf bzw. zehn aus nächster Nähe und unterschiedlicher Richtung abgegebenen Revolverschüssen getroffen worden waren. Auch der überlebende Gino Colombini war in der gleichen Art und Weise von sieben Kugeln getroffen worden. Da gleichzeitig zweifelsfrei feststand, daß die Opfer von den Faschisten anhand einer vorbereiteten „Proskriptionsliste“ ausfindig gemacht worden waren, kam die Staatsanwaltschaft nicht umhin, vom Tatbestand des gemeinschaftlichen Mordes auszugehen ${ }^{77}$.

Doch bei der Verfolgung der Täter kam es zu der üblichen Begünstigung durch die Ermittlungsbehörden. Obwohl der schwerverletzte Colombini unmittelbar nach dem Geschehen zu Protokoll gab, daß er unter den beteiligten squadristi den Unternehmerssohn Alessandro Manfredi und den Vorarbeiter Romeo Carusi zweifelsfrei erkannt hatte, wartete der Ermittlungsrichter bis zum 12. August 1921, also fast drei Wochen, bis er Haftbefehl gegen sie erlie $\mathbf{~}^{78}$. In der Zwischenzeit war der Bruder des Schwerverletzten, Augusto Colombini, ein an einer römischen Carabinieri-Schule als Ausbilder tätiger maresciallo, angereist und hatte private Untersuchungen angestellt, die zur Ermittlung von weiteren sieben mutmaßlichen Beteiligten führten ${ }^{79}$. Es handelte sich um den Bankierssohn Roberto Giampaoli, den Angestellten und ehemaligen Fiume-Kämpfer Ovidio Passani, den Unternehmer Corrado Peragallo, den Oberschüler Emilio Frediani, den Straßenbahner Alessandro Bertoli, den Maurer Ottaviano Roppa und den cavatore-possidente Eugenio Torri. Ohne das verbissene Engagement von Augusto Colombini wäre es wahrscheinlich nie zu einem Verfahren gekommen, denn die eigentlich Verantwortlichen glänzten durch Passivität, und bei den meisten Einwohnern von Fossola fehlte offensichtlich der Mut, sich bei der Identifikation der faschistischen Täter zu exponieren. Augusto Colombini fand Belastungszeugen mit einer Ausnahme nur unter den Verwandten der Opfer, obwohl der Kreis derer, die die squadristi gesehen haben mußten, relativ groß war. Der einzige Zeuge, der nicht mit einem der Opfer verwandt oder verschwägert war, der Buchhalter Giovanni Bernardi, war ein engagierter Republikaner, was

${ }^{76}$ Weiteres hierzu unten, S. $158-160$.

77 ASM, Corte d'assise Massa, Fascicoli processuali, b. 140, f. „A. Manfredi etc.“: Bericht des Sostituto procuratore von Massa vom 28. 2. 1922; Anklagebegründung des Generalstaatsanwalts beim Appellationsgerichtshof Genua vom 30. 3. 1922.

78 Ebenda: Protokoll der Aussage von Colombini vom 23. 7. 1922, aufgenommen von den Carabinieri der Station von Fossola; Haftbefehl des Untersuchungsrichters vom 12. 8. 1921.

79 Il Cavatore vom 20. 8. 1921. 
- wie sich zeigen sollte - seine Glaubwürdigkeit in den Augen von Staatsanwälten und Richtern stark beeinträchtigte.

Als die Haftbefehle endlich erlassen wurden, waren fast alle Verdächtigen flüchtig. Nur Ottaviano Roppa wurde verhaftet, weil er zu diesem Zeitpunkt im Krankenhaus lag. Roppa war der am wenigsten belastete Verdächtige. Gerüchte über seine Teilnahme an der spedizione konnten von keinem der Zeugen eindeutig bestätigt werden. Roppa bestritt die Anschuldigungen, was seine Person betraf, belastete aber dabei Manfredi als den Rädelsführer des Unternehmens. Dieser habe ihn am besagten Tag für eine spedizione gegen die Kommunisten von Fossola gewinnen wollen, aber er habe abgelehnt, weil Manfredi auf die Frage, ob die Aktion vom Direktorium genehmigt worden sei, mit Nein geantwortet habe ${ }^{80}$. Roppa wurde am 20. September 1921 „mangels Indizien “ wieder freigelassen.

Für alle Verdächtige meldeten sich Entlastungszeugen. Es handelte sich dabei allerdings vor allem um Faschisten oder Sympathisanten des $F a s c i o^{81}$. Zum Teil verwickelten sie sich in Widersprüche, und so zog die zuständige Generalstaatsanwaltschaft beim Appellationsgericht von Genua die Glaubwürdigkeit einiger Zeugen in Zweifel. Am 30. März 1922 erhob sie Mordanklage gegen Manfredi, Carusi, Torri und Giampaoli. Eine Anklageerhebung gegen Bertoli, Frediani, Passani und Peragallo unterblieb wegen „Mangels an Beweisen “ und gegen Roppa wegen erwiesener Unschuld ${ }^{82}$. Drei Tage später, am 2. April 1922, kam es in Fossola zu einem schweren nächtlichen Zwischenfall. Eine Gruppe von Faschisten war angeblich mit Handgranaten und Pistolenschüssen angegriffen worden. Merkwürdigerweise hatte es keinen einzigen Verletzten gegeben; auch die Täter konnten später nicht ermittelt werden. Nach diesem nebulösen Vorfall zogen, der Darstellung des Cavatore zufolge, Faschisten und Carabinieri der örtlichen Station zum Haus des Belastungszeugen Giovanni Bernardi. Während die Faschisten in das untere Stockwerk eindrangen und es verwüsteten, stellten sich die Carabinieri vor dem Haus auf. Bernardi, der die Carabinieri offensichtlich nicht bemerkt hatte, trat mit einem Gewehr auf den Balkon und feuerte einige Schüsse in die Luft ab, wahrscheinlich um damit Aufmerksamkeit zu erregen. Daraufhin schossen die Carabinieri auf ihn, ohne ihn allerdings zu treffen. Vater und Sohn Bernardi wurden auf der Stelle verhaftet ${ }^{83}$.

Auf diese Weise war einer der Hauptbelastungszeugen im Gefängnis gelandet, während die mutmaßlichen Teilnehmer an der spedizione vom 23. Juli 1922, außer Eugenio Torri, der mittlerweile gefaßt worden war, sich nach wie vor der Verhaftung entzogen $^{84}$. Zwölf Tage später, am 14. April 1922, zog die Zeugin, die Roberto Giampa-

${ }^{80}$ ASM, Corte d'assise Massa, Fascicoli processuali, b. 140, f. „A. Manfredi etc. “: Aussage von Ottaviano Roppa vom 23. 8. 1921. Möglicherweise war die "spedizione “ aber von Ricci persönlich befohlen worden, denn Manfredi, unterdessen ein faschistischer Dissident, bot im Dezember 1924 dem Korrespondenten von Il Lavoro(Genua), Giovanni Ansaldo, angebliche Beweise dafür an (Bernieri, Fascismo a Carrara, S. 106).

${ }^{81}$ Unter den Entlastungszeugen waren viele Angehörige der Führungsgruppe des Fascio von Carrara: Renato Ricci, Gualtiero Betti, Ottorino Biscioni, Lodovico Canepa, Augusto Dovati, Giovanni Gattini, Silvio Cattani und Demetrio Ghetti (ebenda: Protokolle der Zeugenaussagen, alle vom 10. bzw. 19. 9. 1921).

82 Ebenda: Anklagebegründung der Generalstaatsanwaltschaft vom 30. 3. 1922.

${ }^{83}$ Il Cavatore vom 15. 4. 1922.

${ }^{84}$ Wie Anm. 82: Hier werden sie als "latitanti“ (flüchtig) bezeichnet. 
oli belastet hatte, vor dem Rechtsanwalt des Beschuldigten ihre frühere Aussage zurück, bei der sie noch versichert hatte, sie sei völlig sicher, ihn unter den Tätern erkannt zu haben. Man hatte ihr ein Photo des Bankierssohns vorgelegt. Inwieweit sie beeinflußt worden ist, läßt sich schwer sagen. Aktenkundig ist allerdings, daß der Vater, Arturo Giampaoli, sie schon einige Monate zuvor gebeten hatte, sie solle die Sache auf sich beruhen lassen, sein Sohn sei doch noch ein Halbwüchsiger ${ }^{85}$.

Am 11. Mai 1922 erließ die Sezione d'accusa des Appellationsgerichts Genua das Urteil im Vorverfahren: Nur die Anklage gegen Manfredi und Carusi verwies sie zum Hauptverfahren an das Schwurgericht Massa. Bei Torri und Giampaoli, gegen die die Oberstaatsanwaltschaft Anklage erhoben hatte, nahmen die Richter nun ebenfalls Beweismangel an. Die Zeugenaussage von Bernardi wurde von ihnen mit der Begründung, er sei ein „den Faschisten feindlich gesonnener Parteimensch“, überhaupt nicht mehr berücksichtigt. Sie verfuhren bei ihrer Entscheidung nach dem Grundsatz, daß sie nur gegen jene Angeklagte das Hauptverfahren einleiten wollten, „bei denen zweifelsfreie Beweise ihrer Schuld vorliegen " 86 . Das war bei Manfredi und Carusi offensichtlich der Fall. Bei Carusi schlossen sich die Aussagen der verschiedenen Entlastungszeugen gegenseitig aus, so daß die Richter zu dem Schluß kommen mußten, daß „entweder die einen oder die anderen die Wahrheit sagen, oder weder die einen noch die anderen ${ }^{487}$. Manfredi befand sich in einer noch ernsteren Lage, weil er auch durch die unachtsame Äußerung seines Gesinnungsgenossen Roppa belastet wurde.

Anhand der Prozeßakten können natürlich Falschaussagen einzelner Zeugen nicht nachgewiesen werden, aber es drängt sich der Verdacht auf, daß auch jene Alibis, die von den Richtern des Appellationsgerichts akzeptiert wurden, nicht einwandfrei waren. Selbst die schwer belasteten Manfredi und Carusi konnten mehrere Entlastungszeugen vorweisen, unter denen sich neben verschiedenen Faschisten auch Giulio Lazzoni befand, der zu jenen Marmorunternehmern um Carlo Andrea Fabbricotti zu rechnen ist, die den Faschisten relativ distanziert gegenüberstanden ${ }^{88}$. Wenn die Hinweise auf die Täterschaft von Carusi nicht so eindeutig gewesen wären - unter anderem hatte der verletzte Colombini, den das Gericht für uneingeschränkt glaubwürdig hielt, seinen ehemaligen Schulkameraden Carusi zweifelsfrei erkannt -, hätten Richter und Staatsanwälte Lazzonis Aussage berücksichtigen müssen, so wie sie es bei den anderen honorigen Entlastungszeugen, die nicht zum Kreis der exponierten Angehörigen der faschistischen Organisation gehörten, getan hatten ${ }^{89}$. Auch keiner der übrigen Tatverdächtigen scheint der Tragfähigkeit seines Alibis besonders getraut zu haben, denn alle hielten sich über viele Monate versteckt, bis ihre jeweiligen Haftbefehle aufgehoben wurden, was dazu führte, daß

85 Ebenda: Zeugenaussage von Jole Tonazzini vom 3. 12.1921; Brief des Rechtsanwaltes von Giampaoli, Arturo Cipollini, vom 18. 4. 1922; schriftliche Erklärung von J. Tonazzini vom 14. 4. 1922.

${ }^{86}$ Ebenda: Urteilsbegründung im Vorverfahren vom 11. 5. 1922.

87 Ebenda.

88 Ebenda: Zeugenaussage von Giulio Lazzoni vom 19. 9. 1921.

89 Es handelte sich dabei u. a. um die Unternehmer William Robson, Vincenzo Caniparoli, Giovanni Gattini und Oreste Ascoli (ebenda: Urteil im Vorverfahren vom 11. 5. 1922), wobei die beiden letzten zum Zeitpunkt ihrer Zeugenaussagen (Sept. 1921) mindestens schon als Sympathisanten des Fascio anzusehen sind. 
außer Torri, den die Polizei im Januar 1922 faßte, keiner von ihnen je verhört werden konnte ${ }^{90}$.

Obwohl die Vorgänge um das Fossola-Verfahren anhand der Quellen im einzelnen nicht völlig geklärt werden können, wird deutlich, daß die örtlichen Strafverfolgungsbehörden und die lokale Notabilität die Verurteilung von squadristi nicht wünschten. Die Eröffnung des Verfahrens war gewissermaßen schon ein „Unfall“, zu dem es nur deshalb kam, weil eines der Opfer zufällig der Bruder eines maresciallo der Carabinieri war. Viel lieber, das ist unübersehbar, wären die Strafverfolgungsbehörden nach der Maxime jenes Masseser Staatsanwalts vorgegangen, der im Frühsommer 1921 verkündet hat-

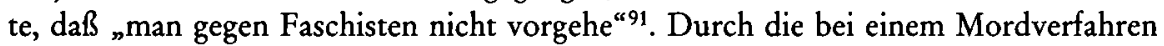
zwingende Einschaltung der Generalstaatsanwaltschaft und des Appellationsgerichts Genua war der Fall den lokalen Justizbehörden allerdings teilweise entzogen. Als der Prozeß dann aber in die Zuständigkeit des Schwurgerichts Massa zurückkehrte, wurde er, wie in allen ähnlich gelagerten Fällen, ein ganzes Jahr lang verschleppt. Am 7. Mai 1923 sprach das Geschworenenkollegium, in das bezeichnenderweise auch der exponierte Faschist Francesco Trombella berufen worden war, die Angeklagten Manfredi und Carusi „mangels Beweisen“ frei" ${ }^{92}$. Den Angeklagten wäre das Gefängnis zwar aufgrund der von der Regierung Mussolini erlassenen Amnestie für Squadrismus-Delikte in jedem Fall erspart geblieben, doch Schuldsprüche bei gleichzeitiger Amnestierung, wie sie das Schwurgericht Massa in anderen Verfahren gegen faschistische Bluttäter erließ ${ }^{93}$, hätten den Entlastungszeugen Falschaussagen attestiert und sind daher wohl vermieden worden.

Entwicklung und Ausgang des Fossola-Verfahrens zeigen in aller Deutlichkeit, wie die Justiz in formal rechtsstaatlichen Bahnen agierte, ohne den Faschismus dabei zu treffen. Die entscheidende Grundlage hierfür war die politische Solidarität der „liberalen“ Notabeln Carraras mit dem Fascio, die ein entschiedenes Vorgehen gegen faschistische Straftäter nahezu unmöglich machte. Diese Solidarität war allerdings in der Phase nach den Erschütterungen der Sarzana-Ereignisse an ein stillschweigendes oder explizites, jedenfalls über die Quellen nur erahnbares Abkommen geknüpft, das den Fascio daran hinderte, aufsehenerregende Terrorunternehmungen, wie es die spedizioni nach Monzone, Sarzana und Fossola gewesen waren, zu wiederholen. Nach den Maßstäben der Durchbruchsphase wäre eine solche Aktion spätestens fällig gewesen, als am 10. September 1921 in Colonnata der Faschist Alcide Andreani von einem Anarchisten erschossen worden war ${ }^{94}$. Der Fascio von Carrara beließ es aber dabei, dem Opfer „Hände

90 Wie Anm. 83.

91 Bericht des Generalinspektors Trani vom 4. 8. 1921 in Costantini, Sarzana, S. 93.

92 ASM, Corte d'assise di Massa, Sentenza 1923/14 (7. 5. 1923) und Fascicioli processuali, b. 140, f. „A. Manfredi etc. “: Liste der Geschworenen vom 7. 5. 1923.

$93 \mathrm{Vgl}$. weiter unten, S. 158.

94 Bei dieser Tat handelte es sich in keiner Weise um Mord, wie das faschistische Lokalblatt behauptete. Der Täter Umberto Nicoli war von Andreani in einer Weise angegriffen worden, die das Schwurgericht Massa in seinem Urteil vom 13. 11. 1922, also schon nach dem „Marsch auf Rom “, als "schwere Provokation“ bezeichnete. Nicoli wurde wegen „eccesso di legittima difesa" (übermäßiger Notwehr) zu nur 5 Jahren und 10 Monaten Haft verurteilt (ASM, Corte d'assise, Sentenza 1922/24). 
voller Blumen am nicht fernen Siegestag" zu versprechen und die angeblich politisch motivierte Untätigkeit des Sanitätsdienstes von Colonnata bei der Hilfeleistung für den tödlich Verletzten propagandistisch wirkungsvoll auszuschlachten ${ }^{95}$. Drei Tage später wurde zwar in Torano Corrado Federici ermordet, ein sovversivo, der den Faschisten in der Vergangenheit zu schaffen gemacht hatte, doch es handelte sich hierbei wohl nicht um eine direkte Racheaktion für den Vorfall von Colonnata ${ }^{96}$. Eine regelrechte „Strafexpedition" nach Colonnata, was die für den Squadrismus "klassische“ Reaktion gewesen wäre, erschien in der jetzigen Phase nicht mehr als sinnvoll. In der Zwischenzeit hatte der Fascio von Carrara eine großangelegte gewerkschaftspolitische Offensive begonnen, und in diesem Zusammenhang hätte eine politisch riskante spedizione punitiva nur die Rolle eines selbstproduzierten Störmanövers gehabt.

95 Alalà vom 19. 9. 1921.

96 ACS, MI, DGPS 1921, b. 101, f. „Fasci Massa“: Divisione polizia giudiziaria an Divisione affari generali e riservati vom 25. 10. 1921. Federici wird hier als „,ardito del popolo“ bezeichnet. $\mathrm{Da}$ es zu dieser Zeit in Carrara keine Formationen von „Arditi del popolo“ gab, bedeutet diese Angabe wohl lediglich, daß er von der Polizei für einen militanten Antifaschisten gehalten wurde. 